\title{
Exosomes as Potential Transport Vehicles of Tetrahydrobiopterin, 6-Pyrovyoltetrahydrobiopterin-Synthase and Tripeptidyl-Peptidase I
}

Kristina Lang 


\title{
Exosomes as Potential Transport Vehicles of Tetrahydrobiopterin, 6-Pyrovyoltetrahydrobiopterin-Synthase and Tripeptidyl-Peptidase I
}

\author{
Doctoral Thesis \\ In partial fulfillment of the requirements for the degree of \\ Doctor rerum naturalium \\ of the Georg-August-University Göttingen \\ in the Molecular Medicine Study Program \\ at the Georg-August-University Göttingen
}

\author{
submitted by \\ Kristina Lang \\ born in Pawlodar
}

Göttingen, October 2018 


\section{Thesis Committee}

\section{Prof. Dr. Dr. Robert Steinfeld}

Department of Child and Adolescent Health

University Medical Center Göttingen

Prof. Dr. Blanche Schwappach

Department of Molecular Biology

University Medical Center Göttingen

\section{Prof. Dr. Silvio Rizzoli}

Department of Neuro- and Sensory Physiology

University Medical Center Göttingen

\section{Examination Board}

\section{Prof. Dr. Ralf Dressel}

Institute of Cellular and Molecular Immunology

University Medical Center Göttingen

\section{Prof. Dr. Hubertus Jarry}

Department of Clinical and Experimental Endocrinology

University Medical Center Göttingen

\section{Prof. Dr. Nuno Raimundo}

Institute of Cellular Biochemistry

University Medical Center Göttingen 


\section{Affidavit}

Here I declare that my doctoral thesis entitled

Exosomes as Potential Transport Vehicles of Tetrahydrobiopterin, 6-Pyrovyoltetrahydrobiopterin-Synthase and Tripeptidyl-Peptidase I

has been written independently with no other sources and aids than quoted.

Kristina Lang

Göttingen, October 2018 


\section{Es kann die Ehre dieser Welt}

Es kann die Ehre dieser Welt

Dir keine Ehre geben, Was dich in Wahrheit hebt und hält, Muß in dir selber leben.

Wenn's deinem Innersten gebricht An echten Stolzes Stütze, Ob dann die Welt dir Beifall spricht, Ist all dir wenig nütze.

Das flücht'ge Lob, des Tages Ruhm Magst du dem Eitlen gönnen; Das aber sei dein Heiligtum:

Vor dir bestehen können.

Theodor Fontane 


\section{Table of contents}

Acknowledgements ..................................................................................................................

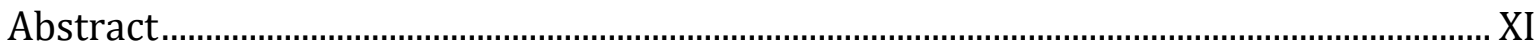

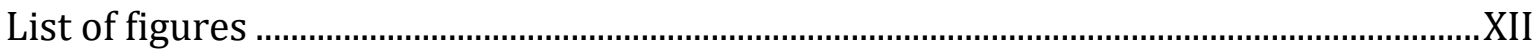

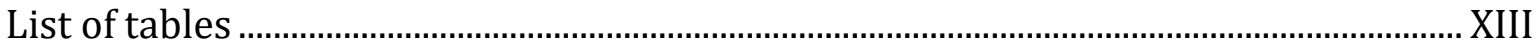

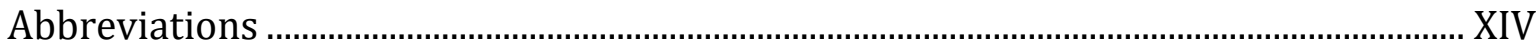

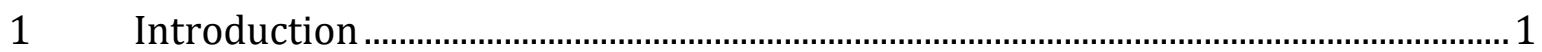

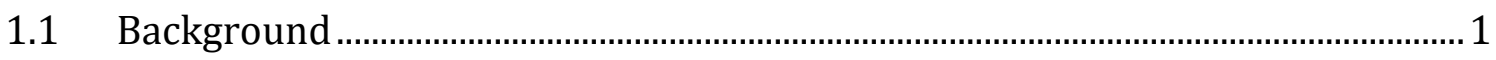

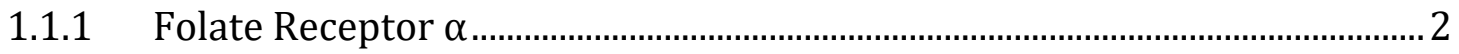

1.2 Extracellular Vesicles .......................................................................................... 4

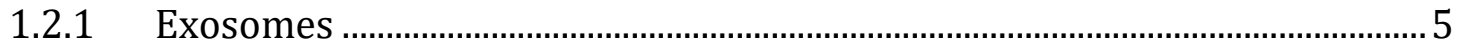

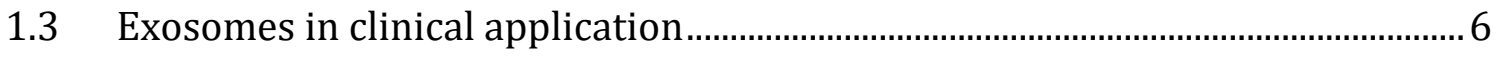

1.3.1 Purification and characterization .....................................................................

1.3.2 Drug loading..................................................................................................

1.3.3 Exosome application and distribution......................................................... 10

1.4 Model diseases suitable for the screening of exosomal transport vehicles.... 11

1.4.1 Late infantile neuronal ceroid lipofuscinosis.................................................. 11

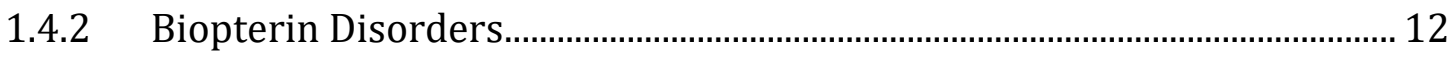

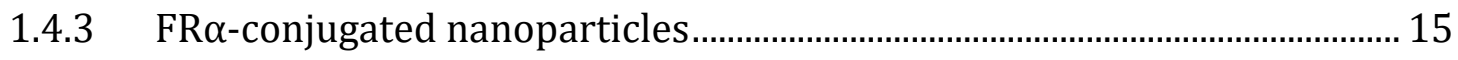

1.5 Aims of the study ……….............................................................................. 16

$2 \quad$ Materials and methods ........................................................................................... 17

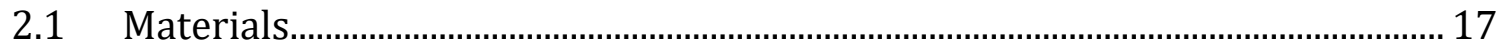

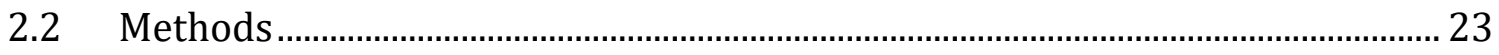

2.2.1 EV sample preparation and cell culturing …………………………………...2 23

2.2.2 Fast performance liquid chromatography ………………………………... 24 


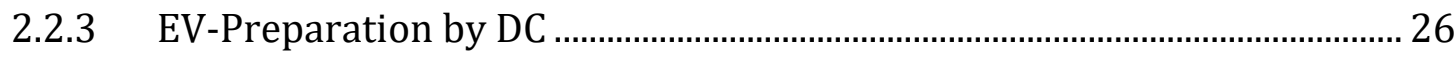

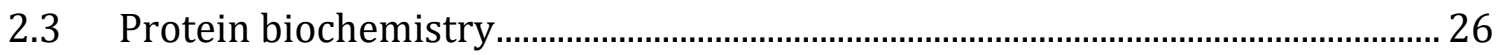

2.3.1 Purification of PTPS from E. coli recombinant production strain.............. 26

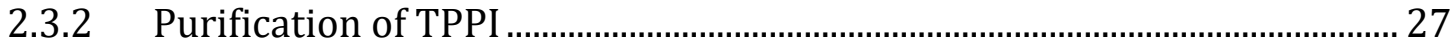

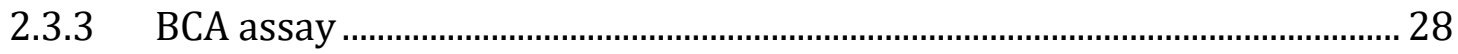

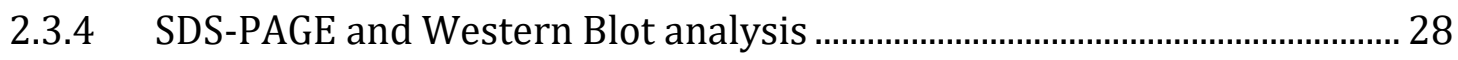

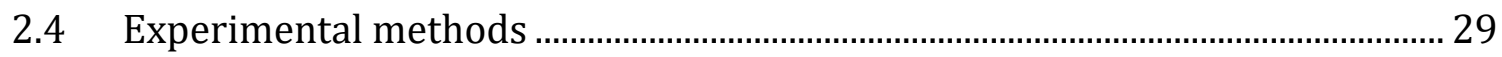

2.4.1 Analysis of density by centrifugation on a sucrose gradient ...................... 29

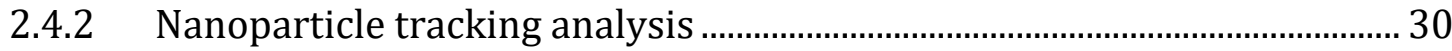

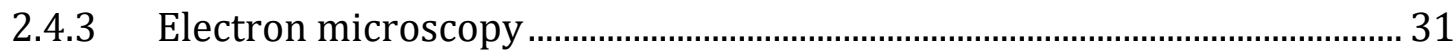

2.4.4 Uptake analysis of EVs by epithelial cells with flow cytometry................... 32

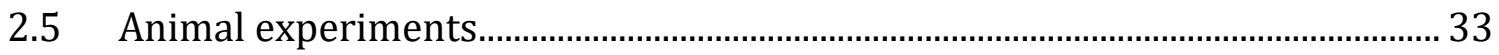

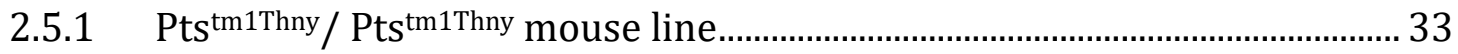

2.5.2 Vesicle replacement therapy of FR $\alpha$-presenting and PTPS-loaded vesicles 34

2.5.3 Analysis of the biodistribution by organ screening........................................ 35

2.5.4 Analysis of the locomotor activity by tracking with an infrared sensor . 36

2.5.5 Analysis of the strength and motor coordination by Rota rod experiment 36

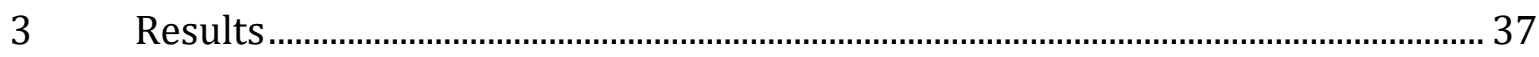

3.1 Purification of extracellular vesicles by chromatographic approaches ........... 37

3.1.1 SEC followed by IMAC for purification of his-tagged vesicles ..................... 37

3.1.2 IEC for purification of unmodified vesicles................................................... 38

3.1.3 Improved purification of not modified vesicles by SEC followed by IEC 39

3.1.4 Method optimization of two-step FPLC method with SEC followed by IMAC 41 
3.2 Method outcome, purity of the product and reproducibility of the method.. 42

3.2.1 Outcome of the different EV isolation protocols........................................... 42

3.2.2 Purity of the different EV-preparations ........................................................ 45

3.3 Vesicle characterization ......................................................................................... 46

3.3.1 Characterization of protein marker ................................................................ 47

3.3.2 Size determination of the vesicles …………………………………………... 50

3.3.3 Characterization of single vesicles.................................................................... 51

3.3.4 Density of the different EV-preparations in comparison .............................. 53

3.3.5 Verification of FR $\alpha$ on the surface of the isolated vesicles ..........................56

3.3.6 Analysis of biological performance by EV uptake ………………………..... 58

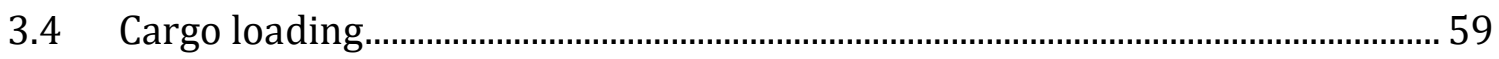

3.4.1 Loading experiments with the TPPI assay …………..................................... 60

3.4.2 Endogenous loading of PTPS ............................................................................ 63

3.5 Analysis of biodistribution of the vesicles after intranasal application ........... 65

3.6 Investigation of the drug vehicle capacity of the FR $\alpha$-presenting EVs equipped with therapeutic cargo ……………………………………………………….... 68

3.6.1 Analysis of the overall performance of the EV-treated KO mice ………..... 71

$4 \quad$ Discussion ......................................................................................................... 74

4.1 Successful isolation of EVs in a high quality by chromatographic approach . 74

4.2 Loading of therapeutic proteins to vesicles by membrane targeting................ 77

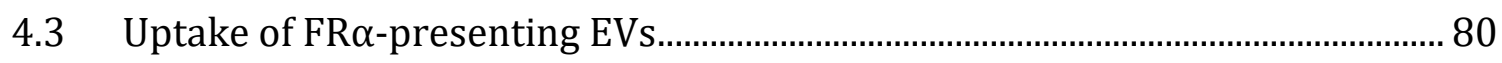

4.4 Biodistribution of intranasally administered exosomes ..................................... 80

4.5 Drug delivery capacity of PTPS carrying and FR $\alpha$-presenting exosomes........ 82

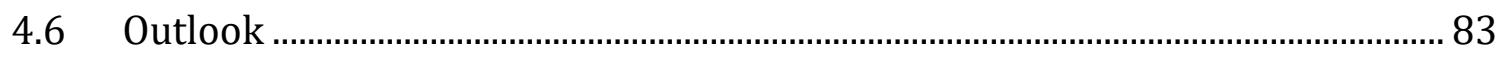

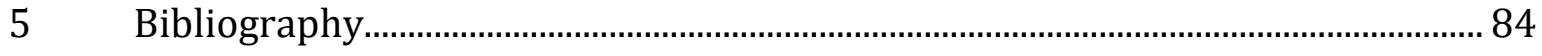


Curriculum Vitae.. 


\section{Acknowledgements}

Das Promotionsvorhaben war für mich ein langer Weg, auf dem mich viele Menschen begleitet und unterstützt haben. Ich möchte mich bedanken bei

Frau Professor Gärtner für die Möglichkeit in ihren Laboren arbeiten zu können und die umfangreichen Unterstützungen.

Professor Robert Steinfeld für dieses großartige Projekt, die Betreuung und die Freiheit auch meine eigenen Ideen umsetzen zu dürfen.

Jan Wehland und der Arbeitsgruppe von Professor Diederichsen für die freundliche Einweisung in die Arbeit mit Liposomen.

Anne Stündl und der Arbeitsgruppe von Frau Schneider für die Möglichkeit den Nanosight LM10 nutzen zu können.

Frau Professor Blanche Schwappach und Herr Professor Silvio Rizzoli für wirklich hilfreiche und inspirierende Besprechungen.

allen Tieren die im Rahmen meines Projektes geopfert wurden, allen voran meiner ersten Knockout-Maus \#188, Rocks.

allen Mitarbeitern der Tierhaltung, jedoch insbesondere Tanja Huttanus. Ohne ihre Hilfe wäre die Arbeit mit der pts-Linie nicht möglich gewesen.

meinen Kollegen aus dem Labor der Pädiatrie für das angenehme Arbeitsklima, die Geduld und Hilfe. Vor allem möchte ich Kathrin Schreiber und Tanja Wilke hervorheben. Sie haben auch bei meinen praktischen Arbeiten mitgeholfen und mich vertreten. Dadurch waren sie eine unglaubliche Unterstützung.

meinem Megaoffice, Rose, Karina, Annika, Maria, Julia, Thomas, Ignacio, Lydia und Kristina. Es war wirklich eine schöne Zeit mit euch, das Kochteam, die Sporteinheiten, der Kleiderkreisel, die Hilfe bei allen Herausforderungen und Matheaufgaben und die perfektesten aller Dinner. Ich bedaure, wahrscheinlich nie wieder in einer solchen Gemeinschaft arbeiten zu werden.

meinen Freunden, in und außerhalb Göttingens, für ihre Unterstützung und das Verständnis in stressigen Phasen.

meinem Freund Benjamin für das offene Ohr, sein Verständnis und Weisheiten aus Rocky I-VII.

meinen Geschwistern, nicht. Tatsächlich habt ihr mir nicht aktiv geholfen. Jedoch bin ich unendlich dankbar dafür, dass es euch gibt, jeden einzelnen.

meinen Eltern für Alles. 


\section{Abstract}

Extracellular vesicles (EV) for the therapeutic application are of growing scientific interest. But even though the number of clinical trials on EVs almost doubled from 29 to 52 within 2017, the number of trials with therapeutically applied EVs was only two. In this project, the performance of folate receptor alpha (FR $\alpha$ ) presenting EVs as drug vehicles in neuropediatric disorders was investigated. FR $\alpha$ was proven to be the key player for the transport of folates to the brain. On that account, FR $\alpha$-presenting EVs are predestined to be used as vehicles for therapeutics which are naturally not processed across the blood-cerebrospinal fluid-barrier. The application of EVs as carriers is hampered by the complex nature of this biological material and a still strongly evolving field of methodology. In this project, central questions of the production of EV therapeutics were addressed: preparation, cargo loading and biological screening. For a reliable purification of large amounts of highly pure EVs, a unique fast performance liquid chromatography purification method for his-tagged vesicles was established. This method is made up by size exclusion chromatography followed by immobilized metal affinity chromatography. The preparation was comprehensively characterized and verified as exosome-like vesicles. In the second phase, the loading of therapeutic cargo was performed. While artificial loading of therapeutic cargo based on the introduction of pores into the vesicles and addition of the drug protein had low efficiency, better results could be achieved by endogenous loading by means of a membrane targeted drug protein. In choroid plexus cells from rat an increased uptake of these modified EVs in comparison to native vesicles could be proven. This uptake tendency could not be manifested for the brain in in vivo experiments using adult mice. Finally, the neuronal drug delivery capacity of these promising vehicles was screened in a mouse model of a biopterin disorder. In these experiments, an enzyme replacement therapy delivered by EVs could be realized for the first time. The mice had a significant improvement in their health status and performed better in a behavioral assay in comparison to not exosome-treated animals. By this successful treatment, evidence for an EV based drug delivery to the central nervous system of an enzyme replacement therapy was given. 


\section{List of figures}

Figure 1.1: Schematic overview of FR $\alpha$ transcytosis in the choroid plexus....................... 3

Figure 1.2: Development of research on extracellular vesicles. ........................................... 4

Figure 1.3: Exosome biogenesis - from formation to release .............................................. 6

Figure 1.4: Metabolism of biopterin adopted and modified from Clot et al................... 13

Figure 3.1: Scheme of two-step FPLC purification of FR $\alpha$-presenting vesicles. ............. 40

Figure 3.2: Comparison of two-step FPLC with different metals in the IMAC column. 42

Figure 3.3: Particle and protein recoveries of different preparations. ............................ 45

Figure 3.4: Purity determined as particle per $1 \mu \mathrm{g}$ protein ratio........................................ 46

Figure 3.5: Exosomal and non-exosomal markers for all FPLC methods in comparison

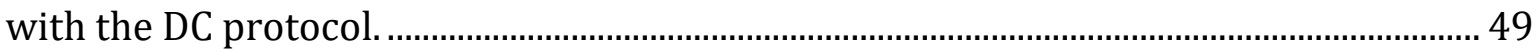

Figure 3.6: Average and median size of each purification step determined by NTA.... 51 Figure 3.7: Electron microscopic examination of vesicles purified by SEC and IMAC. 52 Figure 3.8: Cryo-TEM of native EVs purified by SEC coupled with IEC............................... 53 Figure 3.9: Density determination of EVs prepared by DC and in two-step FPLC

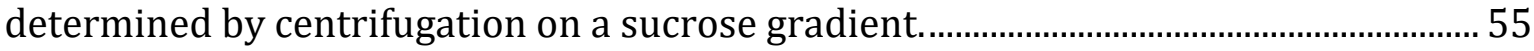
Figure 3.10: Analysis of fluorescent particles by indirect antibody labeling in NTA. .. 57 Figure 3.11: Quantification of EV uptake of BN16 cells quantified by flow cytometry.

Figure 3.12: Extracellular loading of TPPI into EVs

Figure 3.13: Endogenous loading of a drug protein to EVs quantified by Western Blot analysis 65

Figure 3.14: Biodistribution of FR $\alpha$-presenting and control EVs. 67

Figure 3.15: Growth behavior of KO and control mice treated with exosome and the control treatment. 70

Figure 3.16: Performance of the WT and the KO mice in the behavioral tests. 73

Figure 4.1: Schematic size demonstration of an exemplary protein, apoferritin, in comparison to an exosome modified from Li et al. 


\section{List of tables}

Table 1: List of materials .......................................................................................................... 17

Table 2: List of specific instruments ................................................................................... 17

Table 3: List of mammalian cell lines ....................................................................................... 18

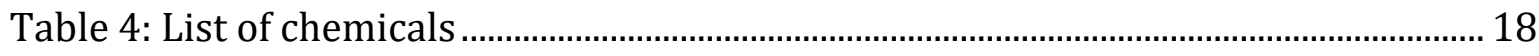

Table 5: List of enzymes and kits ........................................................................................ 19

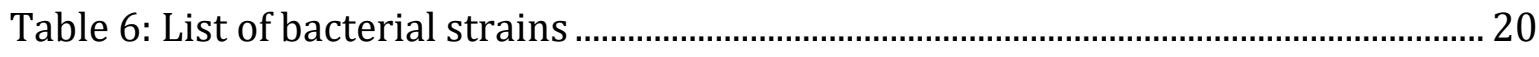

Table 7: List of buffer and media as well as their recipes .................................................. 20

Table 8: List of primary antibodies ....................................................................................... 21

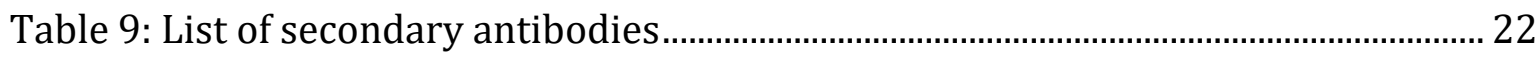

Table 10: List of primers ........................................................................................................ 22

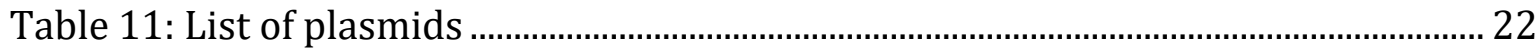

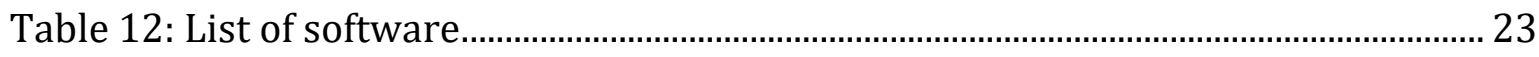

Table 13: Preparation of 10 and $15 \%$ discontinuous polyacrylamide gels..................... 29

Table 14: Preparation of sucrose solutions for sucrose gradient centrifugation. …….. 30

Table 15: Formula for the replacement therapy of the PTPS-KO mice in accordance to

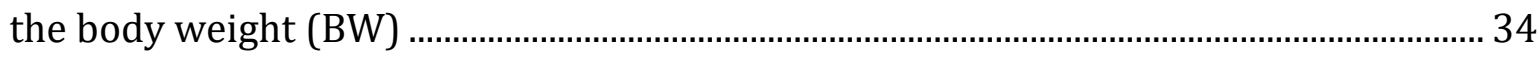




\section{Abbreviations}

\begin{tabular}{|c|c|}
\hline 5HTP & 5-hydroxytryptophan \\
\hline $5 \mathrm{MTHF}$ & 5-methyltetrahydrofolate \\
\hline $\mathrm{BBB}$ & blood-brain barrier \\
\hline BCA & bicinchoninic acid \\
\hline BCSFB & blood-cerebrospinal fluid barrier \\
\hline BH2 & dihydropterin \\
\hline $\mathrm{BH} 4$ & tetrahydropterin \\
\hline BSA & bovine serum albumin \\
\hline BW & body weight \\
\hline CC700 & Capto $^{\mathrm{TM}}$ Core 700 \\
\hline CNS & central nervous system \\
\hline Cryo-TEM & cryogenic transmission electron microscopy \\
\hline CSF & cerebrospinal fluid \\
\hline CV & column volumes \\
\hline DC & differential centrifugation \\
\hline DHPR & Dihydropteridine Reductase \\
\hline DMSO & dimethyl sulfoxide \\
\hline EM & electron microscopy \\
\hline ERT & enzyme replacement therapy \\
\hline ESCRT & endosomal-sorting-complexes-required-for-transport \\
\hline EV & Extracellular vesicles \\
\hline FCS & fetal calf serum \\
\hline FPLC & fast performance liquid chromatography \\
\hline FR & folate receptor \\
\hline FT & flow through \\
\hline GAP43 & growth-associated protein \\
\hline GEEC & GPI-enriched early endosomal compartments \\
\hline GPI & glycosyl-phosphatidylinositol \\
\hline GTPCH & Guanosine Triphosphate Cyclohydrolase \\
\hline HPLC & high-performance liquid chromatography \\
\hline i.v. & intravenously \\
\hline IDA & iminodiacetic acid \\
\hline IEC & ion exchange chromatography \\
\hline IMAC & immobilized metal affinity chromatography \\
\hline IPTG & isopropyl- $\beta$-D-thiogalactopyranosid \\
\hline IRDye800 & near infrared fluorescent dye \\
\hline ISEV & International Society of Extracellular Vesicles \\
\hline KO & knock out \\
\hline LINCL & late infantile neuronal ceroid lipofuscinosis \\
\hline
\end{tabular}




$\begin{array}{ll}\text { mCling } & \text { membrane-binding fluorophore-cysteine-lysine-palmitoyl } \\ \text { MVB } & \text { multi vesicular bodies } \\ \text { NCL } & \text { neuronal ceroid lipofuscinosis } \\ \text { NP } & \text { nanoparticle } \\ \text { NTA } & \text { Nanoparticle tracking analysis } \\ \text { pBS } & \text { pBluescript } \\ \text { PEG } & \text { polyethylene-glycol } \\ \text { Phe } & \text { phenylalanine } \\ \text { PI-III } & \text { peak I -III } \\ \text { PS } & \text { phosphatidylserine } \\ \text { PTPS } & \text { 6-Pyrovyoltetrahydrobiopterin-Synthase } \\ \text { QA } & \text { quaternary amines } \\ \text { rpm } & \text { rounds per minute } \\ \text { RT } & \text { room temperature } \\ \text { SDS-PAGE } & \text { sodium dodecyl sulfate polyacrylamide gel electrophoresis } \\ \text { SEC } & \text { size exclusion chromatography } \\ \text { SEM } & \text { scanning electron microscopy } \\ \text { SR } & \text { Sepiapterin Reductase } \\ \text { TEM } & \text { transmission electron microscopy } \\ \text { TPPI } & \text { Tripeptidyl-Peptidase I } \\ \text { Trp } & \text { Tryptophan } \\ \text { Tyr } & \text { Tyrosine } \\ \text { WT } & \text { wildtype } \\ & \end{array}$




\section{Introduction}

Even though the heart is seen as the driving force of an organism, the brain is the centrum of most actions, decisions and emotions. This central system is a very sensitive organ with its own physiological milieus and a limited capacity for regeneration. For these reasons, the central nervous system (CNS) is protected by barriers like the blood-brain barrier (BBB) and the blood-cerebrospinal fluid barrier (BCSFB). These very selective and effective protection systems are major hurdles for the treatment of CNS disorders. Despite an increase of scientific efforts, the development rate of new drugs does not comply with the growing knowledge of the nervous system. Still most new drugs are not able to pass the BBB (Pardridge, 2003).

William Pardridge nicely outlined the strategies to overcome such biological barriers. In general, he described four delivery strategies (Pardridge, 2003). The first and most straightforward one is the modification of the molecule properties. Particles smaller than approximately $400 \mathrm{Da}$ with lipophilic characteristics are able to pass the BBB (Pardridge, 2005). Another strategy is the disturbance of protecting mechanisms with an additional drug, like the hindrance of an active efflux of therapeutic molecules (Pardridge, 2003). The third approach is the mimicking of intrinsic molecules that are transported to the brain by carrier proteins, as for example, L-Dopa is transported by the type 1 large neutral amino acid transporter (Pardridge, 2003). The fourth strategy is to use existing receptor-dependent transport systems like the insulin receptor or the transferrin receptor and to mask or hide the therapeutic molecules just like in a Trojan Horse (Pardridge, 2003). The fourth strategy resembles most the principal strategy that is presented in the following.

\subsection{Background}

In 2013, Professor Steinfeld's working group was able to resolve the function of folate receptor $\alpha(F R \alpha)$ in the brain (Grapp et al., 2013). Folates are essential metabolites that mammals take up with their diet. They are absorbed by the small intestine and processed to the major physiological form 5-methyltetrahydrofolate (5MTHF) in the 
liver. 5MTHF is then distributed in the blood to all organs. Enzymes functionally depending on folates are involved in the metabolic cycles for the synthesis of thymidylate and purines, precursors for nucleotides and methionine an interconversion of the amino acids serine and cysteine (Pietrzik et al., 2010). Folate deficiency or disruption of the folate metabolism leads to severe diseases. Lack of sufficient folate supply is associated with serious neural-tube defects, malformations evolving during embryogenesis by failure of closure of the neural tube. A supplementation of folic acid, a synthetic form of folate, led to a reduction of the prevalence in various countries (Imbard et al., 2013).

The transport of folates into cells is performed by different transport mechanisms. The major transporter of folates is the ubiquitously expressed reduced folate carrier. This antiporter is able to transport folate into cells at physiological pH of 7.4 (Zhao et al., 2011). The proton-coupled folate transporter is less abundant and has a transport optimum at low pH (Zhao et al., 2011) and is rather active in the digestive system for folate uptake. The third transport mechanism refers to the folate receptors (FRs). These have the highest affinity to folates with a dissociation constant $K_{d}$ of $10 \mathrm{pM}$ (Wibowo et al., 2013).

\subsubsection{Folate Receptor $\alpha$}

There are at least three types of FRs: FR $\alpha, \beta$ and $\gamma$. FR $\alpha$ and $\beta$ are attached to a glycosyl-phosphatidylinositol(GPI)-anchor and are incorporated into lipid rafts of the cell membrane (Ikezawa, 2002). FR $\gamma$ is constitutively secreted by lymphoid cells (Hao et al., 2003) and because of an inefficient anchoring sequence not attached to membranes (Shen et al., 1995). FR $\alpha$ is expressed in epithelial cells of the choroid plexus, the kidney and mammary gland. It is upregulated in a variety of malignancies of these cells and also in malignancies of other origin (Ross et al., 1994). FR $\beta$ is present in neoplastic tissues of non-epithelial origin (Ross et al., 1994), FR $\alpha$ is used for diagnostic imaging of FR $\alpha$-positive tumors (Ke et al., 2003) and FR $\alpha$-binding partners, also called antifolates, were designed to specifically target cytotoxic compounds (Low and Kularatne, 2009). 
Grapp et al. identified several mutations in the FR $\alpha$-encoding gene FOLR1 in patients with reduced concentrations of 5MTHF in the cerebrospinal fluid (CSF) (Grapp et al., 2012). This way, FR $\alpha$ could be identified as the key protein in the transport of folates to the brain. Furthermore, they could show that FR $\alpha$ is internalized at the basolateral side of the choroid plexus in early endosomal vesicles. These vesicles are processed to GPI-enriched early endosomal compartments (GEEC) and to multi vesicular bodies (MVB). MVB fuse with the apical side of the choroid plexus cell layer and the vesicles are released as exosomes to the CSF (Grapp et al., 2013). Furthermore, the researchers could prove the distribution of these vesicles throughout the whole brain parenchyma indicating that $\mathrm{FR} \alpha$-containing vesicles are used as transport vehicles for the supply of the CNS with folates. A scheme of the uptake mechanism is displayed in figure 1.1.

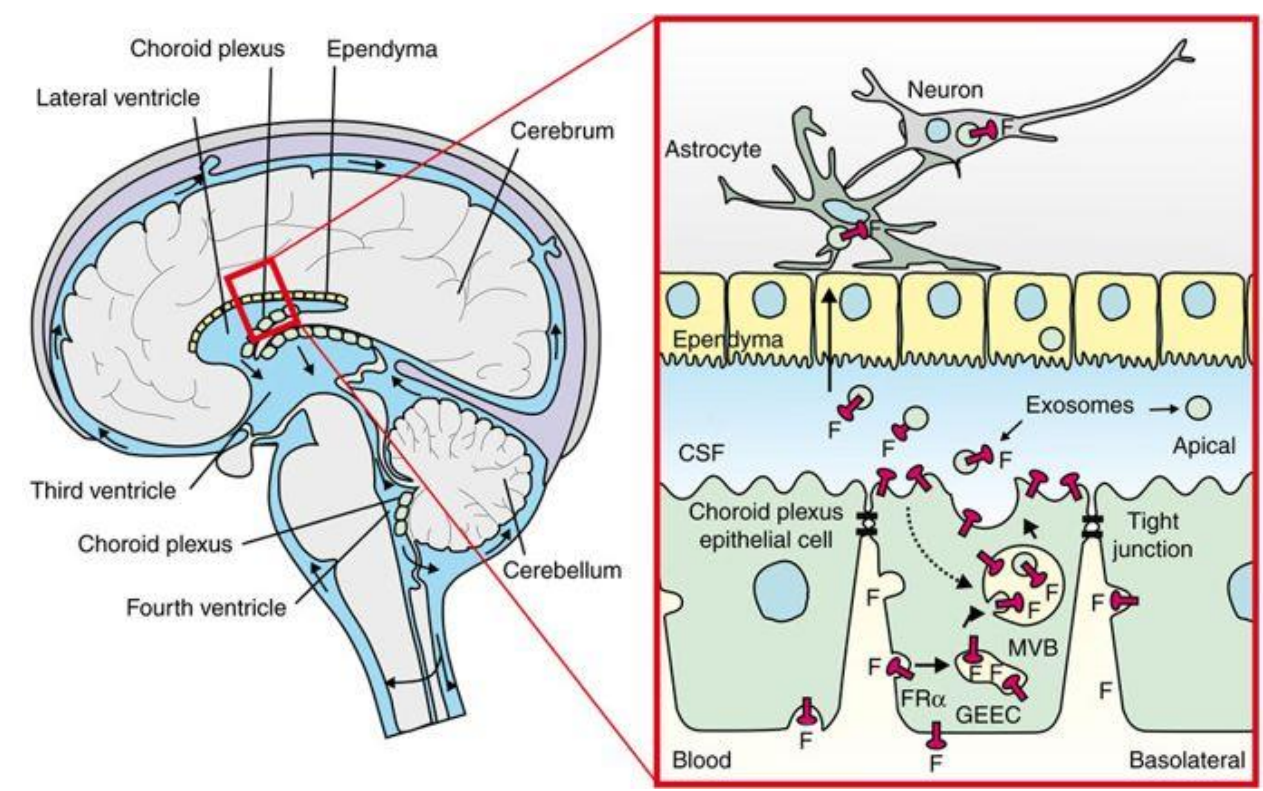

Figure 1.1: Schematic overview of FR $\alpha$ transcytosis in the choroid plexus.

5MTHF (F) binds to FR $\alpha$ at the basolateral side of the choroid plexus and is being internalized to GPI-enriched early endosome compartments (GEEC) and processed through multi vesicular bodies (MVB). FR $\alpha$-positive vesicles are formed by invagination to endosomal vesicles. These FR $\alpha$-positive vesicles are released to the CSF after fusion of the MVB with the cell membrane (Grapp et al., 2013). 


\subsection{Extracellular Vesicles}

Exosomes are one of three types of extracellular vesicles (EVs); the other subtypes are apoptotic bodies and microvesicles. Apoptotic bodies evolve during cell apoptosis and are 1-2 $\mu \mathrm{m}$ of size. These vesicles can be easily distinguished according to their size. Microvesicles form by outward budding of the cellular membrane and have more characteristics, like size and some protein markers, in common with exosomes. Exosomes originate from the endosomal pathway.

The scientific field on extracellular vesicles is strongly emerging. Especially publications on exosomes increased in the last decades as shown in figure 1.2. The interest in exosomes grew rapidly since, it became obvious that exosomes are an important communication tool and are specifically internalized by cells (Pan and Johnstone, 1983). Until this time, it was rather thought of them as waste disposal systems (Sutaria et al., 2017). In general, no unique protein marker for exosomes could be clearly defined yet and the Journal of Extracellular Vesicles recommends referring to extracellular vesicles rather than using the term exosomes (Gould and Raposo, 2013). It must be clear that EVs are a very diverse group of extracellular organelles and must be classified according to their biogenesis pathway (Sutaria et al., 2017).

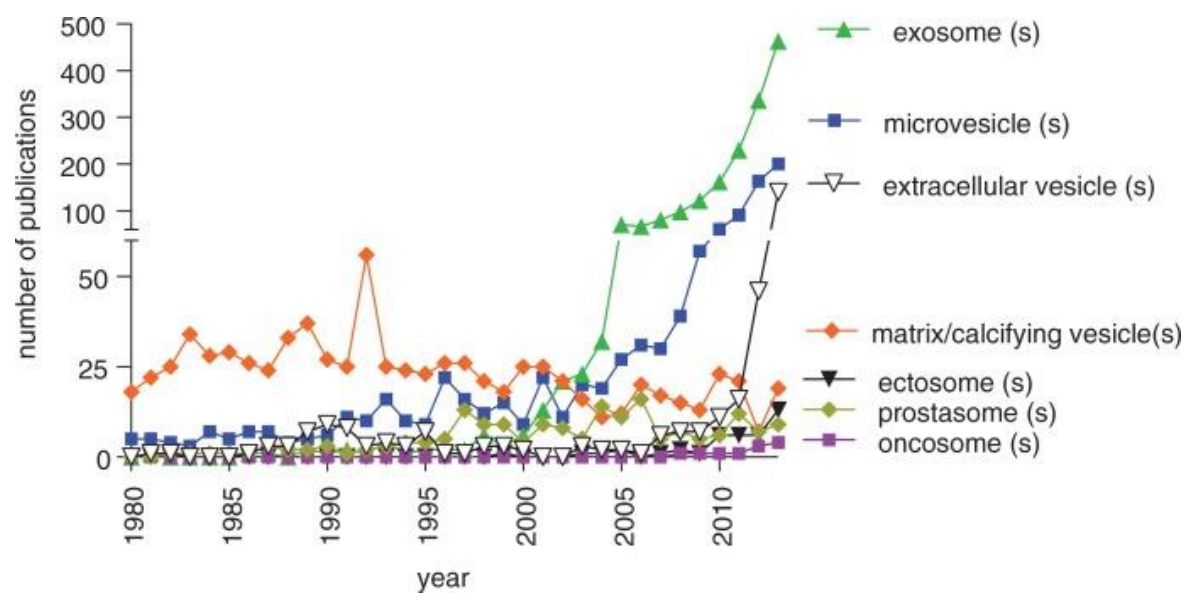

Figure 1.2: Development of research on extracellular vesicles.

The number of publications on extracellular vesicles increased notably from the year 2004 until the time of analysis in December 2013. In 2011 the International Society of Extracellular Vesicles (ISEV) recommended the use of the general term EVs and the use rapidly grew. The numbers were normalized to number of scientific medico-biological publications per year (Lötvall et al., 2014). 


\subsubsection{Exosomes}

Most cells release exosomes. Consequently, all major physiological fluids like breast milk, urine or blood plasma contain exosomes. They are bilayer membrane vesicles with a size of 50-1000 nm (Raposo and Stoorvogel, 2013) and a density of 1.13$1.19 \mathrm{~g} / \mathrm{ml}$ (Kourembanas, 2015). The exosomal membrane forms from inward budding of the endosomal vesicle membrane enclosing intercellular components from the cytosol. Still the exosomal membrane has a different composition than the cell membrane of origin. Disaturated phospholipids are enriched and the protein/lipidratio is higher than in the parental cell, resulting in an increased rigidity (Record et al., 2014). Cholesterol, ceramide and phosphoglycerides are concentrated in exosomes and might be one of the reasons for their stability (Kourembanas, 2015). Lipid sorting occurs in the phase from the early to the late endosomal stage, at the MVB-level (Subra et al., 2007). Lipid rafts are cholesterol-rich membrane regions that are known to contain high amounts of GPI-anchored proteins (Sharma et al., 2004). The intercellular sorting of FR $\alpha$ as a GPI-anchored protein has been demonstrated to be targeted to GEEC (Sabharanjak and Mayor, 2004).

Exosome formation is supported by syndecan-syntenin interacting with ALIX for the endosomal membrane budding. The endosomal-sorting-complexes-required-fortransport (ESCRT) machinery is involved in the exosome biogenesis, but there is also a ESCRT-independent pathway (Zhang and Yang, 2018). Resulting from this, MVBspecific proteins like Alix and TSG101, and endosome-associated proteins like annexins and flotillin are regarded as exosome markers (Kourembanas, 2015, Raposo and Stoorvogel, 2013).

Exosomes contain proteins from the Golgi complex, DNA and different types of RNA, like tRNA, small interfering RNA and miRNA. This content is selectively incorporated during exosome biogenesis and even present in different amounts than in the parental cell. These observations suggest a specific packaging of exosomes for information transfer with other cells (Raposo and Stoorvogel, 2013). Some MVB are also directed to lysosomes for degradation as depicted in figure 1.3. 


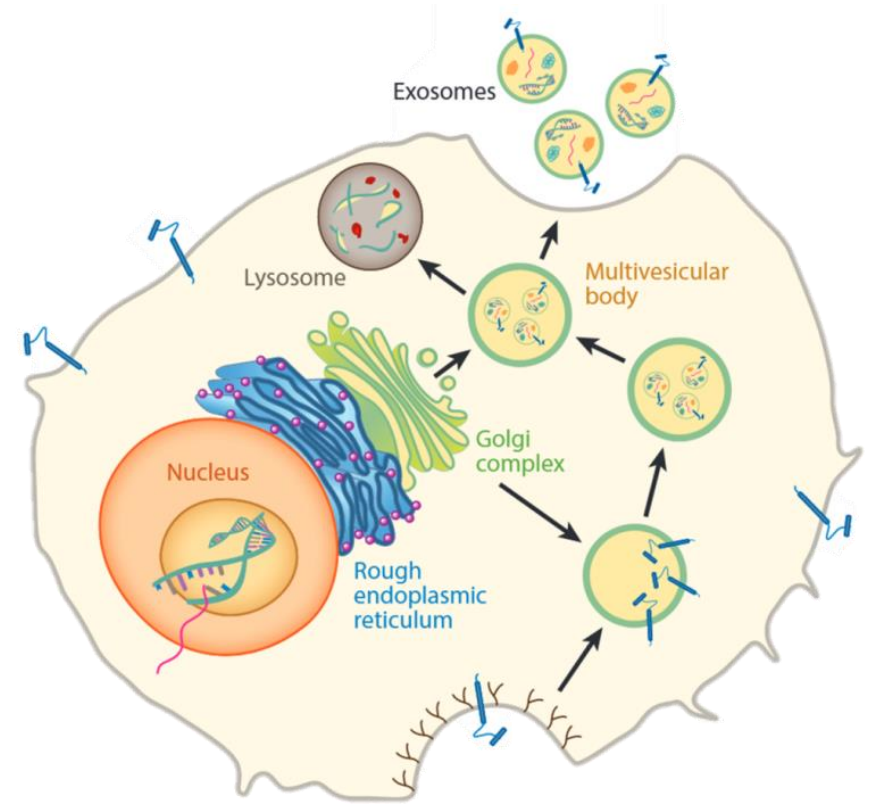

Figure 1.3: Exosome biogenesis - from formation to release.

Exosome formation can be separated in three stages: the first includes the endosome formation from the cell membrane, the second makes up the exosome formation from inward budding of the endosomal membrane and its procession to MVB. At last, these vesicles are released after fusion of the MVB with the cell membrane. Some late endosomal compartments are also directed to lysosomes (Kourembanas, 2015).

\subsection{Exosomes in clinical application}

Exosomes are already in clinical application. There are many publications on the feasibility of exosomes as diagnostic and prognostic tools especially for cancers like mamma carcinoma, pancreatic cancer or glioblastoma (Soung et al., 2017).

In addition, there have been promising results on the application of exosomes for vaccination. For example, in a phase II trial, exosomes were used for activation of the immune system against tumor cells. Patient monocyte derived dendritic cells were isolated and the expression of CD40, CD80, CD86, and CD54 induced (Viaud et al., 2011). An increase of natural killer cells and a stabilization of tumor progression of at least 4 months in patients with inoperable non-small cell lung cancer could be achieved (Besse et al., 2016). Beside their capacity to function as diagnostic or immunological tools, exosomes are excellent candidates for drug delivery because of their stability and the possibility to transport cargo. There are phase I trials on exosomes derived from patient dendritic cells, modified with antigens and again 
administered to the patient (Hosseini et al., 2015). In these experiments the feasibility and safety of EVs derived from dendritic cells could be proven.

In general, the application of EVs in clinic is possible. They would be regarded as biopharmaceuticals and would be covered by guidelines for the manufacturing and the evaluation of biological medicine, that are existing in the United States, the European Union and Australia. Maybe more specific guidelines for EVs will be needed (Lener et al., 2015).

\subsubsection{Purification and characterization}

Despite the increasing interest in EVs, the tools for EV isolation, their modification and application are still in their infancy. A major challenge in the work with exosomes is their intermediate size-range. They are smaller than cells, but bigger and structurally more complex than proteins.

Exosomes are mainly purified regarding their size and density, less common is the isolation by immunoaffinity or surface charge. The most common protocol for EV isolation is differential centrifugation (DC) (Witwer et al., 2013). In several centrifugation steps bigger particles are pelleted and discarded until in a final ultracentrifugation step, exosomes are isolated. This product can be further purified with an additional centrifugation step by washing or by subjection to a density gradient.

The application of density gradient centrifugation with an additional purification by ultrafiltration or a previous washing step have been regarded as superior because of an increased purity (Greening et al., 2015) and a reduced formation of EV aggregates (Momen-Heravi et al., 2013).

More innovative but also requiring more sophisticated equipment is the application of flow field-flow fractionation. This method is based on a thin layer of flow in the one direction of the particulate sample while an additional flow in another direction is applied across the driving flow. The particles are separated according to their diffusion in the fractionating flow (Kang et al., 2008). This method was limited to 
small volumes of 1-2 ml, but a repeated application and pooling of the resulting EVpreparations might allow its application for the production of high scales (Petersen et al., 2014).

From experiences of the virus field, another method based on polyethylene-glycol (PEG) precipitation has been established and is widely used for exosome isolation (Taylor et al., 2011, Zlotogorski-Hurvitz et al., 2015, Rekker et al., 2014). EVs bind to PEG because of negative surface charge and can be easily centrifuged at low speed and isolated. Compared to isolation by ultracentrifugation, the sheer-stress is reduced and less equipment is needed. The main disadvantage is the impossibility to remove PEG and the precipitation of contaminating proteins (Kotmakçı and Akbaba, 2017).

For a characterization of exosomes, the Journal of Extracellular Vesicles names 4 minimal requirements. Only covering all areas can ensure to reliably work on EVs (Lötvall et al., 2014).

1. General characterization of proteins enriched in EVs and proteins absent by Western Blot analysis or flow cytometry

2. Analysis of single vesicles for the shape and homogeneity by electronic microscopy or atomic force microscopy

3. Analysis of the size distribution by nanoparticle tracking analysis or dynamic light scattering

4. Study of the biological activity

\subsubsection{Drug loading}

Since the biological effect of many therapeutics like oligonucleotides, proteins or small molecules is hampered by fast clearance, immunologic reaction and unspecific targeting, there are many efforts to load drugs into EVs. Other approaches like packing in liposomes, viral vectors for nucleotides and peptide conjugation remain problematic (Sutaria et al., 2017).

In literature, experts generally speak of exogenous and endogenous loading. While exogenous loading is performed with purified or isolated vesicles, endogenous loading is depending on the cell system to introduce the drug as RNA or protein to the 
vesicles. In context of exogenous loading, terms of active and passive loading are used (Sutaria et al., 2017), defining passive loading as the incubation of the pure vesicles with the drug and active in means of forming pores into the membrane. These terms are misleading, since active loading could rather be understood as an active action like it is being done within the endogenous loading process of the cell. Because of the small size of exosomes, both exo- and endogenous loading methods are very challenging and the capacity of the EVs is limited to their volume.

For exogenous loading, there are mainly three approaches: loading after formation of pores, loading without formation of pores and loading with the help of an osmotic gradient. The formation of pores in the vesicles is usually done with detergents like saponin to permeabilize the membrane. Mechanical methods for pore formation are electroporation, freez- and thaw-cycles and sonication. When EVs are incubated with the drug without formation of pores, drugs are sometimes modified with cholesterol or other conjugations like ubiquitination to increase their localization to exosomes (Stremersch et al., 2016, Sterzenbach et al., 2017). To permeabilize EVs with the help of osmosis, the vesicles are subjected to a hypotonic solution which induces a swelling and therefore a slight disruption of the membrane. This way, molecules can diffuse into the vesicles (Fuhrmann et al., 2015).

For the endogenous loading, cells are transfected with the gene of the therapeutic protein or RNA and a proportion of the molecule localizes to the EVs. The conjugation and modification of the protein-encoding gene by for example, a C1C2-domain of a vesicle membrane located protein lactadherin (Zeelenberg et al., 2008) or the exosomal membrane protein Lamp2b (Alvarez-Erviti et al., 2011) can enhance the amount in the vesicles. Fusion of the cargo-protein to a vesicle membrane protein results in a high recovery within the exosomes but leads to an anchoring of the protein to the membrane, which might in some cases inhibit the enzymatic activity of the protein.

For all methods used it is crucial to perform appropriate controls. For instance, electroporation has long time been recommended for pore formation in exosomes 
and subsequent loading but by now it is known that molecules tend to aggregate after the application of an electric field (Luan et al., 2017). Therefore, these protein aggregates properties might resemble vesicular properties in centrifugation steps or when applied to size exclusion chromatography columns and thus might lead to false positive results.

\subsubsection{Exosome application and distribution}

Although exosomes reached the clinical application for diagnostic purposes, for example in the diagnosis of lung cancer (Sheridan, 2016) and the number of clinical trials almost doubled in 2017, there were only 2 trials on EVs for therapeutical application (Gimona et al., 2017). There are still major challenges that have to be resolved before they can be applied on regular basis as therapeutics. The production and application of biopharmaceuticals is more difficult than of a single chemical molecule. In contrast, the synthesis of biologicals such as proteins or vesicles is more complex and the delivery is not as straightforward. Other liabilities are the temperature and moisture the product needs to sustain during storage and inside the body (Mitragotri et al., 2014). In case of exosomes or EVs, the screening for a stable product with defined content and properties represent major hurdles that have to be overcome.

At the current state of science it is believed that exosomes can be stored in their biological matrix following a crude purification by which contaminations are removed (Lener et al., 2015). It is also assumed that exosomes are less effected by freeze- and thaw-cycles than proteins (Lener et al., 2015).

EVs have been applied in animal experiments by numerous administration routes: orally (Munagala et al., 2016), intravenously (i.v.) (Takahashi et al., 2013)and intranasally (Zhuang et al., 2011). EVs behave in vivo similar to liposomes of small size and with negative surface charge (van der Meel et al., 2014). Intravenously applied liposomes result in a better overall tissue distribution when the circulation time is extended. Nevertheless, the main organs for the uptake remain liver and spleen (van der Meel et al., 2014). Specific surface ligands, lipid composition and the endo- or 
exogenous origin of the obtained EVs will have substantial influence on their distribution within an organism. For i.v. applied not modified exosomes an uptake in the liver and spleen could be proven in small animal experiments just as for liposomes (Tian et al., 2014). For orally administered vesicles a better overall distribution and a reduced accumulation in the liver than for i.v. applied EVs could be proven. The uptake of the orally administered vesicles and their correct delivery could be proven by the observed anti-tumorigenic effect (Munagala et al., 2016).

The intraventricular and intranasal applications are a more direct routes to the CSF. By this route, the BBB and the BCSFB can be bypassed and the local concentration in the brain is increased in comparison to a systemic application. In other experiments with intranasally applied proteins a passage of $0.001 \%$ of the totally applied protein could be detected in the CSF (Wolf et al., 2012). In the case of intranasal application, the drug is able to be taken up through the mucosa of the nose, passes the olfactory bulb and finally reaches the cerebrospinal fluid.

\subsection{Model diseases suitable for the screening of exosomal transport vehicles}

In this project, two neuropediatric diseases were considered as suitable for the screening of FR $\alpha$-presenting vesicles as drug delivery vehicles to the CNS.

\subsubsection{Late infantile neuronal ceroid lipofuscinosis}

Neuronal ceroid lipofuscinosis (NCL) is a group of rare diseases that belong to the childhood dementias. There are at least 13 genetic defects that are associated with distinct types of NCLs sharing characteristic lysosomal storage (Rakheja and Bennett, 2018). In the past, subgroups were categorized according to their clinical appearance. Late infantile NCL, LINCL has an onset with 2-4 years. All NCL diseases present with similar symptoms like early loss of vision, progressive neuronal degradation and motor dysfunction (Bennett and Rakheja, 2013). The patients have a significantly reduced life expectancy and are strongly impaired by the neuronal loss. This fatal course of disease with no curative treatment generates a pressing need for new treatment strategies. 
The NCL disorders share the accumulation of lipofuscin in the cells resulting from the impaired lysosomal function. Mutations in the gene CLN2 encoding tripeptidylpeptidase I (TPPI) lead to the loss of the lysosomal peptidase activity and the clinical manifestation of LINCL (Wisniewski et al., 2001). While for most forms of NCL no curative treatment is available, for CLN1, CLN2, CLN10 and CLN13 (Neverman et al., 2015) an enzyme replacement therapy (ERT) is feasible and under investigation in clinical trials, after promising results in animal experiments (Wiseman et al., 2017, Chang et al., 2008).

The mouse model for LINCL was established by disruption of the murine TPPIencoding gene by a point mutation (Sleat et al., 2004). These mice have a survival of $138 \mathrm{~d}$ during which $90 \%$ of the animals die. These mice have a similar phenotype as described in human patients: they are born healthy or apparently healthy and then develop tremor, ataxia and show symptoms of neurodegeneration. These mice could be treated by an ERT and disease progression slowed down (Chang et al., 2008). The ERT was administered by intraventricular injection by implantation of an osmotic pump into 60 days old mice. This pump continuously injected $100 \mu \mathrm{l}$ TPPI for 1 month in a concentration of $1 \mathrm{mg} / \mathrm{ml}$.

TPPI is a soluble lysosomal protein (Bennett and Rakheja, 2013). The precursor of TPPI appears with a size of $66 \mathrm{kDa}$ (Guhaniyogi et al., 2009). The mature form has a size of $48 \mathrm{kDa}$ (Golabek et al., 2004). The signal peptide in the precursor directs the protein to the endoplasmic reticulum for glycosylation. The mature form is formed by catalytic processing within the cell in the lysosome at low pH (Guhaniyogi et al., 2009).

\subsubsection{Biopterin Disorders}

Biopterin is an essential cofactor in the synthesis of dopamine, serotonin, tyrosine (Tyr), 5-hydroxytryptophan (5HTP), nitric oxide and glycerol (Niu, 2011). 


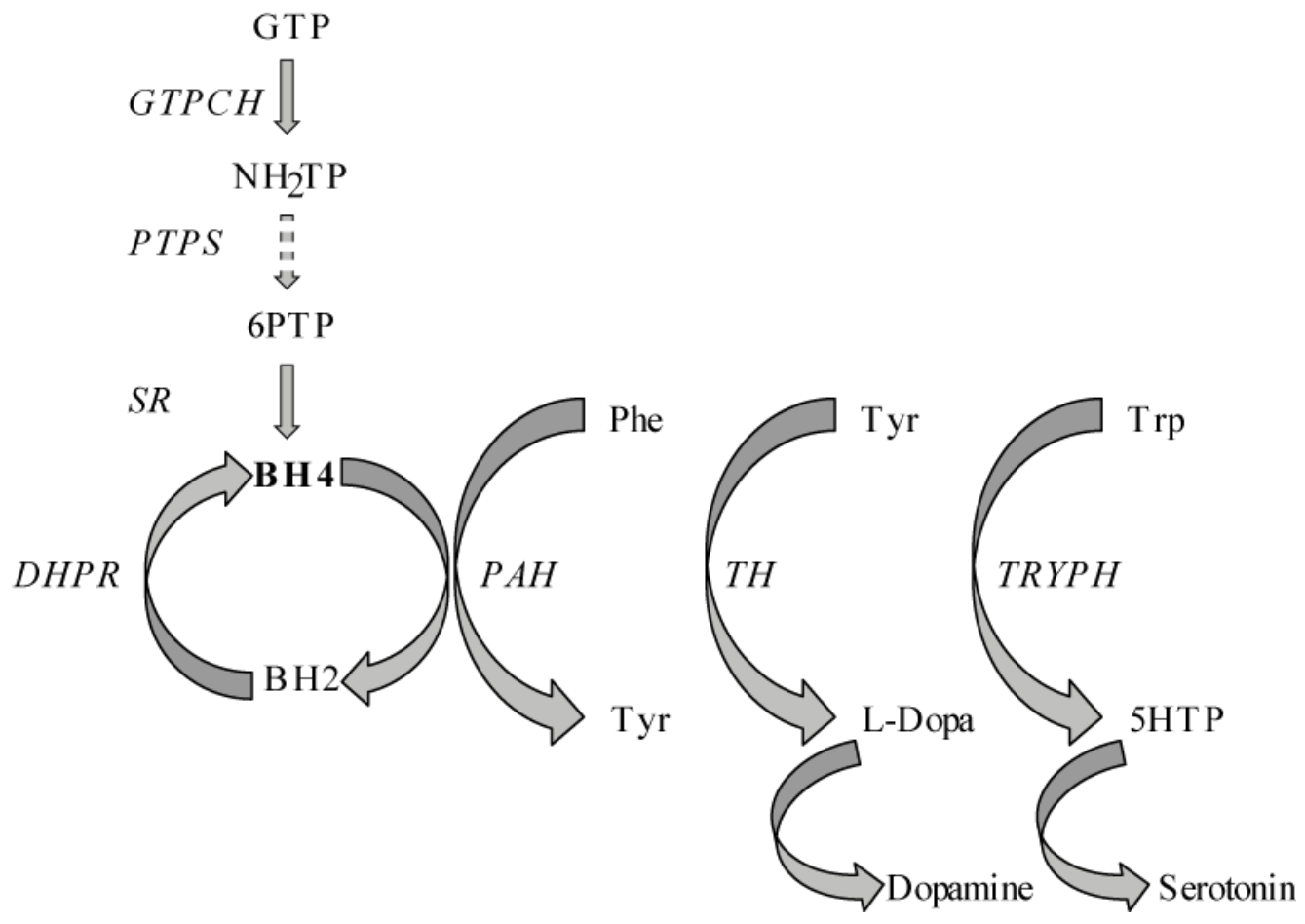

Figure 1.4: Metabolism of biopterin adopted and modified from Clot et al..

Defects in the biopterin metabolism originate from dysfunctions in the synthesis reactions by defects in the Guanosine Triphosphate Cyclohydrolase I (GTPCH), the Sepiapterin Reductase (SR) or the target protein in this project 6-Pyrovyoltetrahydrobiopterin-Synthase (PTPS) or by dysfunctional regeneration of tetrahydropterin (BH4) from dihydropterin (BH2) by the enzyme Dihydropteridine reductase (DHPR). This leads to very severe metabolic disorders among others by imbalances of the amino acids phenylalanine (Phe), Tyrosine (Tyr) and Tryptophan (Trp) or a lack of dopamine and serotonin (Clot et al., 2009).

A biopterin disorder is either caused by a defect in the synthesis or a defect in the regeneration of the cofactor, for instance by dysfunction of the enzyme dihydropteridine reductase (DHPR). The synthesis of biopterin is made up by three enzymatic steps as visible in figure 1.4. Defects in the gene encoding the second enzyme the 6-Pyrovyoltetrahydrobiopterin-Synthase (PTPS) are the most common mutations resulting in tetrahydrobiopterin deficiency (Niu, 2011). Biopterin disorders are nowadays identified by newborn screenings, presenting with elevated phenylalanine (Phe) concentrations in the blood (Mascaro et al., 2016). In the past, prior to the introduction of newborn screenings, the disorder manifested as a neurological disorder with symptoms similar to Parkinson diseases (Liu et al., 2008). Without treatment this disorder leads to death in early childhood. At present, patients 
are substituted with biopterin, 5-hydroxytryptophan and L-Dopa. The long-term treatment of these patients is challenging since medication must regularly be adapted according to the results of the CSF-analysis obtained by lumbar punctuation (Niu, 2011). Despite an early therapy onset there are affected children with reduced IQ score and patients that suffer from dyskinesia (Dudešek et al., 2001).

The enzyme is a small protein of $16.9 \mathrm{kDa}$ with 148 amino acids. Mammalian PTPS is functional in a homohexameric form (Thöny, 2006). It is ubiquitously present (Thöny, 2006) and depends on the presence of magnesium (Bürgisser et al., 1995). The measurement of the PTPS-activity is difficult since the substrate 7,8-dihydroneopterin triphosphate needs to be synthesized in situ and the reaction is therefore based on a multiple step enzyme reaction. Additionally, the third enzyme of the biopterin biosynthetic pathway, sepiapterin reductase, needs to be present to convert the highly unstable 6-pyruvoyltetrahydropterin to biopterin. Biopterin is finally measured by HPLC with fluorescence detection of the fluorescent product (Blau et al., 2008).

Mice lacking PTPS-activity (pts-/- mice) have a very severe phenotype and die perinatal or few hours up to some days after birth (Sumi-Ichinose et al., 2001, Elzaouk et al., 2003). These animals can be rescued by substitution therapy as described for human patients with biopterin, 5-hydroxytryptophan and $L$-Dopa, however with tenfold higher doses needed. The most striking on their phenotype is the strong growth retardation, the pts-/- mice have only one-third of the normal body weight (BW) at maturation with $7.8 \pm 1.5 \mathrm{~g}$ in comparison to $23.1 \pm 2.4 \mathrm{~g}$ of a healthy mouse at that age (Elzaouk et al., 2003). This very severe phenotype and the high amount of substitution result from the higher PTPS-enzyme activity. The murine PTPS is approximately ten times more active than the human one (Elzaouk et al., 2003). The treated $p t s-/-$ mice have more symptoms like hypersalivation, reduced rate of activity and never reach sexual maturity. 


\subsubsection{FR $\alpha$-conjugated nanoparticles}

Another therapeutic approach will be to analyze the performance of FR $\alpha$-conjugated artificial nanoparticles (NPs) that will be loaded with sepiapterin. These particles are designed in Technion by a cooperating group (Prof Sosnik's group). Originally, it was planned to load biopterin to these nanoparticles but because of its low stability, sepiapterin was chosen for the nanoparticles. Additionally, FR $\alpha$ was conjugated by functionalized carboxymethyl- and amine-groups to the surface of the NPs. Since sepiapterin is the product of the reaction of PTPS, this substitution should have a similar beneficial effect as the substitution with PTPS. Providing the enzyme itself to the cells might have a more consistent effect on the biopterin metabolism. The effect is highly depending on the uptake and distribution of the particles just as the amount of enzyme that can be delivered to the cells. 


\subsection{Aims of the study}

Because of the central role of FR $\alpha$ in the transport of folates into the brain and its role in many malignancies, it is an attractive candidate for the conjugation to drug transport vehicles from biological as well as synthetic origin. Nanoparticles are of great interest because of their multimodal properties. Biological NPs like exosomes might have even more advantages because of their biocompatibility, but their production, evaluation and maintenance are at the moment more challenging.

The project can be divided into three main parts:

1. Production and characterization of vesicles for the future therapeutic application

a. Purification of EVs from human cell culture line in a high scale with and without the FR $\alpha$-conjugation

b. Comparison of the most common isolation procedure with the established purification method

c. Full characterization of the EV preparation according to the guideline of the International Society of Extracellular Vesicles (ISEV)

2 . Introduction of therapeutic cargo to the EVs

a. Exogenous loading and quantification of the charged drug enzyme

b. Endogenous loading and quantification of the charged drug enzyme

3 . Investigation of the biological performance of the designed EVs

a. Analysis of the uptake of the prepared EVs outside of the organism

b. Analysis of the biodistribution within mice by screening of the organs

c. Evaluation of the therapeutic capacity in an appropriate mouse model 


\section{Materials and methods}

\subsection{Materials}

Table 1: List of materials

\begin{tabular}{|c|c|}
\hline Materials & Company \\
\hline Amicon ultrafiltration unit $10,50,100 \mathrm{~K}$ & Merck KGaA \\
\hline dialysis tube, Zellutrans 6,0 & Carl Roth GmbH + Co. KG \\
\hline Cuvette, $4 \mathrm{~mm}$ & Bio Rad Laboratories GmbH \\
\hline glas cloning rings & Hilgenberg $\mathrm{GmbH}$ \\
\hline HisTrap ${ }^{\mathrm{TM}}$ FF crude column & GE Healthcare \\
\hline IRDye800 CW & LI-COR Biotechnology GmbH \\
\hline Microplate, 96-well, black flat bottom & Greiner Bio-One GmbH \\
\hline Microplate, 96-well, flat bottom & Greiner Bio-One GmbH \\
\hline MINIPERM $^{\circledR}$ & Sarstedt AG \& Co. KG \\
\hline monolithic column, CIMmultus TM IDA-Cu & BIA Seperations d.o.o., Slovenia \\
\hline monolithic column, CIMmultus TM QA & BIA Seperations d.o.o., Slovenia \\
\hline Nitrocellulose blotting membrane & Amersham TM \\
\hline Protran $\AA 0,45 \mu \mathrm{m}$ & Amersham ${ }^{\mathrm{TM}}$ \\
\hline tubes for flow cytometry, $5 \mathrm{ml}$ & Falcon \\
\hline Vivaspin 10000,30000 MWCO & Sartorius AG \\
\hline 24-well plates & Sarstedt AG \& Co. KG \\
\hline
\end{tabular}

Table 2: List of specific instruments

\begin{tabular}{ll}
\hline Instruments & Company \\
\hline \hline Centrifuge, 5417R & Eppendorf AG \\
\hline Centrifuge, 5424 & Eppendorf AG \\
\hline Centrifuge, Mikro 200R, Rotor 2424-B & Andreas Hettich GmbH \& Co. KG \\
\hline Centrifuge, mini, FugeOne@ & Starlab GmbH \\
\hdashline Centrifuge, mini, Sprout & Biozym Scientific GmbH \\
\hline Centrifuge, Universal 320, rotor 1619 & Andreas Hettich GmbH \& Co. KG \\
\hline FACS Canto II & Beckham Coulter GmbH \\
\hline Gene Pulser Xcell & Bio Rad Laboratories GmbH \\
\hline Microplate reader, Bio Tek Synergy Mx & Bio Tek® Instruments \\
\hline Nanosight LM10-HS & Malvern Instruments \\
\hline Optix 2 & Fa. ART \\
\hline Rota Rod & TSE Systems GmbH \\
\hline Ultracentrifuge, SW 28 rotor & Laborgeräte Beranek GmbH \\
\hline Luminescent image reader, LAS-400 mini & Fujifilm \\
\hline MoUSE E MOTION & INFRA-E-MOTION, Hamburg \\
\hline
\end{tabular}


Amersham $^{\mathrm{TM}}$

Table 3: List of mammalian cell lines

\begin{tabular}{lll}
\hline $\begin{array}{l}\text { Cell } \\
\text { line }\end{array}$ & Cell type & $\begin{array}{l}\text { obtained } \\
\text { from }\end{array}$ \\
\hline \hline HEK293 & $\begin{array}{l}\text { human embryonic kidney } \\
\text { cells }\end{array}$ & ATCC \\
\hline K562 & $\begin{array}{l}\text { human myelogenous } \\
\text { leukemia blood cells }\end{array}$ & ATCC \\
\hline BN16 & $\begin{array}{l}\text { Brown Norway rat } \\
\text { choriocarcinoma cells / } \\
\text { rat yolk sac carcinoma cells }\end{array}$ & $\begin{array}{l}\text { Cooperation } \\
\text { partner: } \\
\text { AG Hammes } \\
\text { MDC Berlin }\end{array}$ \\
\hline
\end{tabular}

Table 4: List of chemicals

\begin{tabular}{ll}
\hline Material & Manufacturer \\
\hline 2-propanol & Merck KGaA \\
\hline $\begin{array}{l}\text { acrylamide solution, } 30 \% \text { with } 0.8 \% \\
\text { bisacrylamide }\end{array}$ & Carl Roth GmbH + Co. KG \\
\hline Agarose & Bioline GmbH \\
\hline Ala-Ala-Phe-7-amido-4-methylcoumarin & Bachem \\
\hline ammonium persulfate (APS) & Serva Electrophoresis GmbH \\
\hline ampicillin sodium salt & Sigma Aldrich \\
\hline BCA assay reagent A & Interchim \\
\hline BCA assay reagent B & Interchim \\
\hline Biopterin (11.203) & Schricks laboratories \\
\hline bovine serum albumin (BSA), Fraktion V & Carl Roth GmbH + Co. KG \\
\hline bromphenol blue & Merck KGaA \\
\hline BSA standard solution 2mg/ml & Interchim \\
\hline Carbon grid Formvar/carbon FCF300-Cu & Agar-Scientific, Stansted UK \\
\hline CoCl 2 & Sigma Aldrich \\
\hline dimethyl sulfoxide & Serva Electrophoresis GmbH \\
\hline ethanol & Merck KGaA \\
\hline ethylenediamine tetraacetic acid (EDTA) & Carl Roth GmbH + Co. KG \\
\hline eye salve Augen- und Nasensalbe & Bepanthen ${ }^{\circledR}$ \\
\hline fetal bovine serum (FBS) & PAA Laboratories GmbH \\
\hline Geltrex & Gibco \\
\hline GeneRulerTM, DNA ladder mix & Fermentas Life Science \\
\hline GlutaMAX & Gibco \\
\hline glycerol, anhydrous & Applichem \\
\hline HCl & Merck KGaA \\
\hline HEPES-buffer & Carl Roth GmbH + Co. KG \\
\hline
\end{tabular}




\begin{tabular}{|c|c|}
\hline $\mathrm{KH}_{2} \mathrm{PO}_{4}$ & Carl Roth GmbH + Co. KG \\
\hline LB-Agar (Luria/Miller), powdered & Carl Roth GmbH + Co. KG \\
\hline L-glutamine solution & Sigma Aldrich \\
\hline Lumi-Light Plus Western Blotting substrate & $\begin{array}{l}\text { Roche Deutschland Holding } \\
\text { GmbH }\end{array}$ \\
\hline lysogenic broth (LB)-medium, powdered & Carl Roth GmbH + Co. KG \\
\hline mCling-Atto647 & Synaptic Systems GmbH \\
\hline methanol & J.T. Baker \\
\hline milk powder & Carl Roth GmbH + Co. KG \\
\hline $\begin{array}{l}\text { N,N,N',N'-Tetramethylethan-1,2-diamin } \\
\text { (TEMED) }\end{array}$ & Carl Roth GmbH + Co. KG \\
\hline $\mathrm{Na} 2 \mathrm{PO} 4$ & Carl Roth GmbH + Co. KG \\
\hline $\mathrm{NaCl}$ & Carl Roth GmbH + Co. KG \\
\hline $\mathrm{NaOH}$ & Carl Roth GmbH + Co. KG \\
\hline PageRulerTM Prestained Protein Ladder & Thermo Fisher Scientific \\
\hline paraformaldehyde sulfonic fluoride (PMSF) & Applichem \\
\hline PBS (Dulbecco's PBS) for cell culture & Biowest \\
\hline Ponceau-S solution & Sigma Aldrich \\
\hline Saponin & Carl Roth GmbH + Co. KG \\
\hline sodium dodecyl sulfate (SDS), $20 \%$ solution & Carl Roth GmbH + Co. KG \\
\hline B-mercaptoethanol & Sigma Aldrich \\
\hline sucrose & Riedel-de Haën \\
\hline Triton $®$ X 100 & Carl Roth GmbH + Co. KG \\
\hline $\begin{array}{l}\text { Tryptan blue, } 0.5 \%(\mathrm{w} / \mathrm{v}) \text { in physiological } \\
\text { saline }\end{array}$ & Biochrom GmbH \\
\hline Tween $® 20$ & Merck KGaA \\
\hline
\end{tabular}

Table 5: List of enzymes and kits

\begin{tabular}{ll}
\hline Enzyme/Kit & Company \\
\hline BamHI & New England BioLabs® Inc. \\
\hline BigDye Terminator v3.1 Cycle Sequencing Kit & Thermo Fisher Scientific \\
\hline Effectene Transfection Reagent & Qiagen \\
\hline HindIII & New England BioLabs® Inc. \\
\hline Lumi-Light Western Blot substrate & Thermo Fisher Scientific \\
\hline NheI & New England BioLabs® Inc. \\
\hline NotI & New England BioLabs® Inc. \\
\hline NucleoBond $囚$ Xtra plasmid purification & Macherey-Nagel \\
\hline NucleoType Mouse PCR & Macherey-Nagel \\
\hline PageRuler Plus Prestained Protein Ladder & Thermo Fisher Scientific \\
\hline PageRuler Prestained Protein Ladder & Thermo Fisher Scientific \\
\hline Pierce ${ }^{\mathrm{TM}}$ BCA Protein Assay Kit & Pierce \\
\hline
\end{tabular}




\begin{tabular}{|c|c|c|c|}
\hline SacI & & & New England BioLabs $®$ Inc. \\
\hline ScaI & & & New England BioLabs $®$ Inc. \\
\hline Trypsin/E & DTA solution, & $0.05 \% / 0.02 \%(\mathrm{w} / \mathrm{v})$ & Biochrom GmbH \\
\hline Name & Cell type & Characteristics & obtained from \\
\hline Top Ten & $\begin{array}{l}\text { Escherichia } \\
\text { coli }\end{array}$ & chemically competent cells & $\begin{array}{l}\text { ThermoFisher } \\
\text { Scientific }\end{array}$ \\
\hline M15 & $\begin{array}{l}\text { Escherichia } \\
\text { coli }\end{array}$ & high-level expression strair & Qiagen \\
\hline
\end{tabular}

Table 7: List of buffer and media as well as their recipes

\begin{tabular}{|c|c|c|c|}
\hline & Media/Buffer & Additives/Recipe & Company \\
\hline $\begin{array}{l}\text { HEK293 } \\
\text { culture } \\
\text { medium }\end{array}$ & $\begin{array}{l}\text { Dulbecco's Modified } \\
\text { Eagle Medium } \\
\text { (DMEM), } 4.5 \mathrm{~g} / \mathrm{D} \text { - } \\
\text { glucose }\end{array}$ & $\begin{array}{l}5 \%(\mathrm{v} / \mathrm{v}) \mathrm{FCS} \\
1 \%(\mathrm{v} / \mathrm{v}) \text { L-glutamine }\end{array}$ & Merck KGaA \\
\hline $\begin{array}{l}\text { HEK293 } \\
\text { serumfree } \\
\text { conditions }\end{array}$ & 293 SFMII & $1 \%$ glutamax & $\begin{array}{l}\text { Thermo Fisher } \\
\text { Scientific }\end{array}$ \\
\hline $\begin{array}{l}\text { K562 } \\
\text { culture } \\
\text { medium }\end{array}$ & RPMI medium 1640 & $5 \%(\mathrm{v} / \mathrm{v}) \mathrm{FCS}$ & $\begin{array}{l}\text { Thermo Fisher } \\
\text { Scientific }\end{array}$ \\
\hline $\begin{array}{l}\text { PBS buffer } \\
\text { (SEC) }\end{array}$ & & $\begin{array}{l}137 \mathrm{mM} \mathrm{NaCl} \\
2.7 \mathrm{mM} \mathrm{KCl} \\
10 \mathrm{mM} \mathrm{Na}_{2} \mathrm{HPO}_{4} \\
1.8 \mathrm{mM} \mathrm{KH}_{2} \mathrm{PO}_{4} \\
\text { pH } 7.4\end{array}$ & \\
\hline PBS-T buffer & & $\begin{array}{l}\text { PBS } \\
0.5 \% \text { Tween }^{\circledR} 20\end{array}$ & \\
\hline $\begin{array}{l}\text { buffer A } \\
\text { (IMAC) }\end{array}$ & & $\begin{array}{l}240 \mathrm{mM} \mathrm{NaCl} \\
20 \mathrm{mM} \mathrm{KH}_{2} \mathrm{PO}_{4} \\
\mathrm{pH} 7.4\end{array}$ & \\
\hline $\begin{array}{l}\text { buffer B } \\
\text { (IMAC) }\end{array}$ & & $\begin{array}{l}240 \mathrm{mM} \mathrm{NaCl} \\
20 \mathrm{mM} \mathrm{KH}_{2} \mathrm{PO}_{4} \\
500 \mathrm{mM} \mathrm{Imidazole} \\
\text { pH } 7.4\end{array}$ & \\
\hline $\begin{array}{l}\text { buffer A } \\
\text { (IEC) }\end{array}$ & & $\begin{array}{l}20 \text { M Tris } \\
\mathrm{pH} 8.0\end{array}$ & \\
\hline $\begin{array}{l}\text { buffer B } \\
\text { (IEC) }\end{array}$ & & $\begin{array}{l}20 \mathrm{M} \mathrm{Tris} \\
1 \mathrm{M} \mathrm{NaCl} \\
\mathrm{pH} 8.0\end{array}$ & \\
\hline $\begin{array}{l}\text { protein } \\
\text { extraction }\end{array}$ & & $\begin{array}{l}50 \mathrm{mM} \mathrm{NaH}_{2} \mathrm{PO}_{4} \\
300 \mathrm{mM} \mathrm{NaCl}\end{array}$ & \\
\hline
\end{tabular}




\begin{tabular}{ll}
\hline buffer & $\begin{array}{l}10 \mathrm{mM} \text { Imidazole } \\
\end{array}$ \\
\hline $\begin{array}{l}\text { flow } \\
\text { cytometry } \\
\text { buffer }\end{array}$ & PH 8.0 \\
\hline sucrose & \\
gradient & $0.5-2.5$ sucrose 20 \\
\hline 4x SDS-PAGE & HEPES-buffer \\
sample buffer & $160 \mathrm{mM}$ Tris/HCl pH 6.8 \\
& $8 \%$ (v/v) SDS \\
& $10 \%$ ß-mercaptoethanol \\
& 0.01 g bromphenolblue \\
\hline SDS-PAGE & $20 \%$ Glycerol \\
running & $25 \mathrm{mM}$ Tris \\
buffer & $192 \mathrm{mM}$ Glycin \\
\hline Western Blot & $0.1 \%$ (w/v) SDS \\
transfer & $25 \mathrm{mM} \mathrm{Tris}$ \\
buffer & $160 \mathrm{mM}$ Glycin \\
& $20 \%(\mathrm{v} / \mathrm{v}) \mathrm{MeOH}$ \\
\hline
\end{tabular}

Table 8: List of primary antibodies

\begin{tabular}{|c|c|c|c|}
\hline Antibody & Host & Dilution & Company \\
\hline anti-AIP/Alix & rabbit & $1: 500$ & $\begin{array}{l}\text { MerckMillipore } \\
\text { Cat\# ABC40 } \\
\text { Lot\# } 2867560\end{array}$ \\
\hline anti-flotillin2 & mouse & $1: 1000$ & $\begin{array}{l}\text { BD Biosciences } \\
\text { Cat\# } 610383 \\
\text { Lot\# } 7006854\end{array}$ \\
\hline anti-FR $\alpha$ (MOV18) & mouse & $1: 400$ & $\begin{array}{l}\text { Enzo Life Sciences } \\
\text { Cat\# ALX-804-439 } \\
\text { Lot\# 12151407 }\end{array}$ \\
\hline anti-FR $\alpha$ (NCL) & mouse & 1:2000 & $\begin{array}{l}\text { Leica Biosystems } \\
\text { Cat\#NCL-L-FR } \alpha \text { Clone BN3.2 } \\
\text { Lot\#L159505 }\end{array}$ \\
\hline anti-PTPS & rabbit & $1: 2000$ & $\begin{array}{l}\text { Thermo Scientific } \\
\text { Cat\#PA5-22121 } \\
\text { Lot\#QH2071081D }\end{array}$ \\
\hline anti-TOM20 & rabbit & 1:1000 & $\begin{array}{l}\text { Santa Cruz } \\
\text { Cat\# sc-11415 }\end{array}$ \\
\hline anti-TPPI & mouse & 1:1000 & $\begin{array}{l}\text { Sigma Aldrich } \\
\text { Cat\#WH00001200 } \\
\text { Lot\#06097-3B1 }\end{array}$ \\
\hline
\end{tabular}


Table 9: List of secondary antibodies

\begin{tabular}{lccl}
\hline Antibody & Host & Dilution & Company \\
\hline \hline $\begin{array}{l}\text { anti-mouse IgG } \\
\begin{array}{l}\text { Alexa Fluor532 } \\
\text { conjugated }\end{array}\end{array}$ & goat & $1: 800$ & $\begin{array}{l}\text { life technologies } \\
\text { Cat\#A11002 }\end{array}$ \\
\hdashline $\begin{array}{l}\text { anti-mouse IgG } \\
\text { HRP-conjugated }\end{array}$ & donkey & $1: 10000$ & $\begin{array}{l}\text { Jackson ImmunoResearch } \\
\text { Cat\#715-035-151 }\end{array}$ \\
\hline $\begin{array}{l}\text { anti-rabbit IgG } \\
\text { HRP-conjugated }\end{array}$ & goat & $1: 5000$ & $\begin{array}{l}\text { Jackson ImmunoResearch } \\
\text { Cat\#711-605-152 }\end{array}$ \\
\hline
\end{tabular}

Table 10: List of primers

\begin{tabular}{|c|c|}
\hline Oligo name & Sequence (5'-3') \\
\hline Pr_pQE-Seq_for & CCCGAAAAGTGCCACCTG \\
\hline Pr_pQE-Seq_rev & GTTCTGAGGTCATTACTGG \\
\hline Pr_PTPS_for & TTTAGATCTAGATCTCGAGCTCTAATGGC \\
\hline Pr_PTPS_rev & AAACTCGAGTTAACCACTTCCCAGCCG \\
\hline Pr_GAP43-for & $\begin{array}{l}\text { CTAGCAGCGCCGGGAAGATGCTGTGCTGTATGAGAAGAACCAAAC } \\
\text { AGGTTGAAAAGAATGATGAGGACCAAAAGATCGAGAGC }\end{array}$ \\
\hline Pr_GAP43-rev & $\begin{array}{l}\text { CTCGATCTTTTGGTCCTCATCATTCTTTTCAACCTGTTTGGTTCTT } \\
\text { CTCATACAGCACAGCATCTTCCCGGCGCTG }\end{array}$ \\
\hline $\begin{array}{l}\text { Pr_PTPS w/o } \\
\text { ATG SacI-for }\end{array}$ & CTAGCAGAGCCGGGAAGAGCTCGGAAGGTGGTGGCC \\
\hline $\begin{array}{l}\text { Pr_PTPS w/o } \\
\text { ATG SacI-rev }\end{array}$ & GGCCACCACCTTCCGAGCTGTTCCCGGCGCTGCTAG \\
\hline Pr_MSY107 & TGACTATGGGCAGAGTTGTT \\
\hline Pr_MSY108 & GATTGTTGCATTTCCCAAAC \\
\hline Pr_PLACZ8 & GGCTCAGTTCGAGGTGCT \\
\hline
\end{tabular}

Table 11: List of plasmids

\begin{tabular}{|c|c|c|}
\hline Plasmid & Characteristics & Reference \\
\hline pBluescript II KS+ & $\begin{array}{l}\text { ampicillin-sensitiv, T7 } \\
\text { promotor }\end{array}$ & \\
\hline XLone-GAP43-PTPS & $\begin{array}{l}\text { ampicillin-sensitive, } \\
\text { blasticidin selection, } \\
\text { pUC57 backbone, high } \\
\text { copy, TRE3G promotor, }\end{array}$ & $\begin{array}{l}\text { Lauren } \\
\text { Randolph } \\
\text { USA }\end{array}$ \\
\hline pQE9-PTPS & $\begin{array}{l}\text { ampicillin-sensitive, } \\
\text { pREP4 repressor, lacIq, } \\
\text { F-factor episome, 6his- } \\
\text { tag, human PTPS }\end{array}$ & Qiagen \\
\hline
\end{tabular}


Table 12: List of software

\begin{tabular}{ll}
\hline Software & Distributor \\
\hline \hline $\begin{array}{l}\text { Nanosight Tracking } \\
\text { Analysis 2.3 }\end{array}$ & Malvern Instrument \\
\hline Fiji (Image J) & Open Source \\
\hline FACSDiva & BD \\
Software 6.1.3 & BD Biosciences \\
\hline Flowing 2.5.1 & $\begin{array}{l}\text { Perttu Terho; Cell Imaging Core of the Turku Centre for } \\
\text { Biotechnology }\end{array}$ \\
\hline Unicorn $^{\mathrm{TM}}$ 5.31 & GE Healthcare \\
\hline
\end{tabular}

\subsection{Methods}

\subsubsection{EV sample preparation and cell culturing}

\section{Preparation of supernatant for EV-isolation}

Initially, the production of eukaryotic EVs was scaled up by the introduction of a production unit. In this project the MINIPERM ${ }^{\circledR}$ bioreactor from Sarstedt was used. There are by now more systems available, for example hollow-fiber bioreactors. The main benefit of a bioreactor is the high cell density that leads to a highly concentrated starting material. In the MINIPERM ${ }^{\circledR}$ bioreactor $10^{7}$ cells per $\mathrm{ml}$ can be applied. $35 \mathrm{ml}$ are in the production unit while $350 \mathrm{ml}$ are in the supply unit. The supply unit contains medium supplemented with fetal calf serum (FCS). FCS contains fetal vesicles; usually it is recommended to remove the particles by ultracentrifugation. In the bioreactor, the cells are separated by a dialysis membrane from the supply unit and big particles are not able to pass. This way the cells are kept in optimum conditions, while contaminations from external EVs are prevented. All samples were centrifuged for $30 \mathrm{~min}$ at $4^{\circ} \mathrm{C}$ with $4500 \mathrm{rpm}$ to remove cell debris and filtered with a $0.4 \mu \mathrm{m}$ membrane, then samples were either directly subjected to the isolation protocol or stored at $-20^{\circ} \mathrm{C}$.

For HEK293 cells stably expressing FR $\alpha$ were cultured in 293 SFMII with $1 \%$ glutamax in the production unit. In the supply unit was filled with DMEM with high glucose and $5 \%$ of FCS. When K562 were used for EV preparation in the bioreactor the cells were cultured in RPMI medium. 


\subsubsection{Fast performance liquid chromatography}

For all protocols run with the fast performance liquid chromatography (FPLC)-system the buffers were filtered through $0.22 \mu \mathrm{m}$ and degassed. The FPLC was run at $10^{\circ} \mathrm{C}$.

\section{Detailed protocol for SEC}

The used material for size exclusion chromatography (SEC) is Capto ${ }^{\mathrm{TM}}$ Core 700 (CC700). CC700 beads have an inactive shell while the surface in the pores of the beads is modified with octylamine ligands. Particles with a size smaller than $700 \mathrm{kDa}$ are able to penetrate the beads and bind to the material because of the positive charge and the hydrophobic nature of the ligand. For this reason, this column functions as a scavenger column. The beads are very pressure-sensitive; this is why columns with great bed diameter need to be used to reduce the backpressure. When column packing is performed according to the supplier's protocol (GE Healthcare), the working pressure should not exceed $80 \%$ of the packing pressure. In this case, it leveled at $0.2 \mathrm{MPa}$. For this project, best experiences were made with the empty column HiScale ${ }^{\mathrm{TM}}$ 16/20 (GE Healthcare) with a diameter of $16 \mathrm{~mm}$ and a tube height of $200 \mathrm{~mm} .1 \mathrm{ml}$ of CC700 material is able to bind $13 \mathrm{mg}$ of contaminating material according to the supplier. On average, the supernatant had a concentration of $2 \mathrm{mg} / \mathrm{ml}$ total protein. The samples from cells with empty vector had lower total protein concentrations. With a typical packing volume of $20 \mathrm{ml}$, a total of $260 \mathrm{mg}$ protein could be applied in about $130 \mathrm{ml}$ of supernatant. To be able to apply such high sample volume, a $50 \mathrm{ml}$ sample loop and an additional pump were used.

Because of the huge amount of retained proteins in the column beads, the column should be immediately regenerated before its storage. For all experiments described in this project, the SEC-column was regenerated by a harsh washing protocol with $1 \mathrm{~m} \mathrm{NaOH}$ in $30 \%$ isopropanol (v/v).

\section{Detailed protocol for IMAC}

For immobilized metal affinity chromatography (IMAC), buffer A was $140 \mathrm{mM} \mathrm{NaCl}$ with $20 \mathrm{mM}$ phosphate at $\mathrm{pH} 7.4$, and buffer B contained additionally $500 \mathrm{mM}$ 
imidazole for elution. The buffers should have $\mathrm{pH}$ higher than 6 to remain histidine sidechains in the deprotonated form. Histidine has a $\mathrm{pK}_{\mathrm{a}}$ of 6 . To reduce unspecific binding, the SEC-product was supplemented with $8 \%$ of buffer B, resulting in a concentration of $40 \mathrm{mM}$ imidazole. The whole product is applied with the $50 \mathrm{ml}$ sample loop in several steps to the column. The column is washed with 20 column volumes (CVs) of buffer A with $8 \%$ buffer B. The stepwise gradient is split in three steps with 20, 50 and $100 \%$ buffer B, with corresponding concentrations of 100, 250 and $500 \mathrm{mM}$ imidazole. Each gradient step is $5 \mathrm{CV}$. Fractions of $2 \mathrm{ml}$ were collected.

This column can be regenerated by washing with $1 \mathrm{M} \mathrm{NaOH}$ with $1 \mathrm{M} \mathrm{NaCl}$. Precipitated lipids should be removed with $30 \%$ isopropanol. The column needs to be recharged with $\mathrm{Cu}^{2+}$ after each cleaning procedure.

\section{Detailed protocol for IEC}

For the ion exchange chromatography (IEC) $20 \mathrm{mM}$ Tris-buffer, pH 8.03 was used, with additionally $1 \mathrm{M} \mathrm{NaCl}$ for elution in buffer B. A stepwise elution gradient with steps of $5 \mathrm{CVs}$ with a flow rate of $2 \mathrm{ml} / \mathrm{min}$, beginning with 20,50 and in the end $100 \%$ of buffer B were applied.

\section{Design of the eukaryotic expression vector XLone-GAP43PTPS}

XLone-GAP43PTPS was designed for analysis of the endogenous loading of a membrane-targeted enzyme. The suggestion to use GAP43 for this purpose was given by Professor Rizzoli (3rd Committee Meeting, 20th Nov. 2017). GAP43 is a nervoustissue specific growth-associated protein with an originally observed size of $43 \mathrm{kDa}$ (GAP43) (Karns et al., 1987). The first 20 amino acids include a palmitoylation sequence and result in membrane localization.

The sequence was provided by Professor Rizzoli's group and was introduced to the vector pBluescript (pBS) by PCR amplification with the primers Pr_GAP43-for and Pr_GAP43-rev. The sequence of the pts-gene (Gene ID: 5805) encoding PTPS was amplified by PCR, resulting in GAP43-pBS. The start-codon was removed and a restriction site for SacI and introduced with the primer Pr_PTPS w/o ATG SacI-for and 
Pr_PTPS w/o ATG SacI-rev. GAP43-pBS was digested with Scal and SacI, PTPS was digested by SacI and NotI and ligation performed. In the end the product GAP43-PTPS was extracted from the vector pBS by digestion with the enzymes NheI and NotI and introduced to the vector XLone for the plasmid XLone-GAP43-PTPS. The sequence was verified by sequencing.

\subsubsection{EV-Preparation by DC}

In the first step, big particles and debris were removed by slow centrifugation for $15 \mathrm{~min}$ at $1500 \mathrm{xg}$ and $4^{\circ} \mathrm{C}$. In the second step, smaller particles are removed by a centrifugation at $10000 \mathrm{xg}$ for $45 \mathrm{~min}$ at $4^{\circ} \mathrm{C}$ and at last, the EVs are pelleted by ultracentrifugation at $100000 \mathrm{xg}$ for $2.5 \mathrm{~h}$ at $4^{\circ} \mathrm{C}$.

\subsection{Protein biochemistry}

\subsubsection{Purification of PTPS from $E$. coli recombinant production strain}

Human PTPS was prepared in bacterial strain to simplify the purification and obtain high yields. For this purpose, the M15 strain and the QE9 plasmid from Qiagen were used. The M15 strain contains the pREP4 plasmid which confers a kanamycin resistance and constitutively expresses the lac repressor protein. The sequence of the pts-gene (Gene ID: 5805) was amplified by PCR. The start-codon was removed, the sequence for a 6his-tag inserted as well as restriction sites for the enzyme BamHI, N-terminally, and HindIII, C-terminally, added with the primer Pr_PTPS_BamHI and Pr_PTPS_HindIII. The PCR product was cloned into the pQE-9 vector after digestion with BamHI and HindIII. After transformation in Top Ten Escherichia coli strain cells, DNA was extracted with the kit NucleoBond ${ }^{\circledR}$ Xtra plasmid purification. The sequence of the product was confirmed by Sanger sequencing with the primer Pr_QE-Seq_for and Pr_QE-Seq_rev with the kit BigDye Terminator v3.1 Cycle Sequencing kit. The final plasmid was transformed to the expression strain M15.

For protein expression, a starter culture of the generated M15 strain in LB-medium with kanamycin and ampicillin was grown over night. Then, a main culture with $25 \mathrm{ml}$ was inoculated $1: 25$ and grown to optical density of $0.4-0.6$ at $37^{\circ} \mathrm{C}$. Induction with $1 \mathrm{mM}$ IPTG was performed. The culture was left at $37^{\circ} \mathrm{C}$ for $4-5$ to allow protein 
expression to take place. Then the cells were harvested by centrifugation at $4000 \mathrm{rpm}$ for $20 \mathrm{~min}$ at $4^{\circ} \mathrm{C}$. The pellet was suspended in $5 \mathrm{ml}$ of protein extraction buffer and frozen in liquid nitrogen. After thawing, the sample was sonicated with maximal power for 6 times $10 \mathrm{~s}$. Cell debris was removed by centrifugation with $10000 \mathrm{rpm}$ for $30 \min$ at $4^{\circ} \mathrm{C}$.

The supernatant was then applied to a HisTrap ${ }^{\mathrm{TM}}$ FF crude column and the bound protein was eluted with stepwise increasing imidazole concentrations of 40, 250 and $500 \mathrm{mM}$. PTPS was eluted in fractions at 250 and $500 \mathrm{mM}$ of imidazole, respectively. The largest amount of PTPS was recovered at the highest imidazole concentration. PTPS activity assay was confirmed by Tanja Scherer according to an established protocol (Bonafé et al., 2001).

\subsubsection{Purification of TPPI}

The purification of TPPI was performed as previously reported with minor modifications (Pal et al., 2008). In contrast to the published protocol a step gradient with three steps with 100, 250 and $500 \mathrm{mM}$ imidazole was applied. The major amount of TPPI was eluted in the first step with $100 \mathrm{mM}$ imidazole, the fractions of the peak were pooled and imidazole removed by concentrating and washing in an ultrafiltration unit.

\section{TPPI-activity assay}

TPPI activity can be measured by an internally not fluorescent substrate, Ala-Ala-Phe7-amido-4-methylcoumarin. The peptidase is able to cleave Ala-Ala-Phe and thus the internal quencher from the fluorophore.

The reaction is performed in a buffer of $100 \mathrm{mM}$ sodium acetate, $10 \mathrm{mM}$ EDTA and $0.02 \%$ sodium azide. $10 \mu \mathrm{l}$ of the sample are acidified with sodium fumarate to a $\mathrm{pH}$ of 3.5. Then the samples are left at RT for $1 \mathrm{~h}$ to allow TPPI to autoactivate to its mature form. The substrate is taken up in a concentration of $30 \mathrm{mM}$ in $10 \mu \mathrm{l}$ of substrate buffer, $100 \mathrm{mM}$ sodium acetate, $10 \mathrm{mM}$ EDTA, $0.02 \%$ sodium azide. $40 \mu \mathrm{l}$ of the reaction buffer, $0.2 \%$ bovine serum albumin (BSA), $0.9 \%(\mathrm{w} / \mathrm{v}) \mathrm{NaCl}, 0.02 \%$ 
sodium azide are preloaded in a black 96-well plate for fluorescent assays. At last, $10 \mu \mathrm{l}$ of sample are added. In case of high concentrated TPPI, the sample can be diluted in $0.2 \% \mathrm{BSA}, 0.9 \% \mathrm{NaCl}(\mathrm{w} / \mathrm{v})$ and $0.02 \%$ sodium azide. Protease inhibitors are given to the reaction with following concentrations: pepstatin $\mathrm{A}(8.34 \mathrm{mM})$ and E64 $(24 \mathrm{mM})$. The plate is placed at $37^{\circ} \mathrm{C}$, mildly shacking and protected from light. Then the reaction is stopped with $150 \mu \mathrm{l}$ per well carbonate glycine buffer at pH 9.7. A calibration curve with 7-amido-4-methyl-coumarin is prepared in water. It is preloaded in duplicates in a range of 285-1 $472 \mathrm{nM}$.

\subsubsection{BCA assay}

Protein quantification was performed with a calorimetric reaction taking place with bicinchoninic acid (BCA). The color change with proteins can be detected at $562 \mathrm{~nm}$ with a photometer. A BCA-kit from Pierce was applied. A standard curve was prepared from BSA standard solution of $2 \mathrm{mg} / \mathrm{ml}$ and applied in duplicates to a transparent 96-well plate in concentrations from 0-30 $\mu$ g per well. Samples were added in volumes of $25 \mu \mathrm{l}$ and in duplicates as well. In each well $200 \mu \mathrm{l}$ of reagent mix $\mathrm{A}+\mathrm{B}(1: 50)$ was added. Reactions were incubated for $30 \mathrm{~min}$ at $37^{\circ} \mathrm{C}$ and then read out with a microplate reader.

\subsubsection{SDS-PAGE and Western Blot analysis}

In order to analyze the protein composition of the EV-preparation or to detect the cargo enzyme, sodium dodecyl sulfate polyacrylamide gel electrophoresis (SDS-PAGE) was performed followed by Western Blot analysis. SDS is a strong detergent binding to proteins in a ratio of 1.4:1 $\mathrm{g}$ and resulting in a negative charge of the protein.

In this project, discontinuous gel electrophoretic systems with a 10 and a $15 \%$ polyacrylamide gel were applied. The gels were prepared according to the recipe in table 13. Protein samples were dissolved to the final protein amount and 4x SDSsample buffer was added. The samples were boiled at $95^{\circ} \mathrm{C}$ for at least $10 \mathrm{~min}$. and then samples were applied to the wells in the gel with a Hamilton syringes. A prestained protein ladder was used. The electrophoresis was run at low current with $20 \mathrm{~mA}$ until the sample dye left the gel. Blotting was performed to a nitrocellulose 
membrane placed in between a Whatman filter paper sandwich within a semi-dry blotting system. This step was performed with $1 \mathrm{~mA}$ per $1 \mathrm{~cm}^{2}$ of membrane area for $90 \mathrm{~min}$. To reduce unspecific binding of the antibody, the blot was placed for $1 \mathrm{~h}$ in $5 \%(\mathrm{w} / \mathrm{v})$ milk powder in PBS-T. Antibodies were diluted in the same buffer. The primary antibody was applied overnight at $4^{\circ} \mathrm{C}$, the secondary for $1 \mathrm{~h}$ at RT. In between, the blot was washed three times for 5 min with PBS-T. The peroxidaseconjugated secondary antibody was visualized with Lumi-Light Plus Western Blotting substrate in the Luminescent image reader.

Table 13: Preparation of 10 and $15 \%$ discontinuous polyacrylamide gels

\begin{tabular}{|c|c|c|c|}
\hline Compound & Stacking gel & $\begin{array}{c}10 \% \\
\text { resolving gel } \\
\end{array}$ & $\begin{array}{c}15 \% \\
\text { resolving gel } \\
\end{array}$ \\
\hline $\mathrm{H}_{2} \mathrm{O}$ & $1.4 \mathrm{ml}$ & $1.9 \mathrm{ml}$ & $1.1 \mathrm{ml}$ \\
\hline $\begin{array}{l}30 \% \text { acrylamide } \\
\text { solution }\end{array}$ & $330 \mu \mathrm{l}$ & $1.7 \mathrm{ml}$ & $2.5 \mathrm{ml}$ \\
\hline 1.0 M Tris, pH 6.8 & $250 \mu \mathrm{l}$ & 1 & 1 \\
\hline 1.5 M Tris, pH 8.8 & 1 & $1.3 \mathrm{ml}$ & $1.3 \mathrm{ml}$ \\
\hline $10 \%$ SDS & $20 \mu \mathrm{l}$ & $50 \mu \mathrm{l}$ & $50 \mu \mathrm{l}$ \\
\hline $10 \%$ APS & $20 \mu \mathrm{l}$ & $50 \mu \mathrm{l}$ & $50 \mu \mathrm{l}$ \\
\hline TEMED & $2 \mu \mathrm{l}$ & $2 \mu \mathrm{l}$ & $2 \mu \mathrm{l}$ \\
\hline final volume & $2 \mathrm{ml}$ & $5 \mathrm{ml}$ & $5 \mathrm{ml}$ \\
\hline
\end{tabular}

\subsection{Experimental methods}

\subsubsection{Analysis of density by centrifugation on a sucrose gradient}

The vesicle samples were prepared as indicated either by SEC followed by IMAC or by DC. For preparation of a gradient, a sucrose stock solution was dissolved to $2.5 \mathrm{M}$ in HEPES. The other sucrose solutions were prepared according to table 14. The gradient was carefully layered from the bottom up, beginning with 2.25, 2.0, 1.75, 1.5, $1.25,1.0,0.75$ and $0.5 \mathrm{mM}$ sucrose. The sample was added in $0.25 \mathrm{mM}$ sucrose with the same volume. From each EV preparation, $700 \mu \mathrm{g}$ were applied onto the sucrose gradient. Then, ultracentrifugation was performed for $16 \mathrm{~h}$ at $4^{\circ} \mathrm{C}$ in a SW28 tube rotor with $26000 \mathrm{rpm}$ which corresponds to $100000 \mathrm{x}$. The fractions were regained in the same manner and of each fraction samples subjected to analysis by Western Blotting. 
Table 14: Preparation of sucrose solutions for sucrose gradient centrifugation.

\begin{tabular}{cccc}
\hline $\begin{array}{c}\text { sucrose } \\
\text { concentration [M] }\end{array}$ & $\begin{array}{c}2.5 \mathrm{M} \\
\text { stock solution [ml] }\end{array}$ & $\begin{array}{c}\text { HEPES } \\
{[\mathrm{ml}]}\end{array}$ & $\begin{array}{c}\text { density } \\
{\left[\mathrm{g} / \mathrm{cm}^{3}\right]}\end{array}$ \\
\hline \hline 2.25 & 13.5 & 1.5 & 1.29 \\
\hline 2 & 12 & 3 & 1.25 \\
\hline 1.75 & 10.5 & 4.5 & 1.23 \\
\hline 1.5 & 9 & 6 & 1.19 \\
\hline 1.25 & 7.5 & 7.5 & 1.16 \\
\hline 1 & 6 & 9 & 1.12 \\
\hline 0.75 & 4.5 & 10.5 & 1.09 \\
\hline 0.5 & 3 & 12 & 1.06 \\
\hline 0.25 & 1.5 & 13.5 & 1.03 \\
\hline
\end{tabular}

\subsubsection{Nanoparticle tracking analysis}

Nanoparticle tracking analysis (NTA) is a new method first sold by NanoSight Ltd in 2003. It composed of a light microscope with an illumination unit, enabling a camera to record the movement of nanoparticles. With this video file along with the temperature and viscosity of the solution, the size of particles can be determined based on the formula of Brownian motion.

The NTA instrument, NanoSight LM10-HS, used in this thesis was provided by the group of Professor Schneider (MPI Experimental Medicine, Göttingen). The NanoSight was equipped with a high sensitivity CMOS camera, a LM14 viewing unit with a $532 \mathrm{~nm}$ laser and a fluorescence filter.

For analysis of particle concentration and the size distribution of the raw, SEC-prepared sample or the EV preparations, a sample concentration needed to be diluted to $2 \times 10^{8}-10^{9}$ particles per ml. To be more precise, the raw sample from cell culture was usually diluted 1: 10 000, the SEC-product 1:1 000and the EV-fractions from the FPLC-purification 1:10. The EV sample from the DC protocol was diluted 1: 10000 with PBS. Approximately $0.5 \mathrm{ml}$ sample were applied with a syringe to the sample chamber. Triplicates of $30 \mathrm{sec}$ videos were recorded. Analysis was implemented by Nanosight Tracking program Analysis 2.3. The mean and mode particle size, sample concentration and a graph of the size distribution were taken for analysis. 
Utilizing a fluorescence filter, an indirect labeling protocol could be performed. Therefore, the sample particle concentration was adapted to $10^{10}$ particles per ml. $1.25 \mu \mathrm{l}$ of primary antibody, MOV18 (Enzo Life Sciences, USA) were added and the samples were placed at $4{ }^{\circ} \mathrm{C}$ for $1 \mathrm{~h}$ with mild agitation to allow binding to form. Access primary antibody was removed by washing with PBS in a small ultrafiltration unit $(50 \mathrm{~K})$ with $3500 \mathrm{rcf}$ with $5 \mathrm{x} 500 \mu \mathrm{l}$. Then, the secondary conjugated antibody, AlexaFluor532 was added in $1.25 \mu \mathrm{l}$ and again incubated at $4^{\circ} \mathrm{C}$ for $30 \mathrm{~min}$. By previous experiments it was shown that there is no need to perform a second wash for removal of secondary antibody. The fluorescent labeled samples were applied to the NTA without further dilution.

Photo bleaching is a major challenge for working with fluorescent particles in NTA because the time frame of a recording takes at least $5 \mathrm{~s}$. For this reason, analysis must be performed with a pump under flow to supply the chamber constantly with fresh sample. The flow rate was as recommended by the supplier for LM10-14 for fluorescent measurement 80 (Malvern Instruments). According to my experience, it is advisable to use the pump in general to be able to analyze an extended volume of the sample rather than to limit the analysis to the small injected volume.

\subsubsection{Electron microscopy}

The ISEV recommends providing high resolution images of the EVs for a complete characterization of the studied preparation. In this project, common electron microscopy, scanning electron microscopy (SEM) and transmission electron microscopy (TEM) were applied to characterize the EVs. Cryo-TEM was implemented by Na'ama Koifman (Technion, Israel).

In SEM, the image is generated from an intensity map which is gained from the detected scattered electron. The focused electron beam scans the surface of the sample, scattered electrons are then detected and an image can be composed. For this reason, SEM provides information about the sample surface. In TEM the image is generated from transmissioned electrons. The resulting image is a two-dimensional projection of the sample. Cryogenic EM has a major advantage for the preparation of 
soft matter samples like EVs: for this method, the sample remains close to its native form (Helvig et al., 2015). The sample is fixated by super-cooling. This way, the liquid solvent is converted to an amorphous solid state, this is called vitrification. Predominantly no ice crystals are formed. Super-cooling must be performed with a high cooling rate, which can be realized by the application of liquid ethane. For TEM, the sample was dropped onto a carbon grid (Agar Scientific Ltd, UK) membrane, dried at RT and then imaged with a TEM (Tecnai G²T20 S-Twin, GEI, Netherlands). For SEM, EV suspension was dropped in volumes of $2 \mu \mathrm{l}$ on a carbon tape. For cryo-TEM specimen preparation was performed by Na'ama Koifman with liquid ethane.

\subsubsection{Uptake analysis of EVs by epithelial cells with flow cytometry}

The internalization was determined by flow cytometry of cells that were incubated with labeled vesicles. For this experiment, the EVs were labeled with mCling-Atto647 because of the appropriate excitation and emission spectrum. mCling, abbreviation for membrane-binding fluorophore-cysteine-lysine-palmitoyl group, is a membrane marker originally designed to track the trafficking of organelles or vesicles. It is made up by a membrane-binding fluorophore with a cysteine-lysine-palmitoyl group (Revelo and Rizzoli, 2016), in total seven lysines are present. Because of the lipophilic chain, mCling easily integrates into membranes and is an easy to handle membrane dye. However, removal of excess dye has to be carefully performed because excess dye might form micelles or lead to membrane disruption. mCling-Atto647 was purchased from Synaptic Systems, in contrary to their protocol it was dissolved in DMSO to a concentration of $50 \mu \mathrm{M}$.

Vesicles were diluted to $10^{10}$ particles per $\mathrm{ml}$ in DMEM without FCS. mCling was added 1:50 to a concentration of $1 \mu \mathrm{M}$. Excess dye was removed by washing in an ultrafiltration (50 K) with $5 x$ of the same volume with DMEM containing $1.5 \%$ BSA.

BN16 cells were grown in 24-well plates to $80 \%$ confluency in DMEM with high glucose concentration and $10 \%$ (v/v) FCS. Cells were washed with PBS and incubated for $2 \mathrm{~h}$ in DMEM with $1.5 \%$ BSA to prevent unspecific binding on the cells surface. Labeled vesicles were added in DMEM with $1.5 \%$ BSA and incubated for the 
designated time. Duplicates were prepared for each time point. Uptake of vesicles was stopped by washing with PBS three times. Cells were trypsinized and trypsin removed by centrifugation. Then cells were resuspended in $200 \mu$ PBS with 10 \% FCS and transferred to flow cytometry tubes. Cells were placed on ice until analysis.

Flow cytometric analysis was performed with a FACS Canto II. Data was processed with the FACSDivaTM Software 6.1.3. Mean fluorescence of all cells was determined with the free software Flowing 2.5.1.

\subsection{Animal experiments}

The animals were kept in animal facility of the University Medical Center in Göttingen according to the European Convention for the protection of vertebrate animals. All experiments were approved by LAVES, the Lower Saxony, Germany, State Office for Consumer Protection and Food Safety (file number: 33.9-42502-04-16/2331).

The animals were fed and given water ad libitum on a daily $12 \mathrm{~h}$ light/dark cycle. Since it was uncertain whether the smaller, $p t s-/-$ animals are able to reach the chow in the grid, they were additionally fed mashed food and oats in a petri dish on the bottom of the cage beginning the $12^{\text {th }}$ day after birth.

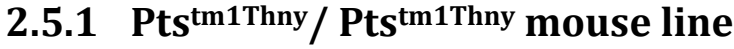

The Pts ${ }^{\text {tm1Thny }} /$ Pts ${ }^{\text {tm1Thny }}$ mouse line was kindly provided by Professor Thöny, Zurich, Switzerland. Shortly, the mouse phenotype was generated by intragenic deletion of parts of the second, the third and fourth exon of the Pts gene. Instead, a cassette containing a lacZ and Pgk-neo was inserted (Elzaouk et al., 2004).

Genotyping was performed with the lyses-kit, NucleoType Mouse PCR. A small piece of tale was amputated one day after birth. Tale biopsy was lysed as described in the protocol (lysis $2 \mathrm{~min}$ at RT, enzyme inactivation for $3 \mathrm{~min}$ at $98^{\circ} \mathrm{C}$ ). Then, PCR was performed as in the kit recommended for short nucleotide sequences with the primers MSY107, MSY08 and PLACZ8. 
PTPS-activity is undetectable in homozygous mutant mice and these mice die during the perinatal period. They can be rescued by feeding tetrahydrobiopterin, but still show a very severe phenotype. The mice are treated twice a day and their weight and overall performance are recorded. The replacement therapy is made up by biopterin, L-dopa, 5-hydroxytryptophan, carbidopa and $\mathrm{N}$-acetyl-L-cysteine according to the recipe in table 15 as published by the group of Professor Thöny (Elzaouk et al., 2004). Biopterin was administered in tenfold higher amount per BW than for human patients lacking PTPS-activity. In our hands, the published treatment with frozen biopterin did not work and the protocol was adapted. All compounds except biopterin were dissolved and kept in aliquots at $-20^{\circ} \mathrm{C}$. Biopterin was dissolved freshly a short time before gavage to the animal. The $\mathrm{pH}$ was adjusted with $1 \mathrm{M} \mathrm{NaOH}$ to $\mathrm{pH}$ 5-6. Biopterin is very unstable at higher $\mathrm{pH}$. Ascorbic acid was not added as described, because of the very low $\mathrm{pH}$.

Table 15: Formula for the replacement therapy of the PTPS-KO mice in accordance to the body weight (BW)

\begin{tabular}{lc}
\hline Compound & $\begin{array}{c}\text { daily dose } \\
{[\mu \mathrm{g} / \mathrm{g} \text { BW] }}\end{array}$ \\
\hline \hline BH4 & 122 \\
\hline L-dopa & 13.5 \\
\hline 5-hydroxytryptophan & 9.5 \\
\hline carbidopa & 2.5 \\
\hline$N$-acetyl-L-cysteine & 50 \\
\hline
\end{tabular}

\subsubsection{Vesicle replacement therapy of FR $\alpha$-presenting and PTPS-loaded vesicles}

The intranasal replacement therapy was introduced in the third week after birth. Every $48 \mathrm{~h}$, the mice were administered intranasally the vesicle-based therapy or control treatment. The mice were not anesthetized. They were fixated in upright position and the suspension applied alternating to both nostrils in a small volume of $1 \mu \mathrm{l}$ per minute. To reduce the stress for the animals and to prevent the suspension to be inhaled to the lungs, it is crucial to apply small volumes with time. $1 \mu \mathrm{l}$ per $1 \mathrm{~g} \mathrm{BW}$ was given up to a maximum of $10 \mu \mathrm{l}$. 


\subsubsection{Analysis of the biodistribution by organ screening}

To be able to track the vesicles in vivo, the vesicles were labeled with a near infrared fluorescent dye (IRDye800). IRDye800-labeled vesicles were administered intranasally to the mice.

The labelling of IRDye800 based on a NHS ester reacting with all primary aliphatic amines in solution was performed as described by the supplier (LI-COR Biotechnology $\mathrm{GmbH}$ ). In short, the vesicles were pelleted and taken up in 50-200 $\mu$ l of PBS in accordance to the pellet size. Protein concentration of the vesicle suspension was determined by BCA assay and adjusted to $1 \mathrm{mg} / \mathrm{ml}$. pH value of the solution was increased with $0.1 \mathrm{M} \mathrm{K}_{2} \mathrm{HPO}_{4}(\mathrm{pH} 9)$ in PBS. The solution was placed at room temperature.

The dye with $0.1 \mathrm{mg}$ in one tube was dissolved in $25 \mu \mathrm{l}$ of ultrapure water. $12.5 \mu \mathrm{l}$ were used to label an aliquot with $500 \mu \mathrm{g}$ of exosomes in $500 \mu \mathrm{l}$. Reaction was incubated for $2 \mathrm{~h}$ at RT. Unbound dye was removed by dialysis against $5 \mathrm{l} \mathrm{PBS}$ at $4{ }^{\circ} \mathrm{C}$ overnight, mildly stirring.

The quality of labelling was checked by screening of the absorption spectrum of the fluorophore. As a control, PBS without any protein or vesicles was labeled in the same way and dialyzed. In the dye control almost no absorbance could be detected, for the labeled vesicles an absorbance beginning at $650 \mathrm{~nm}$ with a maximum at 780-790 $\mathrm{nm}$ was detected as described by the supplier.

Healthy mice were anesthetized with medetomidin, midazolam and fentanyl $(500 \mu \mathrm{g}$, $5 \mathrm{mg}$ and $50 \mu \mathrm{g} / \mathrm{kg} \mathrm{BW}$, respectively). The BW was determined and the mice were anaesthetized by intraperitoneal injection. As soon as the mice were asleep they were placed on a heating panel. Eyes were covered with eye salve to protect them from dryness. When no hind limb withdrawal reflex could be detected, the vesicle suspension was administered with a white tip pipette in a volume of $1 \mu$ in both nostrils alternating every minute. $1 \mu \mathrm{l}$ per $1 \mathrm{~g}$ BW was applied up to a maximum of $10 \mu \mathrm{l}$. 
Then, the mice were antagonized with atipamezol and flumazenil $(750 \mu \mathrm{g} / \mathrm{kg} \mathrm{BW}$, $0.5 \mathrm{mg} / \mathrm{kg} \mathrm{BW}$ ) in $0.9 \% \mathrm{NaCl}$ by subcutan administration. Additionally, the mice were given $100 \mu \mathrm{l}$ of $0.9 \% \mathrm{NaCl}$ to provide them with liquid. After a defined time frame the mice were sacrificed and most organs including the brain screened in the Optix MX2.

\subsubsection{Analysis of the locomotor activity by tracking with an infrared sensor}

The analysis of the locomotor activity of the mice was performed in the fifth week after birth. The mice were kept alone in a mouse cage for $24 \mathrm{~h}$ once a week. A metal mount was installed and a mobile activity monitoring system placed on top. The datalogger, MOUSE E MOTION, is able to detect motion with a passive infrared sensor in an angle of $41^{\circ}$ on the short and $50^{\circ}$ on the long side of the cage for a distance of $5 \mathrm{~m}$. Every second, a motion event can be detected. All motion events are summed up for an interval of $4 \mathrm{~min}$. This total number is saved and can be later downloaded in context with the light intensity in Lux. Food and water were placed at the bottom of the cage to ensure a detection of motion everywhere in the cage. For analysis of the results, all data points were summed. This way, all mice were recorded during a night and day period.

\subsubsection{Analysis of the strength and motor coordination by Rota rod experiment}

The Rota rod experiment was performed to assess the motor coordination of the animals. The experiment was started with 5 rounds per minute (rpm). After $30 \mathrm{~s}$, the instrument is set to accelerating mode and the rotating speed increases within $4 \mathrm{~min}$ in 10 steps to maximum speed. At maximum speed with $40 \mathrm{rpm}$, the mouse is left for one more minute. In this project, the number of rounds was used for analysis. Most healthy adult mice are able to maintain running upon the bar during this time frame.

The $p t s-/$ - mice sometimes did not manage to keep up with the rotating speed. Instead of falling of the rotating arm, they could cling to it because of their low BW. When this happened, and the mouse was not able to return to running on top of the arm after three rounds, the experiment was stopped. For evaluation this was taken as a fall off. All behavioral assays were performed in the fifth week after birth and able to stay on their own. 


\section{Results}

\subsection{Purification of extracellular vesicles by chromatographic approaches}

One major milestone of this project was the establishment of a reliable method for the purification of extracellular vesicles in a large scale and with a high purity. Most EVpreparation protocols are based on a separation by size, density or affinity to EVenriched proteins. These methods rely on the centrifugation of the particles. Many experts are critical about the vesicle integrity and purity after the vesicles have been pelleted (Vlassov et al., 2012, Lu et al., 2017). Furthermore, many laboratories might not have centrifuges with volumes higher than $50 \mathrm{ml}$, at least in the ultracentrifugation range. For these reasons, this project focused on the establishment of an automated, chromatographic purification system.

One important aspect to consider for the purification of vesicles in chromatographic systems is the unusual big particle size. Most chromatography beads, columns and resins are not suitable for EVs because of their small pore size. The vesicles are not able to penetrate the column material and therefore do not undergo the separation but rather pass through in the exclusion volume of the column. In this project, custom-made monolithic columns with a pore size of $2 \mu \mathrm{m}$ were used (BIA Seperations d.o.o., Slovenia).

The samples were prepared in high scale in a production unit as described in chapter 2.2.1 without addition of FCS to prevent contaminations with external EVs. Before application of the sample to the chromatographic ÄKTA-system, they were all subjected to a pretreatment, centrifugation for $30 \mathrm{~min}$ at $4^{\circ} \mathrm{C}$ with $4500 \mathrm{rpm}$ and filtration with a $0.4 \mu \mathrm{m}$ membrane.

\subsubsection{SEC followed by IMAC for purification of his-tagged vesicles}

Another focus of this thesis was laid on the behavior of FR $\alpha$-presenting vesicles. For this purpose, eukaryotic cell lines stably expressing FR $\alpha$ in full length were adapted to the conditions in the bioreactor. FR $\alpha$ is attached to the cell membrane by a hydrophobic glycosylphosphatidylinositol (GPI) anchor. It was shown that FR is 
present in exosomes (Admyre et al., 2007, Raj et al., 2012). A signal sequence in the C-terminus of the receptor sequence is inducing the binding of the lipid-anchor posttranslationally. For the purification of FR $\alpha$-positive vesicles, the receptor sequence was modified N-terminally with the sequence of a 2 his- and 6his-tag. Another cell line was established by transfection with empty vector for experiments with native and unmodified vesicles as control vesicles.

A scheme of the purification method for his-tagged vesicles is shown in figure 3.1. It is a two-step FPLC method made up by a size exclusion chromatography schematically, displayed in A, and an immobilized metal affinity chromatography (IMAC), shown in B. After sample pretreatment as described earlier, the sample was applied to the SEC with the multimodal material CC700. This material has pores with an activated surface for binding of particles smaller than $700 \mathrm{kDa}$. The large sample volume from the bioreactor was applied by a $50 \mathrm{ml}$ sample loop. This way the chromatogram resembles a constant elution of the sample rather than showing single peaks. The product was collected until UV-absorbance decreased. An exemplary chromatogram is displayed in figure 3.1a.

In the second step, the product of the SEC is directed to the monolithic column equipped with iminodiacetic acid (IDA) with immobilized copper. The product of the SEC-column is applied with the $50 \mathrm{ml}$ sample loop in several steps and an elution protocol with imidazole performed. The chromatographic protocol is described in more detail in chapter 2.2.2. Fractions of $2 \mathrm{ml}$ were collected as soon as protein elution was detected and peak appeared. An exemplary chromatogram is displayed in figure $3.1 \mathrm{~b}$.

\subsubsection{IEC for purification of unmodified vesicles}

For the purification of unmodified, native vesicles, a method relying on the surface charge of exosomes was developed. Exosomes have areas on the surface that are enriched in phosphatidylserine (Heijnen et al., 1999), leading to an anionic surface charge. This is why, IEC could be a suitable purification method. Building on the experience of the company BIA separations (Buzzi et al., 2014), a monolithic column 
equipped with quaternary amines (QA) was applied. These are strong anion exchange groups. For this column a protocol with an elution with a strong ionic buffer B was performed.

\subsubsection{Improved purification of not modified vesicles by SEC followed by IEC}

For further polishing of the product of IEC, another method with coupling of the SEC similar to the protocol for his-tagged vesicles was established and screened for EVcharacteristics. The method was performed as described for SEC followed by the IEC protocol. 


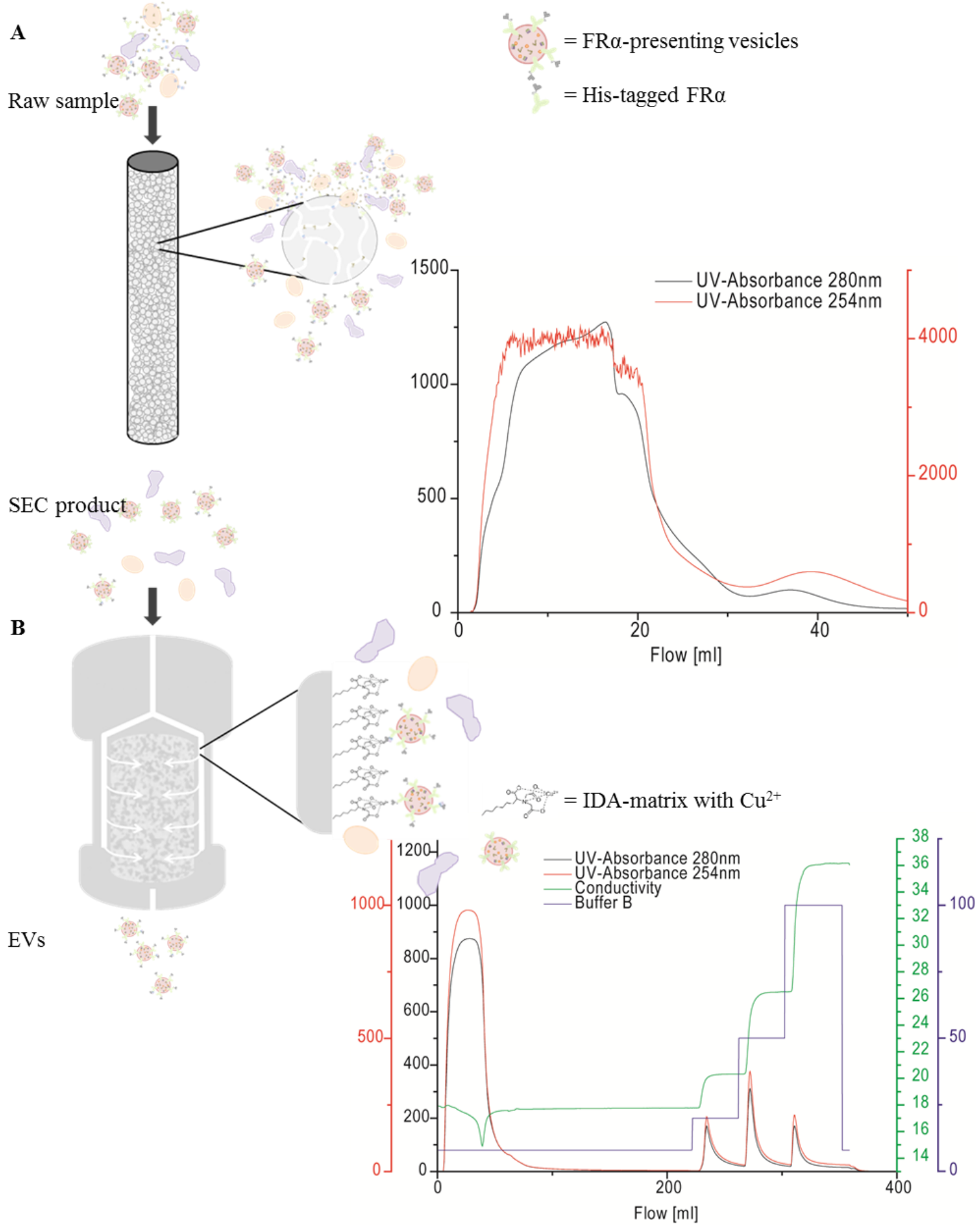

Figure 3.1: Scheme of two-step FPLC purification of FR $\alpha$-presenting vesicles.

A. Samples with his-tagged vesicles are applied to SEC, small contaminating particles are retained in the hydrophobic and positively charged pores. The chromatogram resembles a flow through rather than a gel filtration as it is expected for this material, Capto Core 700. B. Subsequently, the sample is applied to the copper-charged monolithic column. His-tagged particles bind to the $\mathrm{Cu}$-atom and are eluted with imidazole. In the chromatogram, the best product results from the second gradient step with $50 \%$ of buffer $\mathrm{B}$. 


\subsubsection{Method optimization of two-step FPLC method with SEC followed by IMAC}

To optimize the described two-step FPLC method based on SEC and IMAC, a comparison of different immobilized metals was performed. Therefore, samples of 2his-, 6his- and untagged vesicles from stably expressing HEK293 cells were prepared. Each sample was pretreated as described and run through the SEC-column. The IMAC-column was charged with the most common divalent metal cations: cobalt, nickel and copper. Copper is supposed to have the highest affinity for formation of chelates with polyhistidine-tags but also the lowest specificity. Nickel and cobalt have a higher specificity.

Copper and nickel were purchased as sulfates, cobalt as $\mathrm{CoCl}_{2}$. Charging of the monolithic column was performed as described by the supplier. Briefly, the column was washed with deionized water, the IDA-ligands cleared with $1 \mathrm{~N} \mathrm{HCl}$, washed with low ionic charge $(0.1 \mathrm{M}$ Phosphate, $1 \mathrm{M} \mathrm{NaCl})$, washed with water and then charged with the dissolved metals with a concentration of $30 \mathrm{mM}$. Each step was performed for $20 \mathrm{CV}$ and with a high flow rate of $40 \mathrm{ml} / \mathrm{min}$.

To investigate the performance of each divalent metal, the column was run with $30 \mathrm{ml}$ of each one of the three samples in the following order: not his-, 2his- and 6his-tagged supernatant. Between each run, the column was reequilibrated with $5 \mathrm{CV}$ of $500 \mathrm{mM}$ imidazole. The chromatograms were analyzed with the software Unicorn ${ }^{\mathrm{TM}} 5.31$ and areas of the $280 \mathrm{~nm}$ absorbance curve of the flow through as well as the peaks were integrated. The peak areas were normalized to the initially applied protein amount and are displayed in figure 3.2.

The purpose of application of untagged material to the column was to define the background of the column. For every sample, there is unspecific binding of other particles because of naturally occurring histidines in the sample. Meeting the expectations, the curve of copper showed the biggest peaks, especially in the third gradient step. For all other peaks the background was very low as depicted in figure 3.2 . 
2His-tagged vesicles always presented higher protein amount in the eluted peaks, even though the peak area of the flow through was greater as well. This might indicate that the 6his-tagged vesicles remain on the column and are not eluted due to their strong binding of the six histidins. The biggest protein outcome could be achieved with copper and 2 his-tagged vesicles. All following experiments with two-step FPLC prepared vesicles were carried out on a $\mathrm{Cu}^{2+}$-charged monolithic column.
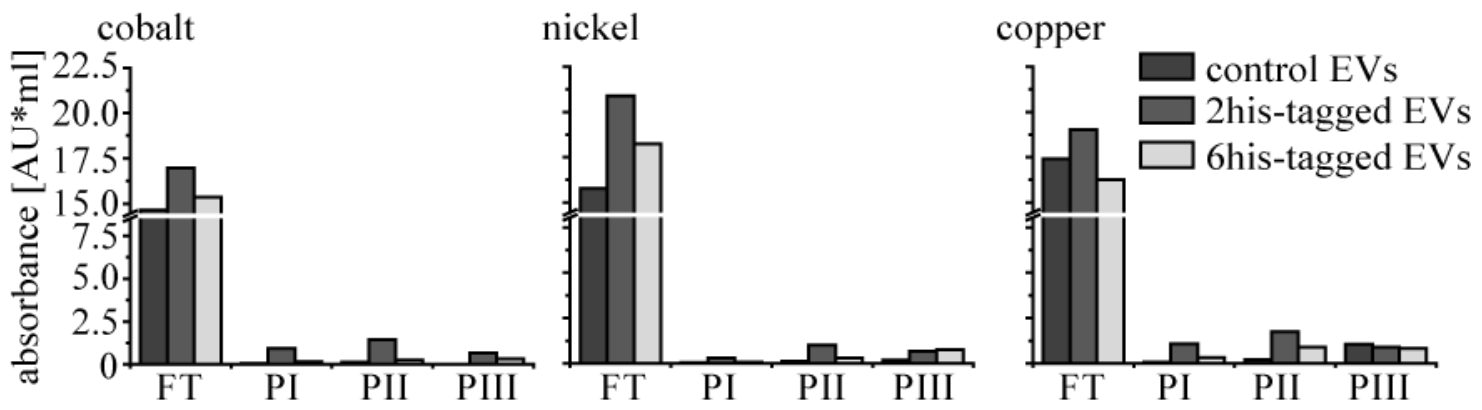

Figure 3.2: Comparison of two-step FPLC with different metals in the IMAC column.

In this experiment, similar amounts of starting material were processed in the two-step FPLC method. The amount of protein in the flow through and all peak fractions was determined by integration of the area of the $280 \mathrm{~nm}$ absorbance curve with the unicorn software. The amount was normalized to the starting protein amount. With nickel as a central atom, the FT has the highest protein amount, while the peaks have the least. The highest outcome could be achieved with $\mathrm{Cu}^{2+}$-ligand with 2 his-tagged vesicles.

All FTs and peaks were analyzed for FR $\alpha$ by Western Blotting. The results were complementary to the analysis of the chromatograms. Both, raw sample and eluates of the 2his-tagged vesicle samples contained more FR $\alpha$ than the 6his-tagged vesicle samples indicating a higher expression level of the former. In addition, the 6his-tagged vesicles showed almost no FR $\alpha$ in the FT. For this reason, it can be assumed that the 6his-tagged vesicles are not completely eluted but partially remain on the column. This might result from the higher density of the histidine residues present on the surface of the vesicles.

\subsection{Method outcome, purity of the product and reproducibility of the method}

\subsubsection{Outcome of the different EV isolation protocols}

There are different methods for the quantification of vesicles and the determination of the yield of isolated vesicles. The most common are the measurement of the 
amount of protein and particles. In most publications EVs are quantified in protein amount (Svensson et al., 2013, Cheng and Schorey, 2016, Nanbo et al., 2013). Since EVs only contribute to a small proportion to the total protein amount derived from cells and since the amount of particles in fluid samples does not exclusively relate to EVs, it is more reasonable to use the terms recovery or output rather than yield. To be able to compare methods with each other, the amount of EVs should always be given in relation to the starting material rather than indicating a total number.

First of all, the reproducibility of the method was determined. The CC700 material can be used several times for the same kind of sample until a total binding capacity of $13 \mathrm{mg}$ per $\mathrm{ml}$ of packing material is reached. Upon repetitive runs, no loss in product amount was observed. The monolithic column charged with $\mathrm{Cu}^{2+}$-ions can be used up to three times without being regenerated, but each time a reduction in the protein amount of approximately $20 \%$ was observed. All columns can be regenerated and recharged several times.

To determine the EV recovery of the two-step FPLC method made up by SEC combined with IMAC, three independent purifications of 2his-tagged vesicles from HEK293 cells have been performed. For the purification by IEC, control EVs were used. Samples with his-tagged EVs as well as samples with untagged vesicles were processed by DC which is the most common method for EV preparation (Théry et al., 2006). In this project, a protocol with three different centrifugation steps was performed. In the first step big particles and debris are removed, in the second smaller particles are removed and at last the vesicles are pelleted by ultracentrifugation.

In figure 3.3 the results for the two-step FPLC with the IMAC and the IEC in comparison to the most common method by DC are displayed. For the protocol using IMAC only samples with 2his-tagged vesicles were used, for the analysis of the product outcome of the IEC only untagged vesicles were used. For the results of the DC various samples were used tagged and untagged vesicles. All values were normalized to the protein and particle amount of the starting material. 
The protein amount and concentration was determined by BCA-assay. Samples with imidazole from the elution buffer were washed in ultrafiltration unit prior measurement. Imidazole is absorbing as the bicinchoninic acid-copper complex at $560 \mathrm{~nm}$ and might falsify a BCA-assay. The particle recovery was determined by NTA.

The CC700 material removes more than half of the contaminating protein amount, which is important to remove $\mathrm{FR} \alpha$ that might be present in soluble and not vesicle bound form. The protein recovery of the DC-protocol is almost four times higher than the amount recovered by chromatographic methods. The difference between the particle recoveries is smaller, but still the particle recovery of the chromatographic purification is smaller. The standard deviation of the particle recovery of the DC is higher in comparison to all other preparations.

Up to now it is not clear to which extent EVs are secreted from cells. This might be highly depending on the cell type and the status of the cell. It is not possible to estimate whether all EVs are recovered by the described chromatographic or the common DC method. In any way, the product of the standard protocol has a higher reconstitution of protein and particle amount than the product of the purification by chromatography, but shows a stronger variation in the protein and particle recovery, figure 3.3. 


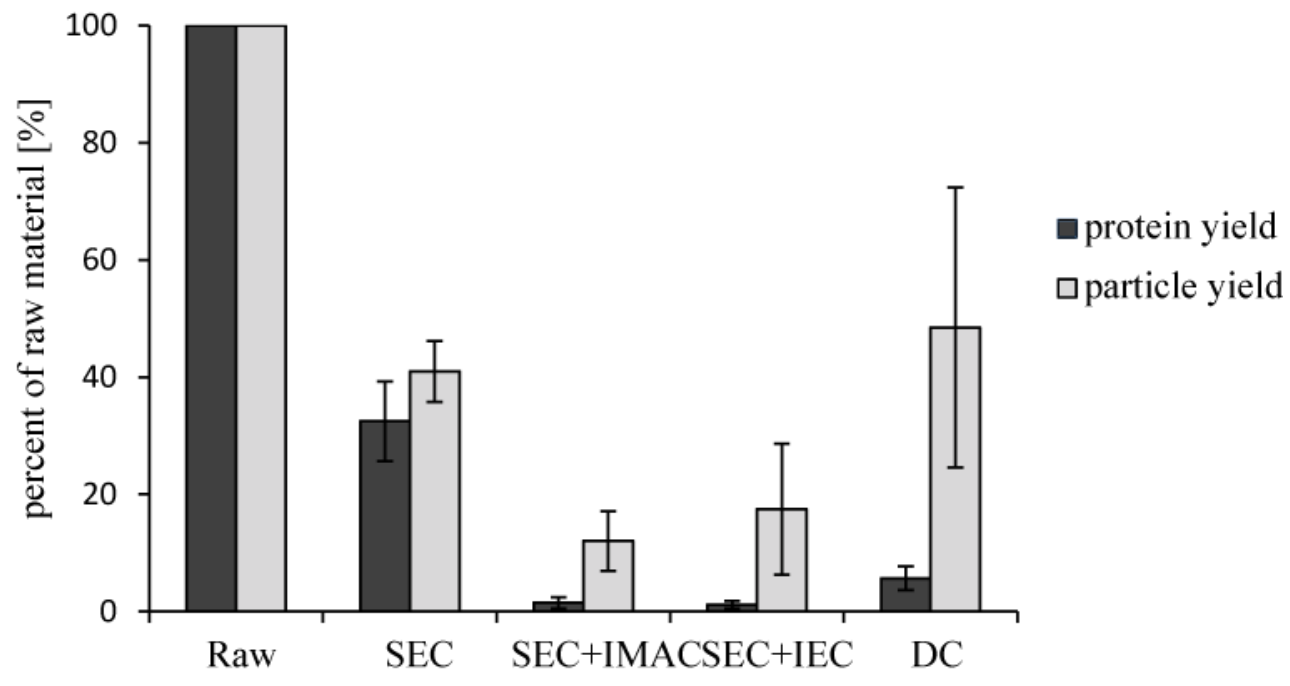

Figure 3.3: Particle and protein recoveries of different preparations.

The protein recovery was determined by BCA-assay and normalized to the amount of the starting material. The particle recovery was determined by NTA and processed just as the protein amount. The CC700 material is able to remove more than half of the contaminating proteins. The IMAC and IEC are able to polish the product further and the protein amount is reduced to less than $10 \%$ of the starting material. The product of the DC protocol shows the highest recovery of protein amount and particles. However, the purification grade remains unclear.

\subsubsection{Purity of the different EV-preparations}

To judge the quality of an EV preparation, different methods for validation of the purity are recommended. One of the most common parameters is the ratio of particles per protein which is usually given as the ratio of the amount of particles per $1 \mu \mathrm{g}$ protein. It is assumed that EV preparations with less than $1.5 \times 10^{9}$ particles per $1 \mu \mathrm{g}$ protein are not pure, $2 \times 10^{9}$ to $2 \times 10^{10}$ particles per $1 \mu \mathrm{g}$ protein are pure and with $3 \times 10^{10}$ and more particles per $1 \mu \mathrm{g}$ protein are considered as very pure (Webber and Clayton, 2013).

The ratio can be easily determined from the particle and protein concentration. For the FPLC-methods, the ratios of all steps, from the starting material, the CC700 product and the IMAC and IEC product were determined. The results are displayed on a logarithmic scale in figure 3.4.

For each sample three or more independent measurements were performed, except for the control sample, the medium. Each value is displayed as one dot in the graph. It 
is noticeable that the purity of the first step, the SEC is low in comparison to the raw material. This might be a technical artefact resulting from the detection limit of the NTA. The NanoSight is not able to track particles smaller than $10 \mathrm{~nm}$, the CC700 mainly binds small impurities.

Even though the difference of the ratio is not significant, the two step affinity chromatography has in average the highest amount of particles per $1 \mu \mathrm{g}$ protein ratio and therefore, the highest purity.

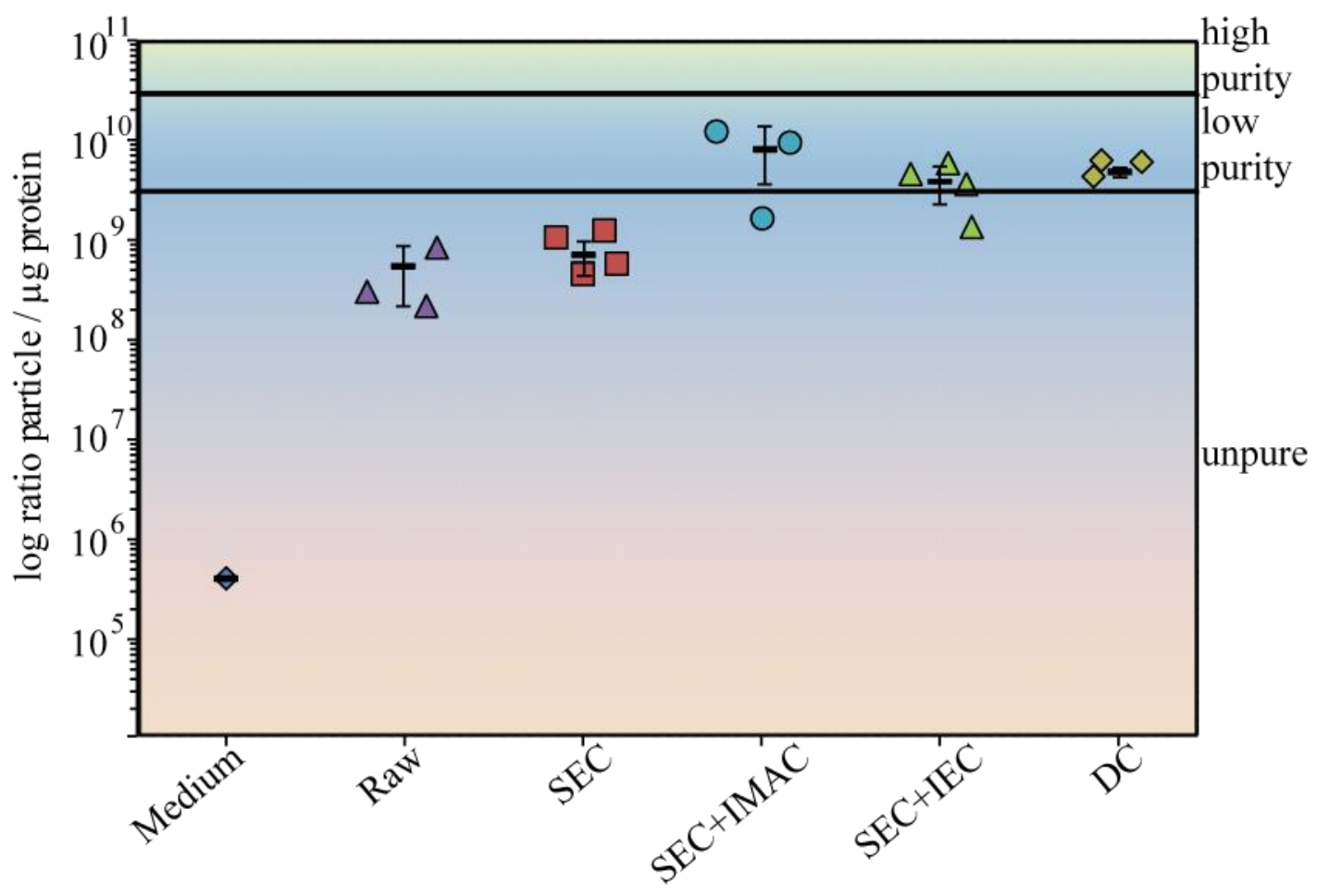

Figure 3.4: Purity determined as particle per $1 \mu \mathrm{g}$ protein ratio.

For all steps of the two chromatographic methods and for the standard protocol as well as the DC, the ratio of particle per $1 \mu \mathrm{g}$ protein was determined. Protein amount was measured by BCA-assay, the particle count was determined with a NTA. For each sample at least three independent measurements were performed. Except for the medium, there, only one measurement was made. The two-step FPLC method with an IMAC-column has the highest ratio indicating the highest grade of purity.

\subsection{Vesicle characterization}

In the next steps, the products of the different EV-preparations were characterized according to the recommendations of the ISEV: a general characterization of the 
exosome enrichment, analysis of single vesicles by electron microscopy, analysis of the size distribution by NTA and study of the biological activity.

\subsubsection{Characterization of protein marker}

To facilitate the comparison of different EV purification protocols, supernatant of the same cell line was used, i.e. HEK293 stably expressing PTPS-2hisFR $\alpha$. Aliquots of each purification step were retained and the protein concentration determined by BCAassay. From each step $1 \mu \mathrm{g}$ of total protein amount was applied to Western Blotting unless otherwise indicated. In the analysis of the IEC column, control cells without the stable expression of FR $\alpha$ were used. In addition to the lack of FR $\alpha$, these cells did not contain any TOM20, neither in EV-fractions nor in the raw input material. Therefore, the detection of both FR $\alpha$ and TOM20 were omitted. All results are depicted in figure 3.5 .

GPI-anchored proteins like FR $\alpha$ do not run in sharp bands in the electrophoresis. This results from the variable degree of glycosylation of the GPI-anchor (Galian et al., 2012). The GPI-anchored protein appears with an apparent bigger size in the gel and with a smeared band. In these experiments FR $\alpha$ is used as an EV-enriched protein together with flotillin and alix which are common exosomal marker (Otto and Nichols, 2011, Xu et al., 2016).

For the common protocol by DC, alix is strongly enriched in the EV-pellet, flotillin and $\mathrm{FR} \alpha$ are not enriched to the same degree. Contaminating proteins like TOM20 from the mitochondrial membrane or the stably expressed protein PTPS are reduced. When comparing the DC derived vesicles with those derived from the two-step FPLC method, the later contained almost no contaminating proteins. In particular, after application of the SEC most of extravesicular PTPS is removed. The exosomal markers are strongly enriched by the two-step FPLC in $1 \mu \mathrm{g}$ protein. Peak two, labelled with PII, shows the highest amount of the exosomal markers flotillin and FR $\alpha$.

The EVs derived from the SEC with IEC purification show a similar enrichment of the EV markers when compared to the IMAC methods. The IEC alone shows a smaller enrichment of the EV markers, however, the peak fractions contain a higher protein 
composition. In peak one (PI) mainly the protein PTPS is eluted. This indicates that the SEC purification step is required to remove the bulk amount of contaminating proteins and to optimize any further chromatographic purification method. The second and third peak of this purification might though contain relatively pure exosomes since, PTPS is reduced and the exosomal markers are enriched. 
DC

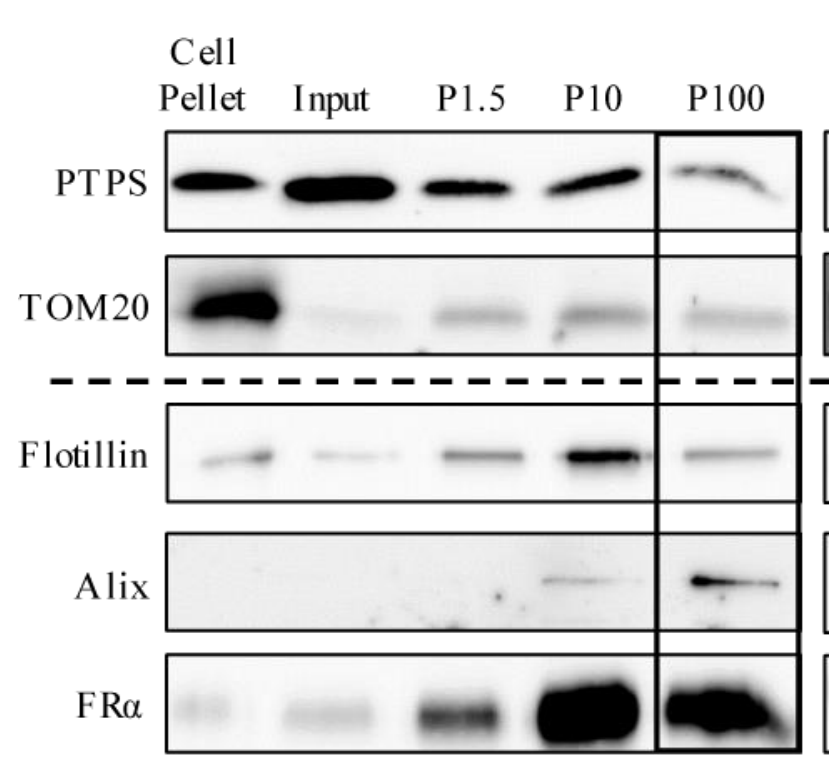

EV

fraction

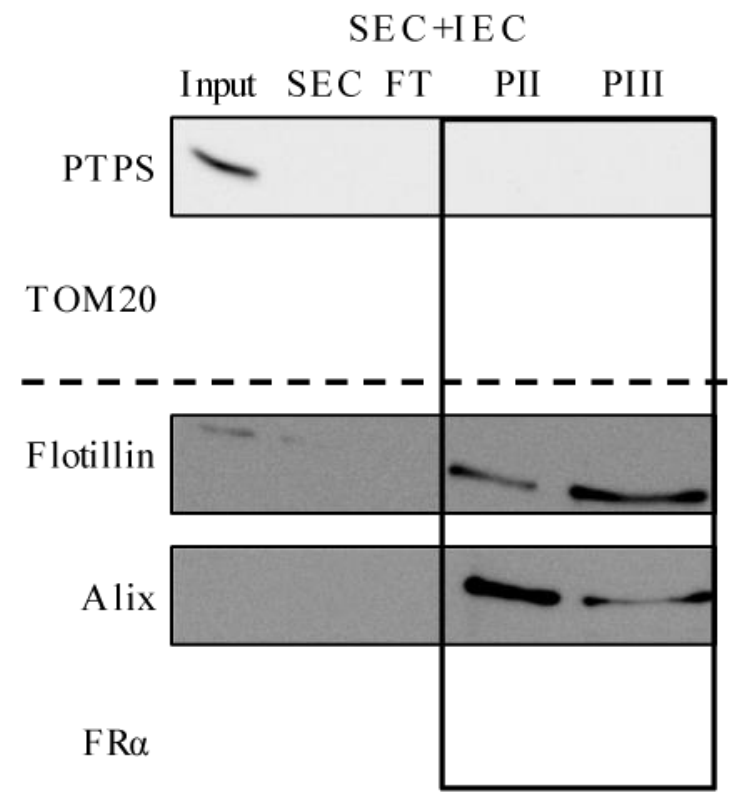

EV

peaks
SEC +IMAC

Cell
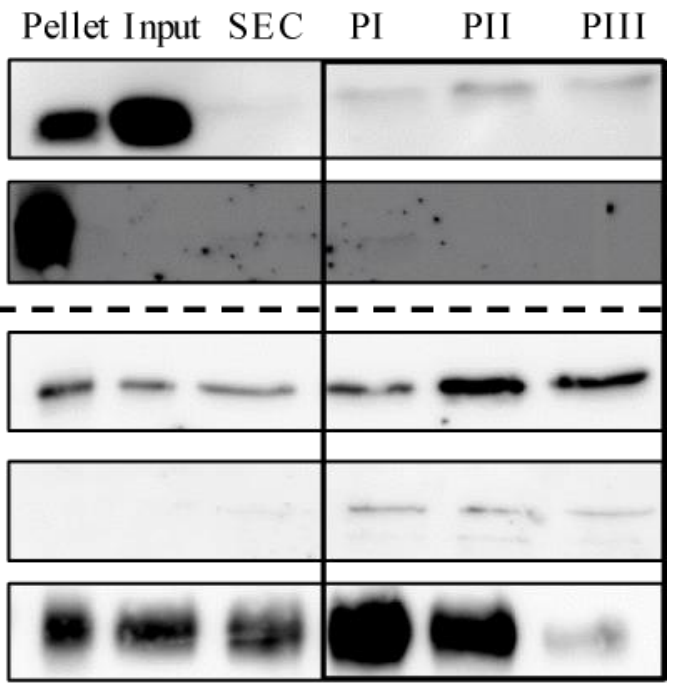

EV

peaks
Flow

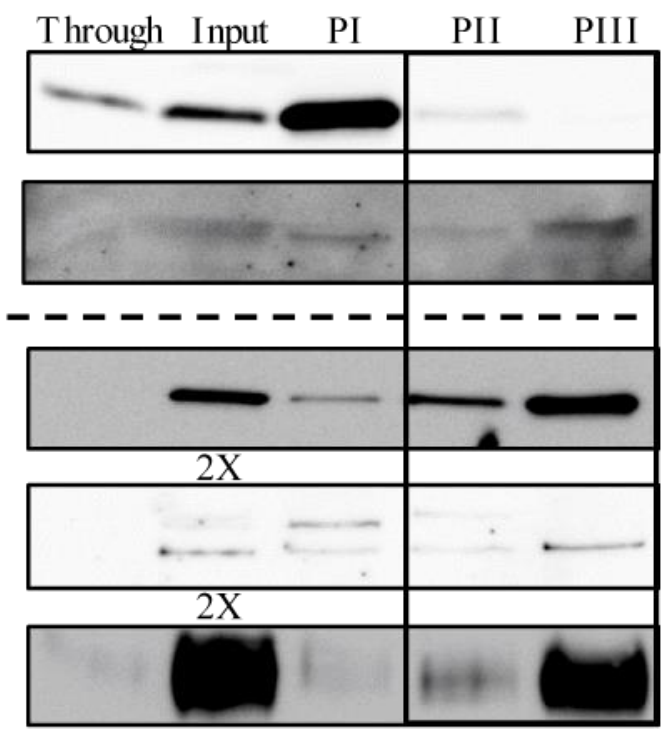

EV

peaks

Figure 3.5: Exosomal and non-exosomal markers for all FPLC methods in comparison with the DC protocol.

EVs were prepared as described for the specific method. For comparison of DC with the chromatographic protocols the same sample from HEK293 cells expressing 2his-tagged FR $\alpha$ were used. For the evaluation of the SEC followed by IEC supernatant from HEK293 cells not expressing any his-tagged protein was used. For each step and method $1 \mu \mathrm{g}$ total protein was loaded onto a gel, except otherwise indicated. The blots were probed for exosome enriched proteins like FR $\alpha$, flotillin and alix. Additionally, the reduction of intra- and extracellular contaminations was investigated with the proteins TOM20 and the stably expressed PTPS. 
Peak II (PII) of the two-step FPLC combining SEC and IMAC shows the strongest recovery of exosome markers while negative markers are reduced.

Based on the results from the analysis of the EV-enriched and the contaminating proteins, the IEC alone shows the worst ratio of the marker proteins. Because of the high rate of contaminating proteins the IEC was not further used for EV preparation in following experiments.

The combined procedure of SEC and IMAC shows the best results, since intercellular and extracellular contaminations are removed, while EV markers are manifold enriched. Even though the DC shows a high ratio of particles per $1 \mu \mathrm{g}$ protein in Western Blot analysis, the high amount of contaminating proteins becomes obvious.

\subsubsection{Size determination of the vesicles}

As suggested from the ISEV, the size distribution was investigated by NTA. Samples of each preparation step were collected and adapted to an approximate concentration of $2 \times 10^{8}-10^{9}$ particle/ml. If samples were too concentrated, a dilution in PBS was prepared and the measurement repeated. Each sample was analyzed by three independent experiments as triplicates for each measurement.

In general, the mean size of the prepared EVs is similar when comparing the mentioned purification methods. The raw material and the product of the SEC show a higher degree of variability than the final products. By application of the CC700 purification step, most proteins and most small particles are removed and the mean size increases when compared with the raw material. Peak three (PIII) from the purification with SEC and IEC was recognized as the main EV-containing fraction by Western Blot analysis. The size of the particles eluted from the IEC-column is on average smaller than the size obtained by IMAC. These results are shown in figure 3.6.

The size of the particles obtained from the SEC followed by IMAC was increasing, peak I to III. According to Western Blot analysis peak fractions with the highest amount of exosomes is PII. The particles in this fraction are close to the maximum size of exosomes. The native and untagged particles gained from DC protocol have a smaller 
mean and median size. The difference of the mean and median size of the DC preparation is significant in contrary to all other aliquots. This indicates a considerable population of small particles in this sample.

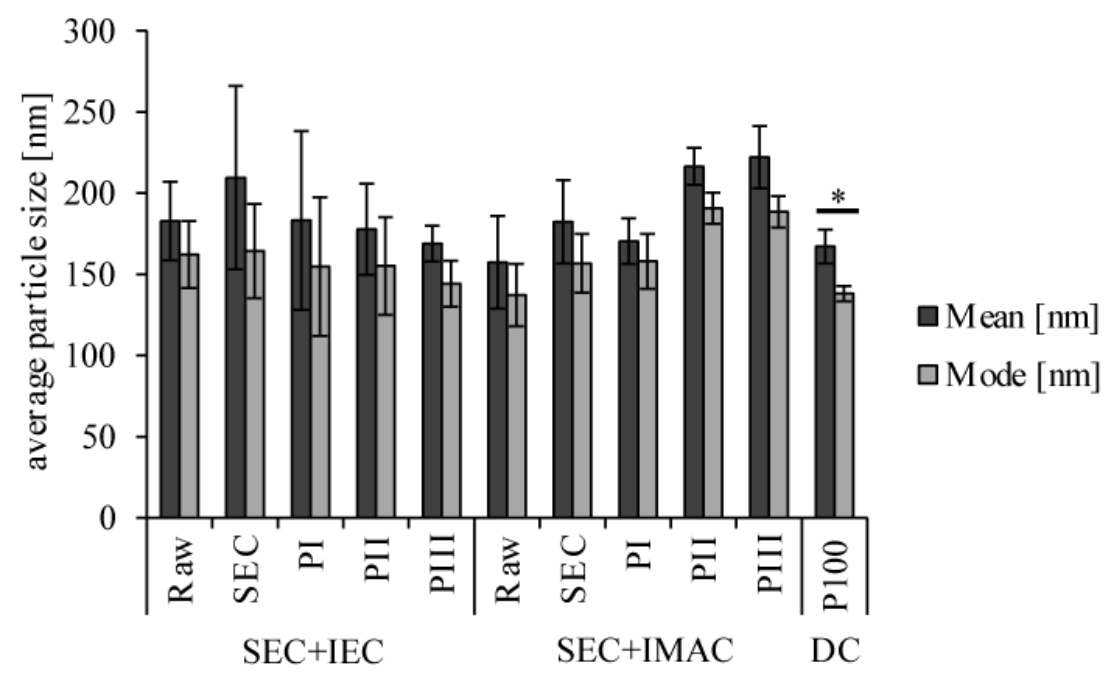

Figure 3.6: Average and median size of each purification step determined by NTA.

The control EVs were prepared by SEC followed by IEC. Vesicles presenting 2his-tagged FR $\alpha$ were purified by the described two-step FPLC method. The exosome preparation obtained from DC, labeled as P100, show the highest difference between the mean and the median size. This indicates that particles obtained by DC are highly variable in size and particularly contain higher proportions of particles smaller than the mean size. The products PI-PII from two-step FPLC protocols are more homogenous, especially in PII of SEC and IMAC. The particles obtained by SEC are more heterogeneous and show a large variation in size.

\subsubsection{Characterization of single vesicles}

To characterize single vesicles, obtained by the different protocols, samples were prepared as described above. FR $\alpha$-presenting vesicles were gained from supernatant of HEK293 cells stably expressing 2hisFR $\alpha$. All electron microscopic images were made at the Technion in Haifa, Israel with the kind help of Professor Sosnik's group.

For SEM, the EVs were dropped onto carbon-tape, dried and covered with $\mathrm{Au} / \mathrm{Pd}$ coating. The vesicle preparations show a cup-shaped morphology that is characteristic of exosomes (figure 3.7a and b). The collapsed impression is a technical artefact resulting from drying of the sample. Larger vesicles were sucked by the vacuum and lead to the black holes visible in figure $3.7 \mathrm{a}$ and $\mathrm{b}$. The vesicle preparation appeared uniform and there were almost no contaminations of debris and other particles like microvesicles were not visible. 
By transmission electron microscopy a higher resolution can be achieved but the sample is degraded very fast. In figure 3.7c many vesicle parts are visible which degraded while taking the image. Dark spots in TEM may relate to lipoproteins as seen on the left side of figure 3.7c. It was even possible to capture the double membrane of an exosome as nicely depicted in figure $3.7 \mathrm{~d}$.
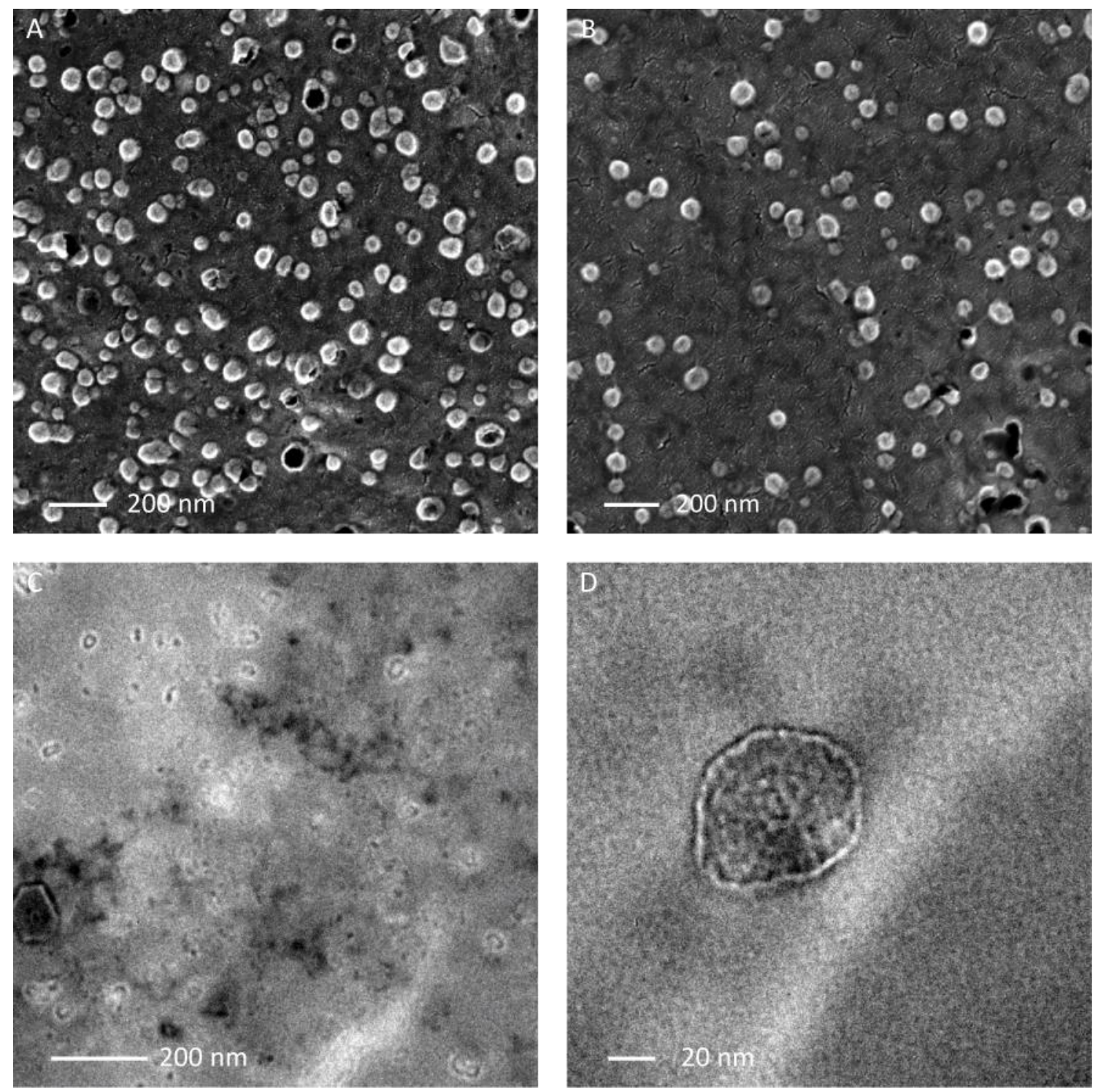

Figure 3.7: Electron microscopic examination of vesicles purified by SEC and IMAC. Samples were prepared by two-step FPLC-method as described. FR $\alpha$-presenting exosomes from HEK293 cells in A and B imaged by scanning electron microscopy. The vesicles are of exosome-like size $<200 \mathrm{~nm}$ and cup shaped. As shown in C and D, a homogenous size distribution as well as a double membrane could be proven by TEM. 
For native EV isolated by SEC combined with IEC, it was not possible to take images of single vesicles in TEM or SEM. After analysis in cryo-TEM by Na'ama Koifman, who is specialized on the imaging of EVs, it became clear that many lipoprotein particles were present in these preparations, as indicated in figure 3.8a by white arrow heads. In contrast to EVs lipoprotein particles are not enclosed by a double membrane and show a more homogenous structure than vesicles as nicely demonstrated in figure 3.8c. For cryo-TEM, the sample does not need to be dehydrated. This is the major advantage in comparison to other EM imaging techniques. This way a more native form for image taking is preserved. In this case, the analysis of cryo-TEM images revealed the presence of some multilamellar vesicles as visible in figure $3.8 \mathrm{~b}$.
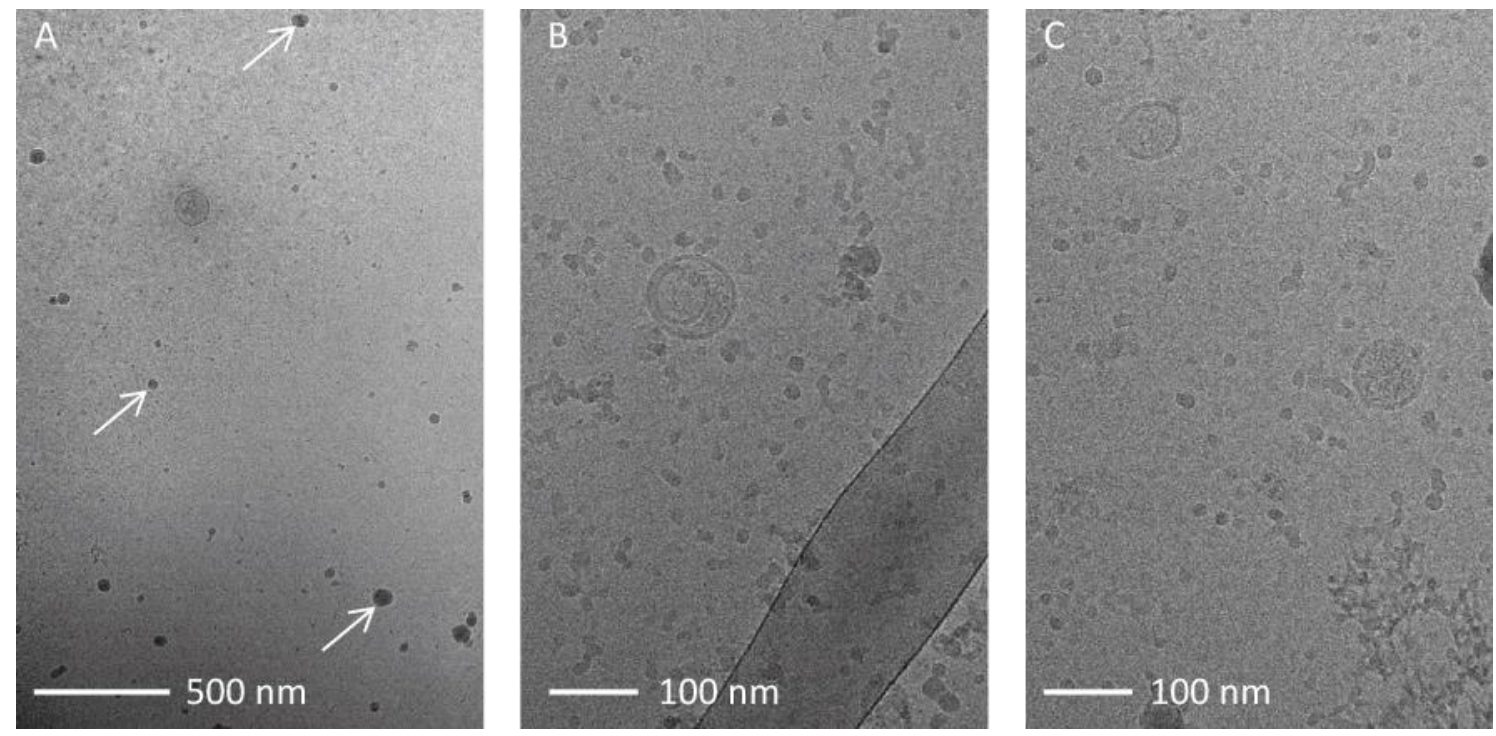

Figure 3.8: Cryo-TEM of native EVs purified by SEC coupled with IEC.

The sample was purified as earlier described by SEC and IEC of HEK293 cells. The specimen preparation for the cryo-TEM images were made by Na'ama Koifman. The images revealed a high amount of lipoproteins as indicated in A by the arrows. There are exosome-like vesicles with a double membrane and a heterogeneous interior as seen in C. Multilamellar EVs can occur, shown in B.

\subsubsection{Density of the different EV-preparations in comparison}

Additionally to the characterization requested by ISEV, the density of the different EV preparations was determined. Since the established method is based on purification by size and affinity, the density is a parameter that can give further information about the isolated particles. Both, samples from the two-step FPLC and the DC method were subjected to a sucrose gradient. The gradient was carefully layered from the bottom- 
up with decreasing concentration. The sample was added in $0.25 \mathrm{mM}$ sucrose in the same volume. Samples were taken from HEK293 stably expressing PTPS-2hisFR $\alpha$. In two independent experiments, a sample was purified with the two-step FPLC method and in parallel by DC. From each layer the same volume of sample was subjected to Western Blotting and analyzed for the presence of flotillin and FR $\alpha$. One exemplary blot is shown in figure 3.9. For evaluation, the images were analyzed with image J. All pixels of one sucrose gradient were summed up to $100 \%$ and each band was normalized to the total pixel amount. These results are summarized in bar diagram above the associated Western Blot image in figure 3.9.

The particles purified by two-step FPLC reached their equilibrium density at $1.16-1.19 \mathrm{~g} / \mathrm{cm}^{3}$. Though, the isolated vesicles were slightly bigger in size, the density corresponds to exosomes perfectly well. The increased size might results from the fact that the cell lines overexpress FR $\alpha$. and PTPS. In fact, the control cells without overexpression show normal sized EVs.

For the EVs derived from the DC, two distinct populations could be distinguished. The density of one of them is similar to the density of exosome-like EVs obtained from the two-step FPLC product at $1-1.19 \mathrm{~g} / \mathrm{cm}^{3}$ whereas the second one with a higher density at $1.25-1.29 \mathrm{~g} / \mathrm{cm}^{3}$ rather corresponds to microvesicles of other origin. 
FPLC

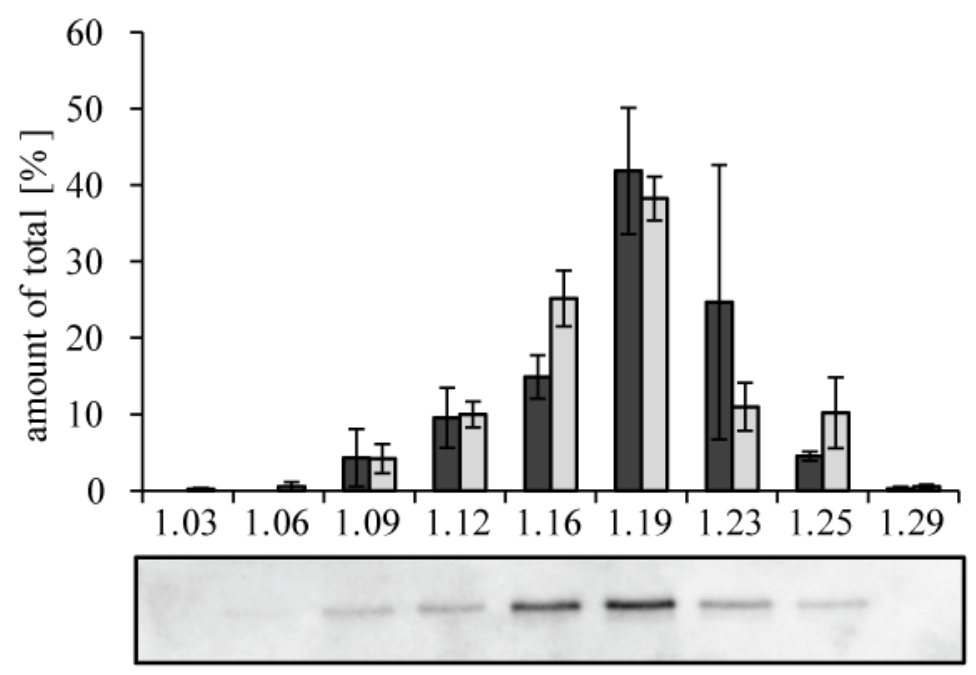

FR $\alpha$

口Flotillin

density $\left[\mathrm{g} / \mathrm{cm}^{3}\right]$

Flotillin

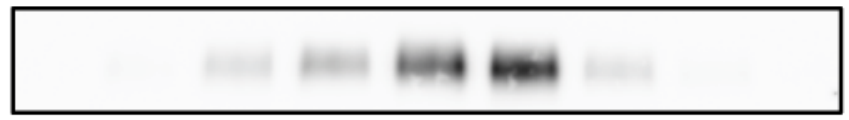

$\mathrm{FR} \alpha$

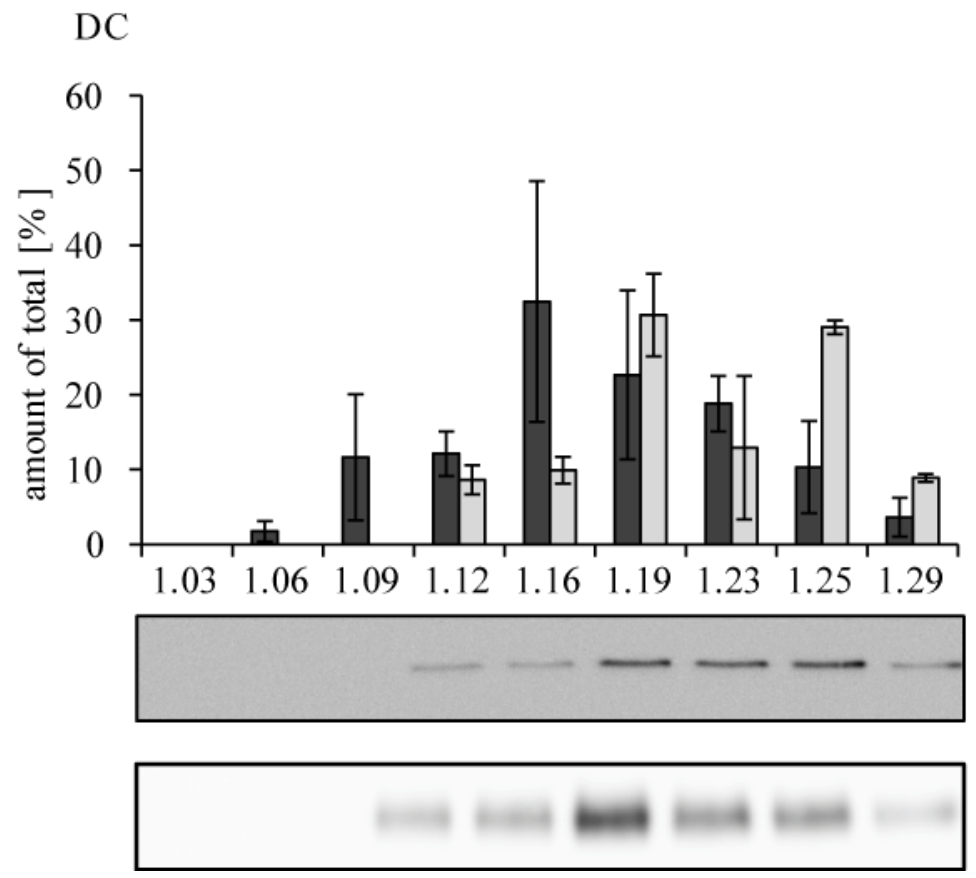

$\square \mathrm{FR} \alpha$

$\square$ Flotillin

density $\left[\mathrm{g} / \mathrm{cm}^{3}\right]$

Flotillin

$\mathrm{FR} \alpha$

Figure 3.9: Density determination of EVs prepared by DC and in two-step FPLC determined by centrifugation on a sucrose gradient.

EVs were prepared by two-step FPLC and DC, followed by a separation by centrifugation in a sucrose gradient for $16 \mathrm{~h}$ with $100.000 \mathrm{xg}$. Data was taken from two independent experiments. The EVs resulting from purification by the established two-step FPLC method have a density similar to exosomes of $1.13-1.19 \mathrm{~g} / \mathrm{ml}$. 


\subsubsection{Verification of FR $\alpha$ on the surface of the isolated vesicles}

To verify the amount of FR $\alpha$-presenting vesicles in the final FPLC product with the help of NTA, an indirect labeling similar to a labeling protocol for flow cytometric analysis was performed. Therefore, the raw material, the product of the SEC-column and the second peak fractions of the elution from the IMAC column were diluted to an appropriate concentration, labelling with a primary antibody against FR $\alpha$, MOV18 added, washed and labeled with a secondary, fluorescence-conjugated antibody. The sample was gained from supernatant of HEK293 cells stably expressing 2 hisFR $\alpha$.

In figure 3.10 the results of this experiment are depicted. Three curves of the size distribution corresponding to three independent experiments are exemplary depicted as solid, dashed and dotted lines. The size distribution of the fluorescent particles is displayed in blue color, the black lines resemble recordings of all particles. In comparison to the laboriously purified SEC- and final FPLC-product, the raw material contains a high amount of labeled particles. This might result from a high number of soluble FR $\alpha$ in the beginning, which is then removed by SEC.

The FPLC-derived EVs are almost exclusively FR $\alpha$-positive as demonstrated by the bars in the graph on the right side. However, there is still a considerable amount of particles in this sample that are not fluorescent and therefore not FR $\alpha$-positive. Most contaminations are of small size and were not detected in the other sample preparations. However, these particles are too small to be regarded as EVs. They are smaller than $30 \mathrm{~nm}$.

In conclusion, the analysis of FR $\alpha$-positive particles during every purification step represents a reliable assessment of the efficiency and purity of the EV preparations. 
Raw

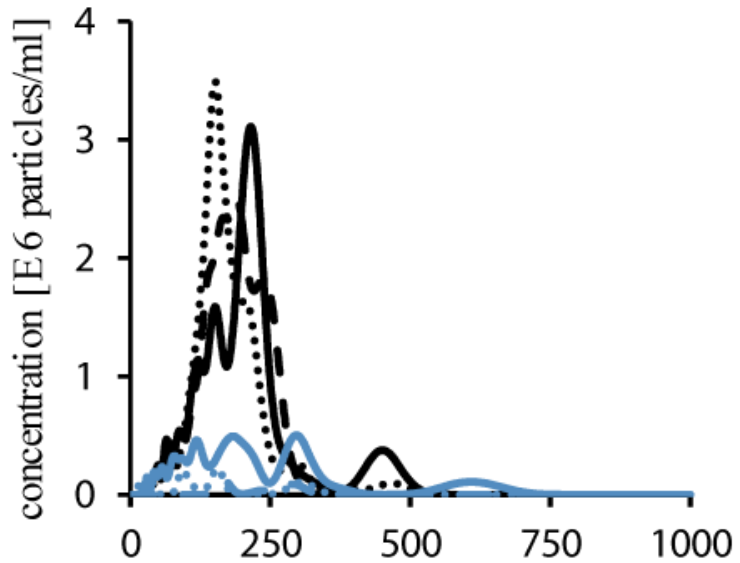

SEC

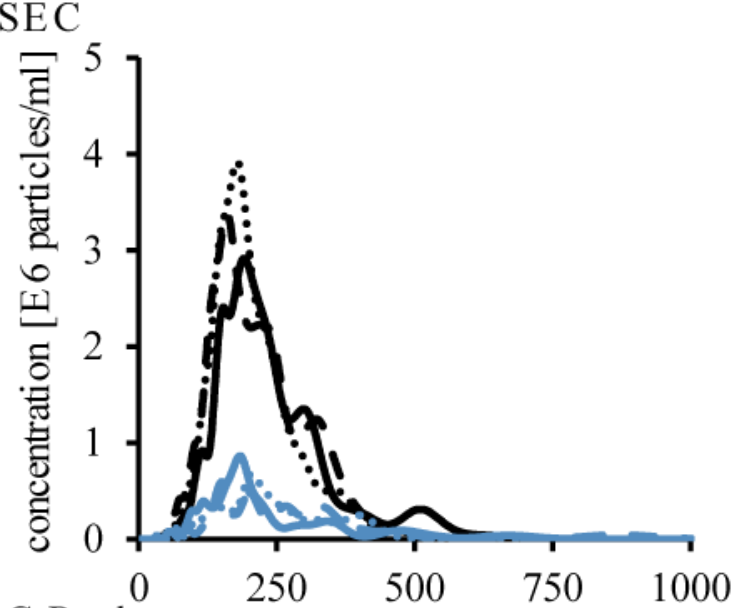

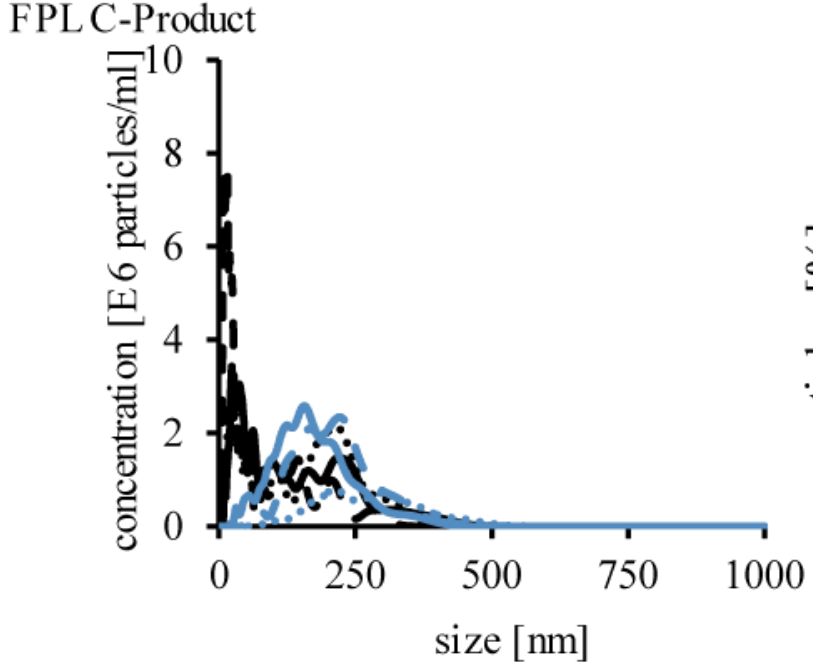
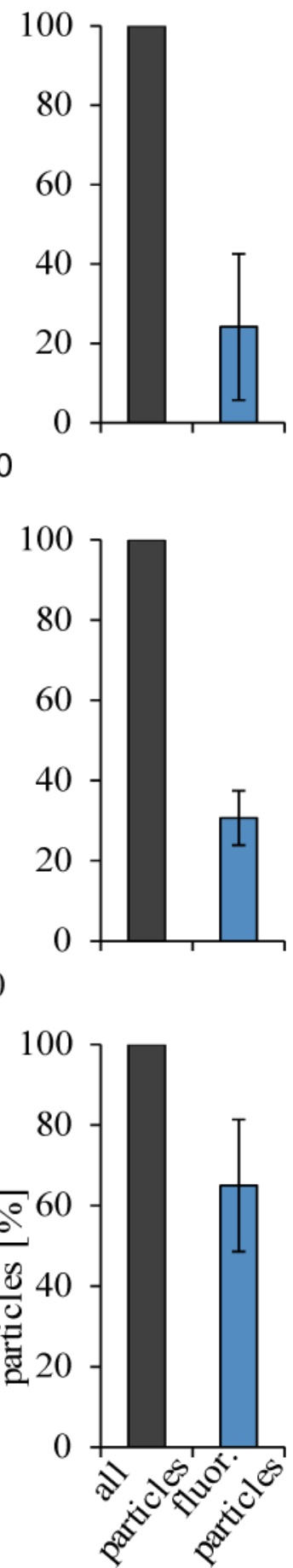

Figure 3.10: Analysis of fluorescent particles by indirect antibody labeling in NTA.

Each preparation step was labeled with anti-FR $\alpha$-antibody from mouse, MOV18, washed and then labeled with a secondary antibody conjugated with anti-mouse IgG Alexa Fluor532. The samples were not further processed but analyzed by NTA for all (black) and fluorescent particles (blue). In the left column the size distribution of one analysis from three independent experiments is depicted as solid, dashed or dotted line. The right column displays the average amount of all (black bar) and of the fluorescent particles (blue bar). The amount of FR $\alpha$-positive particles is increasing with each purification step. 


\subsubsection{Analysis of biological performance by EV uptake}

It is difficult to prove the biological activity and integrity of EVs. The uptake of cells demonstrated by microscopy and by flow cytometric analysis are used in other scientific groups (Balaj et al., 2015, Escrevente et al., 2011). In this project, a flow cytometric analysis of the up taking cells was performed. Therefore, the vesicles are labeled and added to the cells which are then screened for the fluorescent signal. In this case, the dye mCling was applied. mCling was originally designed for the visualization of synaptic vesicles (Revelo et al., 2014). The dye is made up by a poly-Llysine tale bound to a fluorescent molecule, in our case ATT0647. Poly-L-lysine is a lipophilic tale that easily integrates in membranes.

Vesicle labelling was performed with concentrated vesicle suspensions for a short time of a few minutes. Unbound mCling was removed by ultrafiltration with Hydrosart. Due to the hydrophobic tale, mCling will tend to form micelles which might behave like vesicles and might not be removable by ultrafiltration units. For this reason, a control with just dye, which was also washed, was included. It is referred to as mCling and depicted as green-dot in figure 3.11.

In parallel, vesicles without FR $\alpha$ were purified by DC and labeled in the same manner. For the experiment shown the particles in the final product were counted with NTA and added in the same number as described in section 2.4.4.

BN16 cell line was chosen for this experiment. This is a cell line of epithelial cells, that are able to polarize just as choroid plexus cells, where the FR $\alpha$ is taken up. The cells were grown to $60 \%$ confluency and labeled vesicles added for different periods of time from 5 min to 16 h. 10000 cells were counted by flow cytometry and the mean fluorescence of all cells taken for analysis. The FR $\alpha$-positive vesicles are taken up faster and lead to a higher mean fluorescence of the cells. The experiment was repeated with the same conditions, except the vesicles were not counted by NTA but quantified according to their protein amount. The result was similar; the uptake of FR $\alpha$-positive vesicles was faster compared to the vesicles not expressing FR $\alpha$. 
After $8 \mathrm{~h}$, a saturation of the uptake is reached. The fluorescence even decreases after $16 \mathrm{~h}$. This will be presumable a technical artefact resulting from the procession of the vesicles and with them the fluorophore leading to a reduction of the average fluorescence. Another explanation might be that some vesicles are secreted and therefore, the overall fluorescence reduces.

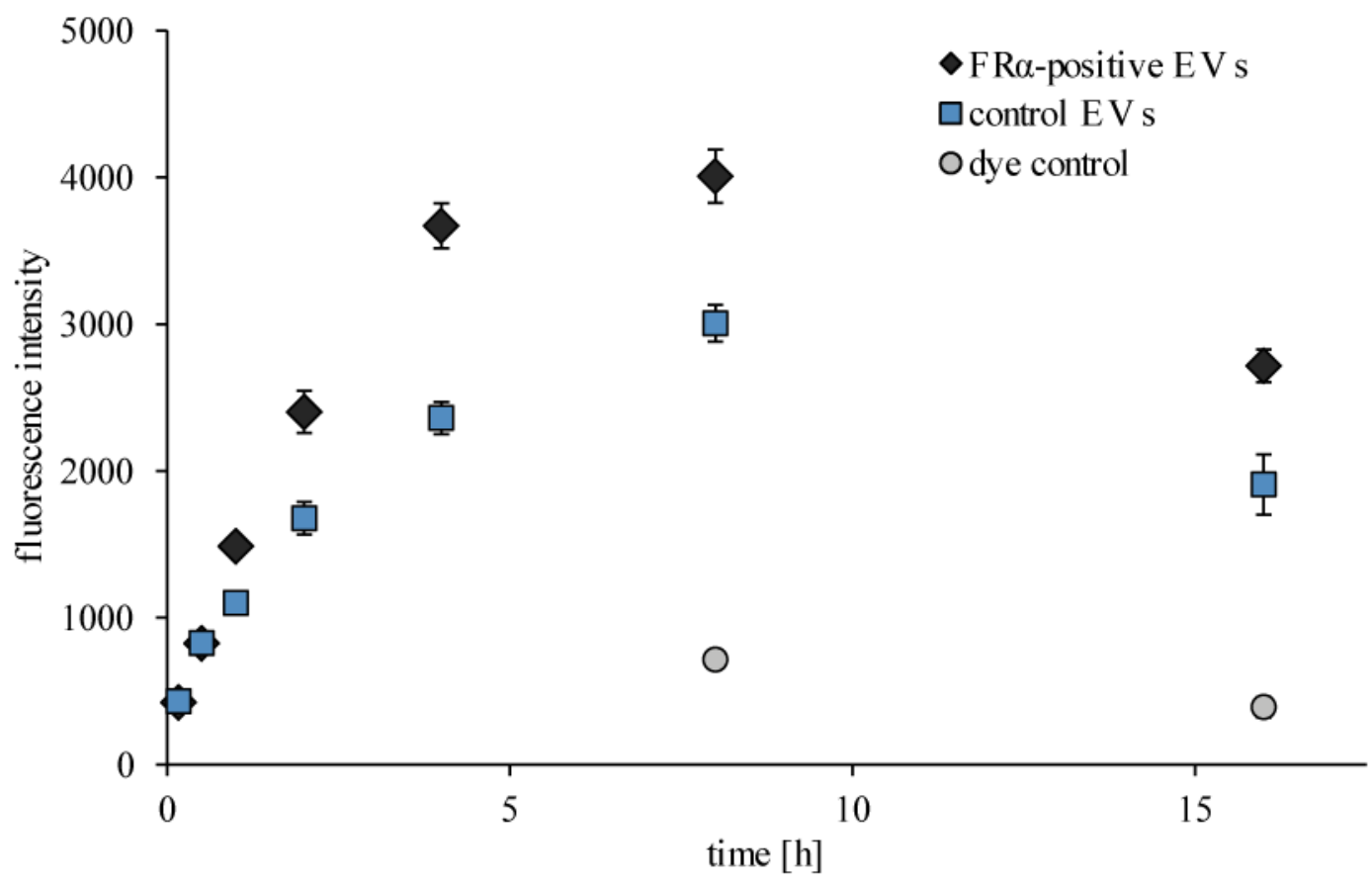

Figure 3.11: Quantification of EV uptake of BN16 cells quantified by flow cytometry. BN16 cells were grown to $60 \%$ confluency in a 24-well plate. FR $\alpha$-presenting and control EVs were labeled with mCling-ATT0647, washed in a Hydrosart ultrafiltration device and added to each well. A dye control consisting of dye without vesicles was subjected to the same protocol and added. Cells were harvested with trypsin and uptake was quantified by analysis of mean fluorescence by flow cytometry. FR $\alpha$-presenting vesicles are taken up faster than control vesicles.

\subsection{Cargo loading}

There are many ways to introduce drugs into extracellular vesicles. In case of small molecules it might be sufficient to initiate the formation of pores into the double membrane and enable the drug to flow in the vesicles along a concentration gradient. However, it is not possible to target high amounts of the cargo into the vesicles since the vesicles volume is rather small in relation to the total volume. For example, exosomes recovered by DC and reconstituted in a very small volume have a 
concentration of $10^{12}$ particles per $\mathrm{ml}$. Presumed these EVs have a theoretical diameter of $100 \mathrm{~nm}$, they would have a theoretical total volume of $0.52^{*} 10^{-3} \mathrm{ml}$ or $0.052 \%$. Since, it is not possible to increase the targeting of molecules into vesicles without any molecules that promote an active transport, the concentration of the drug corresponds inside and outside the EVs with each other; therefore, the total amount of the drug that is encapsulated into the EVs only equals $0.052 \%$ of the total amount of the drug that was added to the total volume of EV solution.

\subsubsection{Loading experiments with the TPPI assay}

To be able to detect very low amount of loaded protein to EVs, a very sensitive assay needed to be found for the extracellular loading experiments. In this project the enzyme TPPI was chosen, since there is such assay established in our laboratory for dried blood spots (Lukacs et al., 2003). This assay allows the detection of the proteinase in the low nanomolar range. The activity can be measured after one hour of reaction by cleavage of the substrate Ala-Ala-Phe-7-amido-4-methylcoumarin. Fluorescence emission is measured at $460 \mathrm{~nm}$ after excitation at $355 \mathrm{~nm}$. With the help of a calibration curve of 4-methylcoumarin, the amount of cleaved substrate and the concentration of TPPI can be determined. Other proteases are inhibited by pepstatin A and E64.

EVs were harvested from supernatant of cells stably expressing FR $\alpha$ and TPPI. This way, EVs contained a small amount of TPPI and had a basal TPPI activity. The basal activity of EVs in approximate concentration of $10^{12}$ particles per ml was below $50 \mathrm{nmol} / \mathrm{h} / \mathrm{ml}$ TPPI activity. TPPI was added to the loading experiments in concentration of $0.052 \%$ to $1.2 \mathrm{mg} / \mathrm{ml}$ and protease activities higher $18500 \mathrm{nmol} / \mathrm{h} / \mathrm{ml}$. This would result in at least $74 \mathrm{nmol} / \mathrm{h} / \mathrm{ml}$, if $0.052 \%$ would be recovered. The basal activity of these EVs is used as $100 \%$ for the visualization in figure 3.12 .

TPPI is a lysosomal protease, that is expressed as a preprotein and subsequently, is proteolytically activated by cleavage in the lysosome (Guhaniyogi et al., 2009). The activation is induced by low $\mathrm{pH}$. The mature enzyme has its optimum at $\mathrm{pH}$. To 
investigate the loading of the different isoforms of TPPI, the experiment was performed at different $\mathrm{pH}$ values starting at physiological $\mathrm{pH}$ of 7.4 and at lower $\mathrm{pH}$ values.

Additionally, saponin and chlorpromazine were used to introduce pores into the vesicles. Chlorpromazine embeds in the inner membrane leaflet of cell membranes and therefore leads to a deformation of the cell morphology from discocytes to stomatocytes (Favretto et al., 2013). Since, this process is reversible just as the incorporation of saponin, these reagents are suitable for the loading of clinical grade vehicles. Saponin was used at $0.2 \mathrm{mg} / \mathrm{ml}$ and chlorpromazine at 200 and $100 \mu \mathrm{M}$.

Another described method is the loading by hypotonic dialysis. For this purpose, the EVs are incubated in hypotonic solution to induce a swelling and dissociation of the membrane, in this case in diluted PBS (70\% PBS). TPPI was added at $1.2 \mathrm{mg} / \mathrm{ml}$ for $1 \mathrm{~h}$ at $4^{\circ} \mathrm{C}$ stirring in a dialysis tube. Subsequently, the vesicles were introduced to hypertonic solution, twofold concentrated PBS (200\% PBS). Then, the vesicles were washed with a commercial SEC-column, qEV. In these experiments, the amount of TPPI-activity in the recovered vesicles was even reduced in comparison to the control EVs.

Electroporation is a common method for the transfection of cells. Cell membrane can be porated by application of an electric field with usually thousands of volts (Liang et al., 2015, Chang et al., 2016, Ghanta et al., 2018). For exosomes, electrical fields with lower voltage have been described (Alvarez-Erviti et al., 2011). This experiment was performed with 400 and $750 \mathrm{~V}$ in a Gene Pulser Xcell in a $4 \mathrm{~mm}$ cuvette. To allow the membrane to close the pores the vesicles were recovered for $30 \mathrm{~min}$ at $37^{\circ} \mathrm{C}$. After loading, the vesicles were regained by purification with a $\mathrm{qEV}$ column to remove excessive TPPI. In my hands, the electroporation of EVs was not successful and it was not possible to retrieve any TPPI in the vesicles. The amount of TPPI in the regained fractions from the qEV column did not show any in- or decrease as depicted in figure 3.12. The formed pores might not have been sufficient to allow the passage of a protein. 


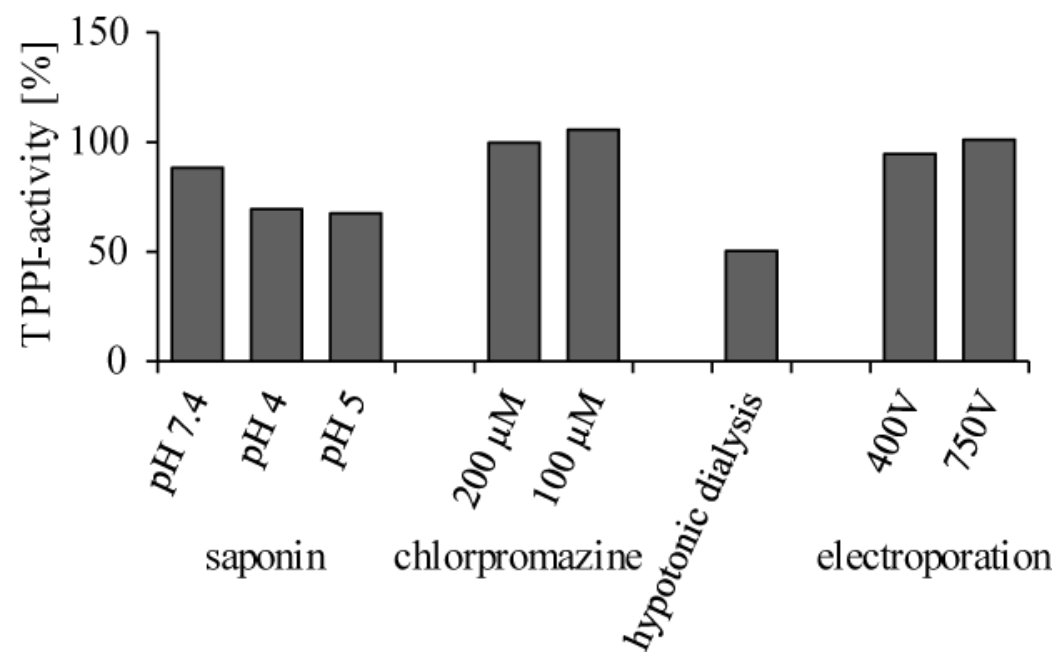

Figure 3.12: Extracellular loading of TPPI into EVs.

EVs were treated with different reagents, hypotonic dialysis an electroporation to introduce pores to the membrane and allow the entrance of TPPI. In summary, the artificial loading procedures had no effect or even led to a reduction of the existing basal TPPI-amount.

In literature, there is one new approach described for the engineering of exosomes by means of fusion with liposomes (Sato et al., 2016). The liposomes are specifically designed with the desired surface molecules or lipid composition and then are fused to exosomes by a freeze-thaw method to overcome the hydrophobic properties of the lipid layers (Sato et al., 2016). With the kind help of Jan Wehland from Professor Diederichsen's group, a similar strategy was approached in this project. Liposomes with TPPI were prepared by extrusion with a small diameter of $100 \mathrm{~nm}$. These TPPIcarrying vesicles were added to exosomes. The attempt was to simply open the vesicles by extrusion and fuse with the fusogenic and small liposomes. The product was purified with a qEV column. The data is not shown, but in the end, only a reduction of the basal TPPI concentration could be observed.

As a result of the experiences with the exogenous loading, no further exogenous loading experiments of vesicles with proteins were performed. Further, the amount of TPPI contained in EVs required to treat TPPI deficient mice efficiently was assessed. It was calculated that at least $10 \mu \mathrm{g}$ of TPPI in a maximum volume of $10 \mu \mathrm{l}$ would be necessary to substantially provide TPPI to a mouse's brain. Since, the estimated amount of TPPI to be encapsulated by exosomes was below $0.1 \mu \mathrm{g}$ per injection further animal experiments were omitted. 


\subsubsection{Endogenous loading of PTPS}

Since EV-associated TPPI activity was generally higher by endogenous loading of the cell, further experiments were performed to enhance endogenous drug loading. PTPS is located in the cytosol and might be therefore preferentially be packed into exosomes since these intraluminal vesicles are formed within MVB by invagination of the cytosolic matrix. These vesicles carrying PTPS are then excreted as exosomes.

PTPS catalyzes the formation of 6-pyrovyol tetrahydropterin from 7,8-dihydroneopterin triphosphate. There is an activity assay that is very sensitive to oxidation and the substrate 7,8-dihydroneopterin cannot be stored but is prepared in situ. The quantification of the PTPS loading was performed by Western Blotting and is summarized in figure 3.13. Since Western Blot analysis is a semi quantitative method, the samples were additionally sent to Professor Thöny's group where Tanja Scherer kindly performed a PTPS activity assay. The samples were prepared in Göttingen. Before shipping, the vesicles were ultracentrifuged to pellets and then sent on dry ice to Zurich.

It was published that some toxins are able to intervene in the endosomal pathway and are packed into vesicles in the MVB. They are then released in exosomes and overcome not only the lysosomal degradation but are also bypassed to other cells (Zhang et al., 2009). This phenomenon was described for K562 cells. For this reason, additionally to the HEK293 cells in this experiment K562 cells stably expressing PTPS-2hisFR $\alpha$ were grown and adapted to the MINIPERM ${ }^{\circledR}$ bioreactor. Supernatant was collected and 2his-tagged FR $\alpha$-positive vesicles purified as previously described by SEC followed by IMAC. From each purification step and similarly as for the purification from HEK293 cells $1 \mu \mathrm{g}$ was applied to analyze by Western Blotting.

For comparison, the samples were also analyzed for FR $\alpha$ as depicted in figure 3.13. For FR $\alpha$, the enrichment per $1 \mu \mathrm{g}$ total protein is nicely visible in PI and PII for both cell lines. The concentration of FR $\alpha$ is very high, while the endogenous PTPS remains undetectable. In case of PTPS, it is the other way around; the amount per $1 \mu \mathrm{g}$ protein is reduced during the purification of the vesicles. It seems like more PTPS is targeted 
to the EVs in the cell line K562 but in relation to the amount of pixel present in the first line, in the raw material of the cell line per $1 \mu \mathrm{g}$ protein, the protein is only slightly higher recovered in EVs than in HEK293 as visualized in a bar diagram in figure $3.13 \mathrm{~b}$. The choice of K562 as cell line for targeting of the overexpressed protein had no significant effect.

Targeting of the protein PTPS to the vesicles was also performed by introduction of a membrane tag. In this project a short sequence of GAP43 was used. The short sequence encodes a palmitoylation sequence of growth-associated protein from the nervous tissue. Vesicles from cells that were engineered to express PTPS with the small tag, GAP43-PTPS, show an enrichment rather than a reduction in the vesicle preparation. The enrichment in the EV fractionis threefold higher than without tagging. A significant proportion of GAP43-PTPS was purified from the supernatant of cells and is detectable within the vesicles as nicely visible in figure $3.13 \mathrm{~B}$. 
A

HEK

$\mathrm{FR} \alpha$

PTPS

K 562

HEK,

G A P-tagged

$\mathrm{FR} \alpha$
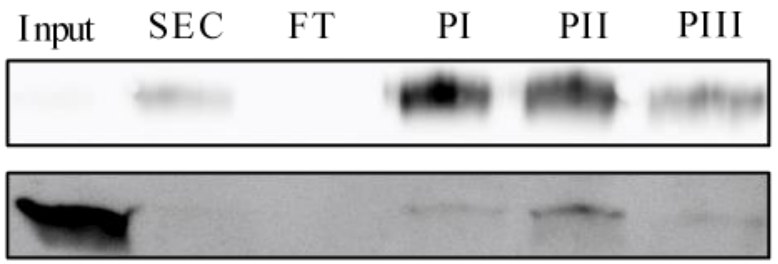

Input SEC PI PII PIII

$\mathrm{FR} \alpha$

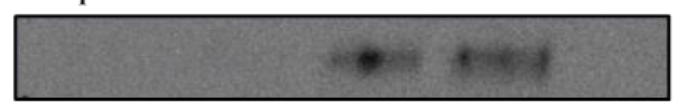

PTPS

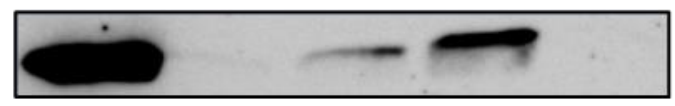

PTPS
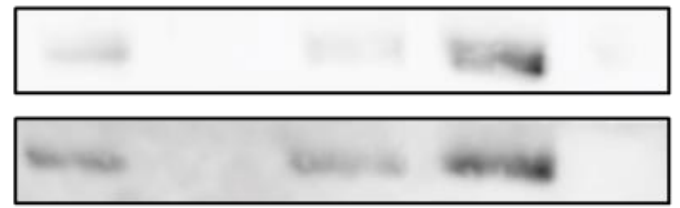

B

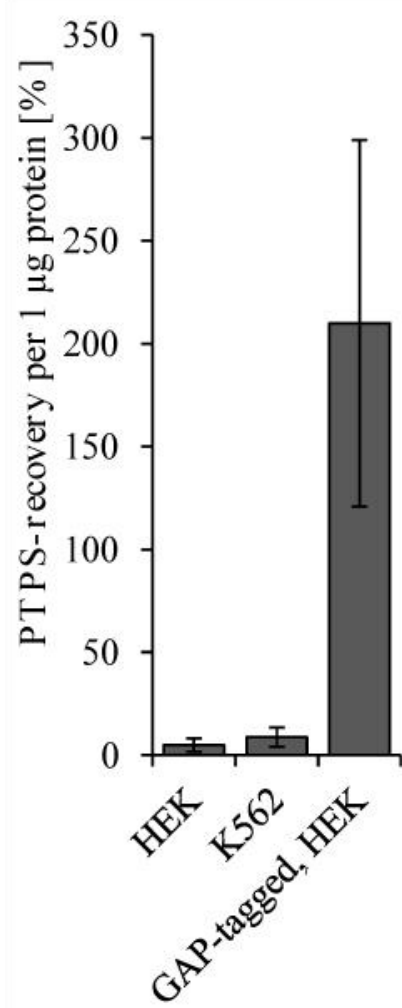

Figure 3.13: Endogenous loading of a drug protein to EVs quantified by Western Blot analysis.

His-tagged vesicles were isolated from supernatant of stably PTPS expressing cell lines, HEK293 and K562, in comparison with a GAP43-tagged version of PTPS analyzed by Western Blotting. The highest amounts of PTPS were found in EVs for the GAP43-tagged protein. PTPS is enriched in PI and PII just as FR $\alpha$. For HEK293 and K562, only traces of the originally present PTPS are recovered in EVs.

These results were underlined by the PTPS activity assay. It was determined that K562 cells expressing PTPS showed $63.43 \mu \mathrm{U}$ PTPS-activity per mg protein while HEK293 had a slightly reduced amount in their EV fraction with $54.25 \mu \mathrm{U}$ per mg protein. The GAP43-tagged version PTPS showed a stronger targeting to EVs with $132.57 \mu \mathrm{U}$ per mg.

\subsection{Analysis of biodistribution of the vesicles after intranasal application}

To investigate the faith of intranasally administered EVs, the EVs were labeled with near infrared fluorescent dye. For this purpose, the vesicles needed to be pelleted by ultracentrifugation and resuspended in PBS to reach a concentration of $1 \mathrm{mg} / \mathrm{ml}$. The 
EVs were gained from supernatant of HEK293 cells stably expressing FR $\alpha$. For comparison of the distribution, FR $\alpha$-negative, native vesicles were recovered by DC from HEK293 transfected with empty vector.

The mice were narcotized and placed onto a warming plate. The vesicles were applied in small steps of $1 \mu \mathrm{l}$ per min in each nostril alternating up to a total volume of $10 \mu \mathrm{l}$. Then, the mice were awaken, sacrificed and the organs screened for fluorescent signal of the vesicles imaging in an Optix 2.

Background fluorescence of the organ was measured and subtracted. Overall, the fluorescence signal of the intranasally applied vesicles in the organs was very low. For both, the FR $\alpha$-positive and -negative vesicles, there was some signal in the brain but there was no significant difference between the two types of vesicles. 
A

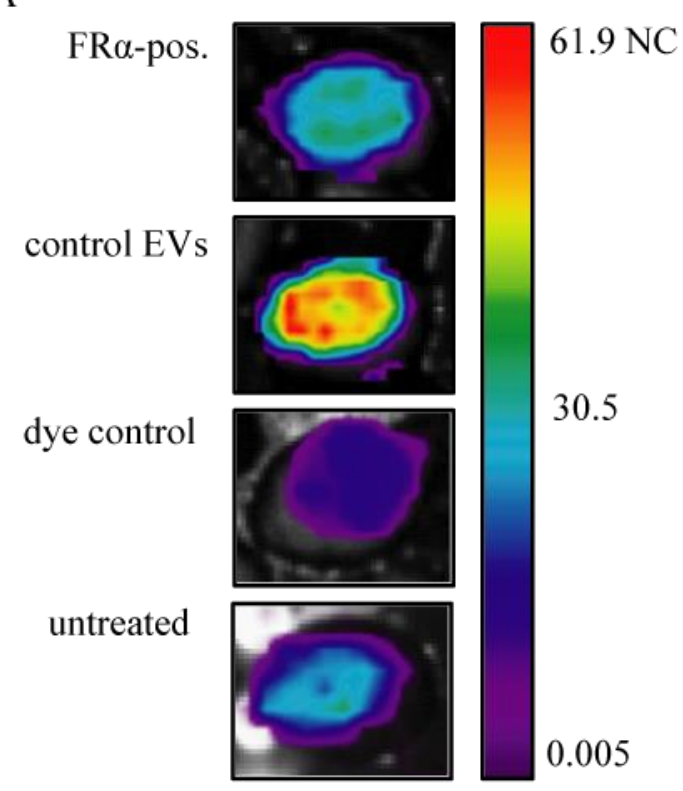

B

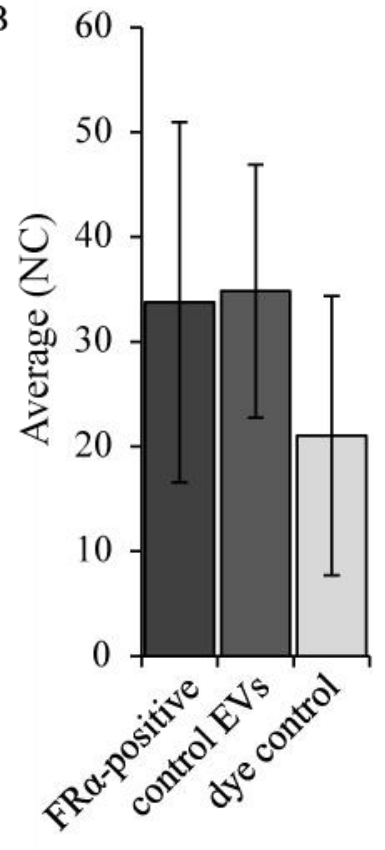

$\mathrm{C}$

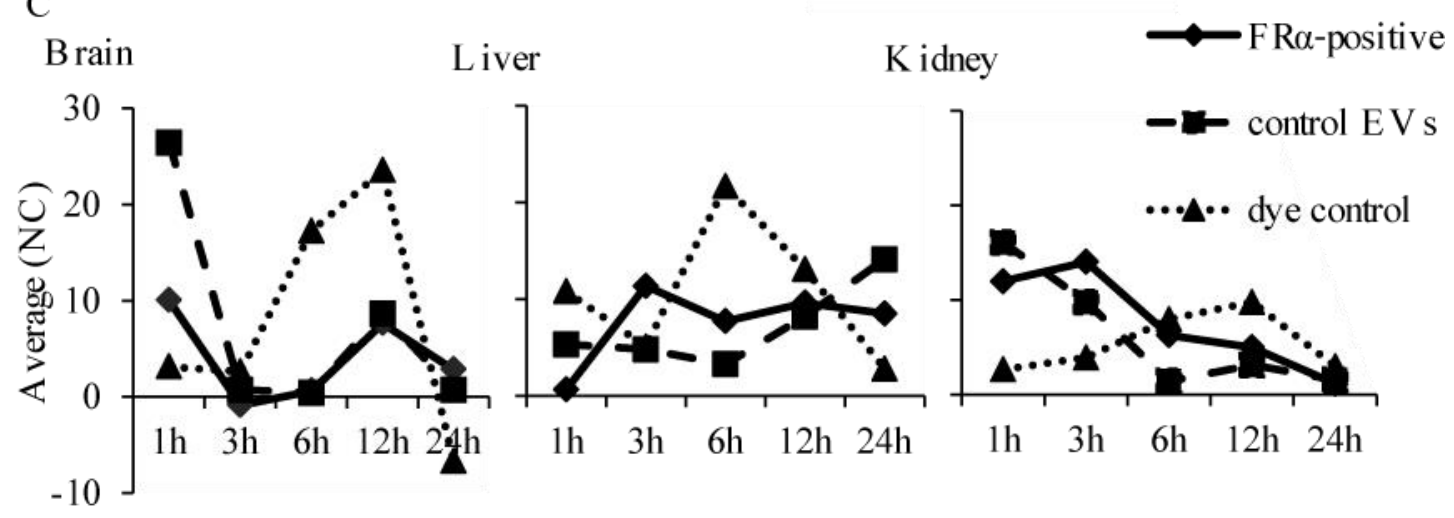

Figure 3.14: Biodistribution of FR $\alpha$-presenting and control EVs.

FR $\alpha$-presenting and control EVs were labeled with IRDye800 and administered intranasally to healthy mice. Treatment was performed under anesthesia and the mice were awakened after treatment. After the defined time periods the mice were sacrificed and their organs were screened for fluorescence. A. Comparison of the brains of the treated mice, the dye-control and an untreated mouse. Overall, the signal was very low. B. Three mice were treated with $10 \mu \mathrm{l}$ of $1 \mathrm{mg} / \mathrm{ml}$ concentrated and labeled EVs. There is no significant difference in the uptake by the brain of control EVs and FR $\alpha$-positive vesicles. C. The dye alone reoccurs after 6 and $12 \mathrm{~h}$ in liver, kidney and the brain. The EVs behave like liposomes and can be detected after $24 \mathrm{~h}$ in the liver.

The dye had a maximum signal in the organs after 6 to $12 \mathrm{~h}$. In contrast to the EVs that behaved differently. Especially in the liver, the amount of fluorescence was increasing after $24 \mathrm{~h}$. This is an observation from the liposomes field; the vesicles are circulating in the system and then accumulate in the liver, at least for i.v. application (van der Meel et al., 2014). 


\subsection{Investigation of the drug vehicle capacity of the FR $\alpha$-presenting EVs equipped with therapeutic cargo}

For the investigation of the exosomes as drug delivery vehicles in vivo, the mouse model of a biopterin disorder was chosen. Since the enzyme TPPI could only be loaded in very low amounts, the mouse model of CLN2 was excluded.

The knockout mice (KO) were generated by mating of heterozygous mice of the pts-/mouse line. All born pups were initially treated by the substitution therapy until a genotyping was performed with tale biopsies. Then, only KO and control mice were treated. KOs treated as published by Elzaouk et al. showed the described growth abnormalities, were less active and had difficulties in swallowing (Elzaouk et al., 2003). In average, a BW of $8.0 \pm 0.3 \mathrm{~g}$ was reached calculated as the mean of four KO animals. Wildtype or heterozygous knockout mice reached an average weight of $17.7 \pm 0.3 \mathrm{~g}$ at this age of 31 days.

The first treatment approach of the KO mice was performed by oral gavage. There is evidence of exosome uptake upon oral administration (Munagala et al., 2016). Two mice were treated with exosomes administered orally in parallel to the oral substitution treatment published by Elzaouk et al. that is necessary to rescue the mice (Elzaouk et al., 2003). The general health of these two mice rather deteriorated throughout the treatment. They did not show any improvement in the growth rate. Both mice developed more symptoms like apathy and a strongly bend posture which is an indicator of pain. After approximately 25 days, they had to be sacrificed. Behavioral experiments could not be performed. The growth curve of these mice are depicted in figure 3.15a. In parallel, two wildtype mice were treated in the same manner with exosomes. One of these two showed a stronger growth than normal mice and died unexpectedly after 22 days. The growth curve of the two orally treated mice is displayed in figure 3.15c in blue. These results might indicate that FR $\alpha$-presenting vesicles are not taken up in the intestine but for therapeutical purpose need to be applied directly to the blood or the cerebrospinal fluid 
Before performing experiments with PTPS loaded vesicles, a control with direct application of the purified and vesicle-free enzyme PTPS was done. For this purpose, PTPS was purified by a his-tag using a commercially available IMAC-column. The protein was rebuffered in PBS and the concentration adjusted to the concentration achieved by exosomes being targeted EVs by GAP43-tag. The activity of the recombinantly produced PTPS was verified by an activity assay in fibroblasts that was performed by our cooperation partners in Zurich (Thönys group).

The mice were treated intranasally every $48 \mathrm{~h}$ with $1 \mu \mathrm{l}$ of enzyme suspension per $1 \mathrm{~g}$ BW up to $10 \mu \mathrm{l}$. The animals accepted the slow application into the nose. The mice never showed any shortness of breath. The aim of the very slow application was, apart from stress reduction, to achieve a slow uptake of the vesicle suspension through the nasal mucosa. Otherwise the suspension could be inhaled and get to the lung.

These two KO mice treated with vesicle-free PTPS survived 27 days before they had to be sacrificed because of a reduction of the health. They did not show any significant increase in their growth in comparison to the KO animals treated without any PTPS. The vesicle-free enzyme seems not to be able to pass through the nasal mucosa and to reach the central nervous system. These mice had to be sacrificed before they were able to reach 28 days and first behavioral experiments could be performed. The growth curve of these mice in visualized in figure $3.15 \mathrm{~b}$ as blue curves.

Approximately after 3 weeks mice are fully weaned by the mother mouse and all mice, KO and WT, showed growth retardation for a few days. In this time frame the KO mice were struggling even more. The orally treated KO mice and the PTPS control mice were not able to overcome this period. 

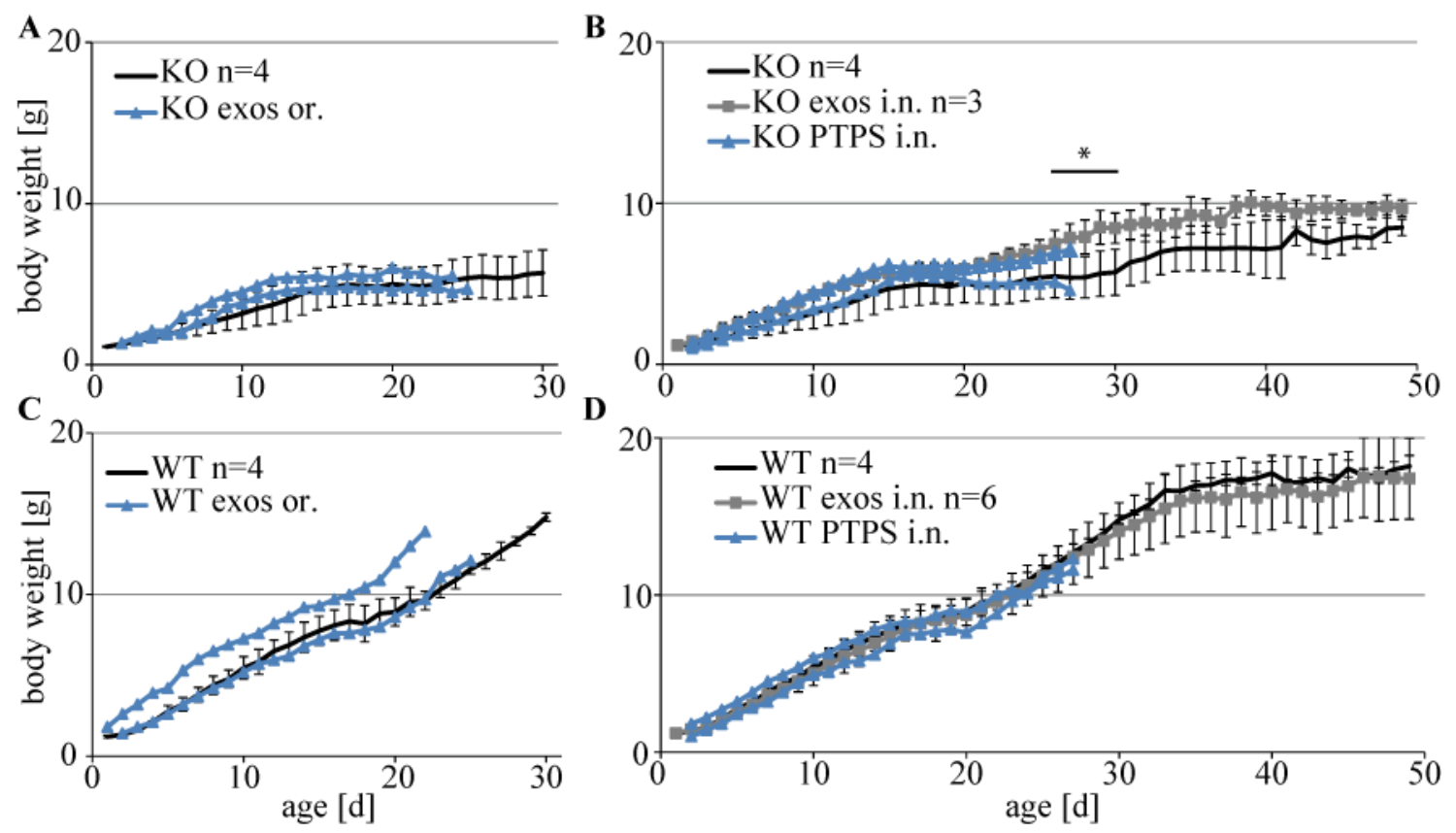

Figure 3.15: Growth behavior of $\mathrm{KO}$ and control mice treated with exosome and the control treatment.

PTPS KO, WT and heterozygous KO mice were treated with the respective therapy and their weight determined. When not differently indicated one exemplary mouse is depicted. For groups in which 3 or more mice were treated an average with the standard deviation is depicted. In A and B treated (blue and grey) and untreated (black) KO mice are depicted. In A two animals were given exosomes orally. These mice had rather a worse health condition than the control KO mice and had to be sacrificed. In B the mice were treated intranasally. Two mice were given PTPS, one died and one had to be sacrificed. The group of exosometreated mice survived and even showed a significant higher weight curve. In C and D healthy mice were treated by corresponding settings. The growth behavior of the healthy mice was mostly unaffected by the treatment.

The oral application of exosomes did not show any improvement in the growth behavior and health condition of the KO mice. Other modes of application intraventricular injection or intranasal administration are targeting the vesicles to the CSF. For the intraventricular injection, a cannula is implanted through the cranial bone directly connecting to the ventricles. To ensure a stable fixation of this cannula, a mouse must be at least 3 weeks old and weigh more than $10 \mathrm{~g}$ to have a bone structure that is stable enough. For this reason, the intranasal administration route was the only one applicable for the PTPS KO mice. The established GAP43-PTPS enriched EVs were used. KO and WT mice were treated by daily substitution therapy as described above as well as with PTPS containing exosomes every $48 \mathrm{~h}$ in a protein 
concentration of $0.1 \mathrm{mg} / \mathrm{ml}$. The weight of the mice was monitored daily and the results are summarized in figure $3.15 \mathrm{~b}$ as grey curve.

From the very beginning the exosomes treated mice showed a better overall performance compared with the not EV-treated KO mice. During the first days, it was even not possible to distinguish the afflicted animals from their healthy littermates. This improvement of the overall performance reflects in the BW of the animals. The treated KO mice showed a slightly stronger increased growth rate than not EV-treated KOs. From the $27^{\text {th }}$ to the $30^{\text {th }}$ day after birth, the weight of the EV-treated mice is significantly higher than of the untreated. These mice were even able to gain weight after the critical time of the third week. It seemed like they would continue growing and almost complete recovery was achieved by the EV delivered PTPS. But, after approximately 4 weeks, the mice began to show more symptoms and the growth rate decreased. Up to the end of eighth weeks the animals were able to maintain their weight and presented a higher overall performance.

The WT mice treated intranasally with exosomes did not show any adverse effects. They presented a slightly lower average BW than the untreated WT mice. One heterozygous mouse treated with exosomes had a strongly reduced growth rate; it remained very small, almost as small as the KOs and did not become heavier than $12 \mathrm{~g}$ at the end of the experiment. This might explain the large standard deviation of the curve, depicted in figure $3.15 \mathrm{~d}$ in grey.

The intranasal administration seemed to be accepted well by the animals. They did not show any infection or adverse effects of the nasal mucosa.

\subsubsection{Analysis of the overall performance of the EV-treated KO mice}

In addition to the BW, more parameters were acquired on the health of the treated animals. For this purpose, two behavioral tests were performed. The first assay was the determination of the performance by tracking their locomotor activity in their home cage for $24 \mathrm{~h}$ once a week. This observatory test seemed very promising because already by eye examination for short time a difference between the activity of the KO and the healthy animal could be observed. The second experiment was the 
Rota rod test. In this test, the mice are placed on a rotating bar and the speed of rotation is increased. Most healthy mice are able to stay on the bar. The KO animals often were not able to keep up the speed. In contrary to the healthy mice, they were able to clench to the bar and rotate with it.

The results of the behavioral tests are depicted in figure 3.16. In A, the results of the activity assay for the healthy and the affected mice are summarized. The difference between WT and KO animals is significant, but no effect of the exosome treatment can be detected. In contrary to the observation of the examiner, these mice were not more active and did not move more than the normally treated KOs. The EV-treated WT mice showed a decreased activity but the difference is not significant.

A significant difference was obtained in the Rota rod experiment in the performance when EV-treated and the not EV-treated KO mice were compared. In this experiment, the EV-treated KOs performed equally well with the healthy mice and could run on the bar until the end of the experiment. For the healthy animals, no difference, except in the $6^{\text {th }}$ week after birth was detectable. In this case, the EV-treated mice showed a better performance and all mice were able to stay on the bar until the end of the experiment with 380 rounds. 


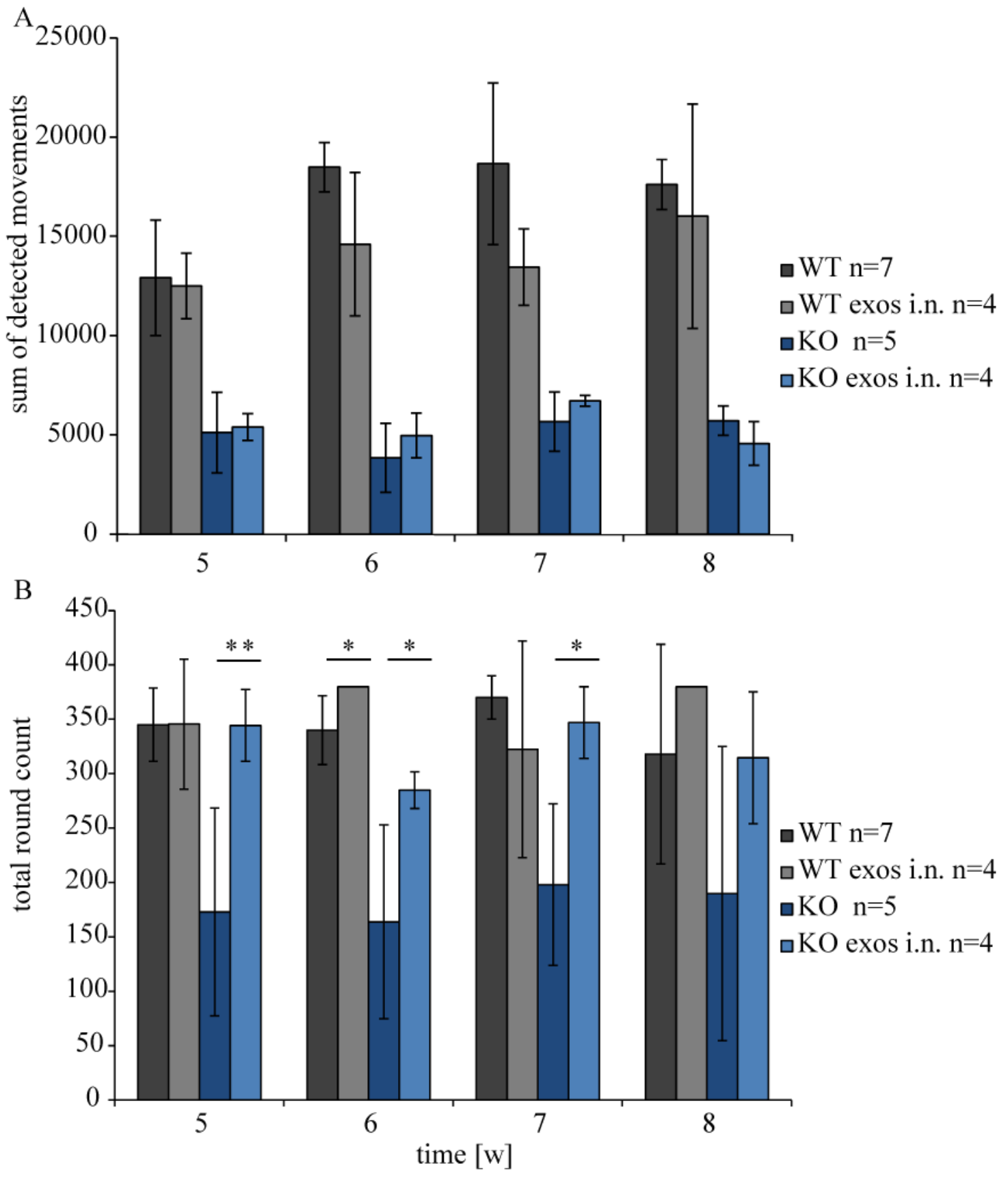

Figure 3.16: Performance of the WT and the KO mice in the behavioral tests.

KO and healthy mice treated with PTPS-carrying exosomes and the untreated control mice were screened for their performance by A detection of their locomotor activity in the cage and B their performance in the Rota rod experiment. For the healthy mice in both experiments almost no difference for the treated and untreated mice could be measured. The EV-treated mice almost showed a normal behavior in the Rota rod experiment. 


\section{Discussion}

This present study investigates the question whether extracellular vesicles can be utilized as drug delivery vehicles. Further, our investigations address the following aspects of biopharmaceuticals: purification from biological source, cargo loading, in vitro and in vivo performance and finally the therapeutic capacity of the designed formulation.

\subsection{Successful isolation of EVs in a high quality by chromatographic approach}

The research field around EVs is quite young one and many fundamental questions are still not clarified. There are no clear definitions of the different types of EVs, neither the size or density nor exclusive protein markers could be identified yet. The situation is even more complicated by the fact that many purification and analysis methods result in an alteration of the vesicles, e.g. from shear forces and aggregate formation. Facing these challenges and uncertainties, everybody performing research on EVs needs to work very cautiously and to take into account all available tools to put the puzzle together.

The gold standard protocol for EV preparation, for microvesicles and exosomes is the DC (Momen-Heravi et al., 2013). The other commonly used and regarded as the superior method is the density gradient (Lobb et al., 2015). According to the literature and claimed by a company, the product ExoQuick ${ }^{\mathrm{TM}}$, a new purification kit based on the precipitation of the vesicles by PEG, promises an easy and quick purification in one step (Antes et al., 2015). Even though a high purity in combination with a high yield is described, a major drawback is the polymer PEG which is difficult to remove from the vesicles (Li et al., 2017). The advantage of methods based on centrifugation is the availability in most laboratories. However, vesicles undergo shear forces and all these protocols are limited to sample volumes complying with the centrifugation flasks.

Another size-based approach is the SEC. There are commercially available columns like $\mathrm{qEV}$ or Exo-spin ${ }^{\mathrm{TM}}$. These methods are advantageous because the vesicles do not 
undergo great mechanical stress and remain in their physiological form. On the other hand, the maximum volume of these products is $10 \mathrm{ml}$. In this project, a chromatographic method with a SEC coupled to an affinity chromatography was established. This protocol unifies many benefits: high volumes of sample can be processed, the mechanical stress is limited and the system can be reused several times. The method has drawbacks, e.g. not every lab has a suitable chromatographic system, the protocol establishment is very time consuming and only large amounts of sample can be processed. The recovery of protein and particle amount is for all methods very low. The two-step FPLC method for his-tagged vesicles recovers only $1.5 \pm 1 \%$ of the originally applied protein amount. The DC protocol in contrary maintains $5.0 \pm 2 \%$ of the original protein mass. Many methods are in criticism for their low yield. But, up to now, there is little data on the amount of exosomes being secreted by cells. For this reason, the yield of an isolation method can hardly be judged at the current state of knowledge. A high recovery of protein amount can also be an indicator for protein contaminations.

Even though the newly established method results in lower particle and protein recovery, the purity associated for this method is higher. The purity of the product was calculated by the ratio of particles per $1 \mu \mathrm{g}$ protein. The ratio of the two-step FPLC method is superior in comparison to the standard protocol using DC.

In this project the IEC did not work well for extracellular vesicles. When only IEC was applied many intercellular contaminations remained in the preparation as visible in the Western Blot analysis in figure 3.5. In general, it is not advisable to rely on one isolation technique for EV preparation. The protocol coupling SEC and IEC showed a relatively high purity in the particle-per-protein ratio, but in the EM analysis revealed that this preparations contained a high amount of contaminations by lipoproteins. The IEC protocol is based on the surface charge of the vesicles. though, it is not shown for all exosomes to have an increased amount of PS and a negative surface charge, since this is also an "eat-me" signal that would lead to a clearance in the system (Skotland et al., 2017). These results from this project indicate a more complex surface composition with no uniform negative charge. 
The results of the IEC purification demonstrate once more the necessity of a complete characterization of an EV preparation. The particles of the preparation had the right size and reasonable ratios in particle per protein analysis. Only the EM was able to reveal the high proportion of contaminating lipoproteins.

Apart from the enrichment of exosomal markers and the reduction of contaminating proteins, the size and density of the vesicles recovered by SEC followed by IMAC correspond to exosomal features. They have a mean size of $177.7 \pm 28 \mathrm{~nm}$. These samples contain a high amount of alix which represents a specific marker from the exosomal pathway and in addition, these fractions also contain flotillin2 as seen in figure 3.5 which is present in other EVs as well.

Analyzing the size and density of the different preparations, the product of the twostep FPLC method is more homogenous than the product of the DC protocol. At this point it needs to be considered that the raw sample used in this project is not a native sample, but supernatant from transfected cells. This overexpression most likely affects the vesicle populations in the sample. In the analysis of the density it stands to reason that the population recovered by DC is different than the one gained by twostep FPLC.

In general, the question whether these designed vesicles are exosomes will be discussed in the following lines. The EM-images show EV-like vesicles. The proteins found in the preparations are EV-enriched proteins (alix, FR $\alpha$ ) and contaminating proteins are reduced (TOM20). Flotillin2 can also be a marker for microvesicles (Simpson et al., 2008). Despite these numerous proves for the EV-like features of the preparation, it is possible that this vesicle population is mixed. However, almost all of these particles are FR $\alpha$-presenting as could be proven by fluorescent particle analysis. Nevertheless, a purification of microvesicles secreted from the plasma cell membrane with his-tagged FR $\alpha$ cannot be excluded. These vesicles would not be discriminated in the established two-step FPLC method. 


\subsection{Loading of therapeutic proteins to vesicles by membrane targeting}

Loading of cargo into EVs is very difficult. On the one side, the volume of EVs is small in relation to a protein. On the other hand, there might be not natural targeting of the protein to EVs or the chemical nature of the protein might hamper the localization in vesicles.

Since, in literature successful loading by exogenous and endogenous loading approaches have been described, in this project both variants have been challenged. The exogenous loading was not successful. One very challenging aspect of cell free loading of EVs is the recovery of the vesicles from the drug suspension for removal of excessive drug without major loss of particles. This problem is not existing for endogenous loading since, the vesicles are recovered by the two-step FPLC protocol with the cargo already loaded. For exogenous loading experiments, washing in a ultracentrifugation unit was described as suitable for vesicle recovery (Alvarez-Erviti et al., 2011). Since precipitated drug molecules could be recovered as well in an ultracentrifugation unit, a chromatographic column was used in this project as a better alternative. The main advantages are that the vesicles remain intact and do not experience mechanical stress, which might be of relevance for the clinical application. However, the purification by chromatographic columns does not completely ensure the removal of extravesicular cargo; some proteins or molecules of hydrophobic nature might stick to the surface of extracellular vesicles and cannot be removed by SEC.

There are publications on efficient exogenous loading of cargo to exosomes. In particular, electroporation is up to now the method most often described and recommended for introduction of RNA (Marcus and Leonard, 2013). Since biomolecules start to aggregate when subjected to an electric field (Kooijmans et al., 2013), this method is not appropriate for EVs. For cells being transfected by electroporation this approach might be suitable since cells can be washed by centrifugation with low speed. Transfected cells can be selected by application of a selective pressure by antibiotics. All these mechanisms cannot be transferred to the 
work with EVs. And in this study, the approaches with electroporation have not been successful.

There is a company selling a product named ExoFect. Customers are able to introduce nucleic acids to self-prepared exosomes, which are then incorporated with the help of a chemical substance within 20 minutes. This kit is sold for the transfection of cells. In this project, the loading by artificial formation of pores with chemicals and incubation with the drug did not result in enrichment within the exosomes.

Loading of the protein TPPI has not been as successful as needed for in vivo experiments. Despite the observation that small amounts of remaining TPPI-activity have an influence on disease progression (Wisniewski et al., 2001), the enzyme replacement therapy is performed with great amounts of protein corresponding to $100 \mathrm{mg}$ per injection. For this purpose, TPPI targeting into exosomes was not considered in the further project development.

For protein cargo, endogenous loading approaches appear to be of higher efficiency. Two cell lines were investigated for their capacity of packing proteins into exosomes: HEK293 and K562. Because of toxins secreted in exosomes by K562 cells (Zhang et al., 2009), we hoped to observe a similar effect on the overexpressed protein. Almost no difference in the relative packaging efficiency of these two cell lines could be observed.

Many groups use proteins enriched in exosomes and tag the drug using for instance the C1C2 domain of lactadherin (Zeelenberg et al., 2008) or Lamp2b (Alvarez-Erviti et al., 2011). All these tags result in a membrane localization and potentially on the surface of the vesicles. However, then the protective effect for the drug protein that is a main advantage of exosomes as drug delivery vehicles is reduced due to the localization. In the end, the localization of high amounts of PTPS to EVs was successfully realized by a similar strategy: engineering a membrane targeting amino acid sequence to the N-terminus of PTPS. In this project the neuronal cell associated GAP43 membrane targeting sequence was added. With this approach, finally a high increase in the exosome associated protein PTPS could be observed. The aspect that 
GAP43 is in vesicles that are transported in the nervous system might enhance the feasibility of these vehicles in neurological disorders. However, GAP43-tagging could result in a surface localization of PTPS and reduce the capacity of the established drug delivery vehicle. The localization on the vesicle surface could be checked by gold labeling of PTPS in EM.

The EVs in the FPLC preparation have a size between $20-200 \mathrm{~nm}$. A protein with 50$100 \mathrm{kDa}$ has the smallest possible radius of 2.4-3.05 nm (Erickson, 2009). In figure 4.1, the dimensions and the ratios are depicted for the carrier protein ferritin. This image clearly illustrates the limitations of exosomes as delivery vehicles. This volumetric capacity must be kept in mind, especially since exosomes cannot be concentrated to more than the maximum of $10^{12}$ particles $/ \mathrm{ml}$. Beyond this particle concentration visible aggregates start to form. For this reason, exosomes as drug delivery vehicles are limited to disorders in which small amounts of cargo are likely to be sufficient.

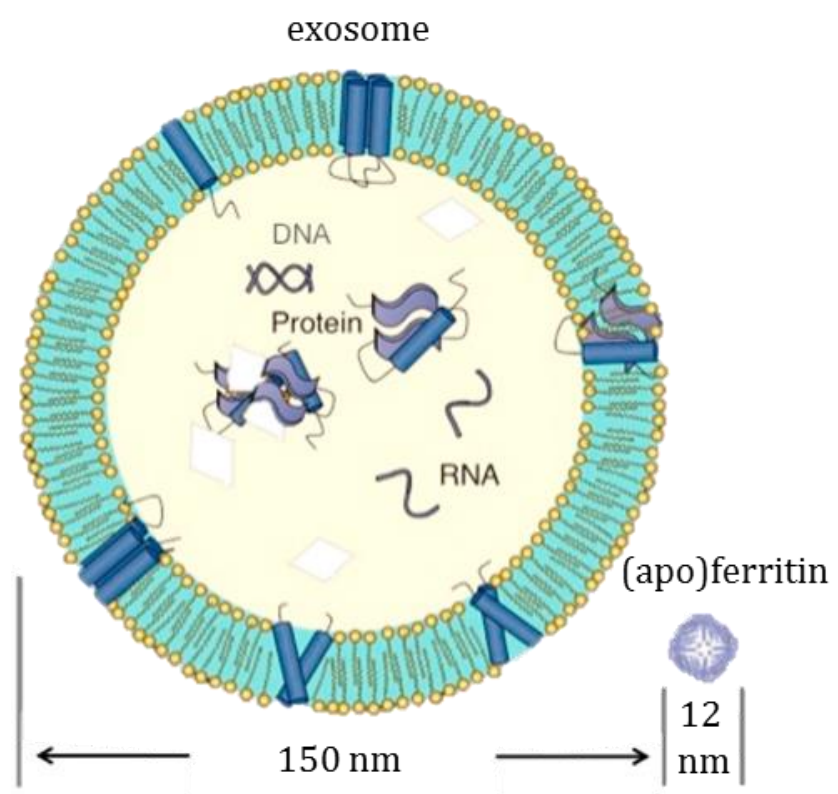

Figure 4.1: Schematic size demonstration of an exemplary protein, apoferritin, in comparison to an exosome modified from Li et al.

Loading of proteins to vesicles is strongly limited by the volume of the EVs. Additionally, EVs are not empty sleeves. There is content like proteins and nucleic acids that are already present in the vesicles (Li et al., 2016). 


\subsection{Uptake of FR $\alpha$-presenting EVs}

The FR $\alpha$ is used as a common tool in drug targeting (Sudimack and Lee, 2000). FR $\alpha$ is utilized in two manners: either FR $\alpha$-targeted antibodies or antifolates are conjugated to the drug. FR $\alpha$ is present in the choroid plexus and for example in related malignancies. Several groups published FR $\alpha$ as a protein present in exosomes (Admyre et al., 2007, Raj et al., 2012). Grapp et al. could prove that FR $\alpha$-presenting exosomes are distributed throughout the whole brain parenchyma (Grapp et al., 2013). Most likely, FR $\alpha$ stabilizes 5MTHF and promotes its transport and distribution throughout the brain parenchyma.

Exosomes are mainly taken up by four mechanisms: endocytosis, micropinocytosis or phagocytosis and fusion with the up taking cell (McKelvey et al., 2015). To investigate the FR $\alpha$ mediated transepithelial transport, the cell line BN16 from rat egg yolk was chosen. BN16 cells are expressing megalin and it was published that FR is colocalizing with megalin (Birn et al., 1997) and soluble FR is internalized by megalin (Birn et al., 2005).

Analyzing the biological activity of the vesicles a higher uptake of FR $\alpha$-positive vesicles in comparison to native EVs could be proven. Therefore, these results with BN16 cells might confirm the hypothesis that the receptor and the vesicles are taken up by megalin. To further investigate the uptake mechanism uptake experiments with other cell types should be performed. Moreover, it would be very interesting to image the uptake with the help of microscopic tools. Once, the EVs reached the cells it is unclear how they are processed. For the treatment of lysosomal disorders, a procession to the lysosome would be advantage but for the biopterin disorder, it would be a terrible failure. However, the establishment of a FR $\alpha$-decorated and chargeable drug vehicle enlarges the possibility of FR $\alpha$-based therapy.

\subsection{Biodistribution of intranasally administered exosomes}

Exosomes are natural occurring vesicles that resemble liposomes. In the liposome field, great advances have been made. They have similar characteristics as exosomes, 
but are fully artificial. Therefore, these designed vesicles are easier to modify, the lipid composition can be influenced, hydrophilic molecules can be loaded inside the liposomes, and lipophilic ones can be localized to the membrane. Furthermore, the size can be influenced. Exosomes are more difficult to modify than liposomes, but exosomes provide the biological stability and compatibility.

Liposomes are mainly processed by macrophages in the liver. PEG-coated liposomes have a longer circulation time in the blood and are also taken up by other tissues (Immordino et al., 2006). Larger particles, $\geq 250 \mathrm{~nm}$ are retrieved in the spleen. This results from fibers running parallel to the blood vessel of the spleen. They are organized in approximately $250 \mathrm{~nm}$ distance for filtering of older and more rigid blood cells (van der Meel et al., 2014).

In contrary to a lipophilic dye, the used dye IRDye800 that was attached by an amide bond to proteins on the surface of the vesicles. This way, a flipping of the dye to other membranes is unlikely, but the observed distribution, might result from dye distribution and not from exosome distribution. The dye might be taken up and processed by macrophages inside the tissue. The dye-control in this experiment has a peak of $6 / 12 \mathrm{~h}$ after application inside the liver, the kidney but also in the brain. This seems to be a systemic presence of the dye. The vesicles in contrary show an increase in the liver $24 \mathrm{~h}$ after application. This corresponds to the behavior of long circulating liposomes applied intravenously (van der Meel et al., 2014) implies that the vesicles have a longer circulation time than the dye itself. Even though the exosomes are of greater size, no signal could be detected in the spleen.

In another project, intranasally applied exosomes were tracked in the brain and showed a similar behavior: their concentration was highest one hour after application and then steadily decreased (Zhuang et al., 2011). The peak observed in several organs in our experiment after $12 \mathrm{~h}$ was not described. In this project, the distribution was assessed by measuring the concentration of curcumin, which was inside the vesicles. Our results indicate that the administration and the targeting of exosomes to the brain is possible by intranasal application. 
Resulting from the limited knowledge on cellular uptake of exosomes, the distribution in organs is even less understood. There are publications in which virus-derived proteins or peptides like the central nervous system-specific rabies viral glycoprotein peptide were able to enter neuronal cells (Alvarez-Erviti et al., 2011). The FR $\alpha$ presenting vesicles behaved in the in vivo experiment similar to the negative vesicles. The better uptake of FR $\alpha$-presenting vesicles observed in a cell culture line of epithelial cells, BN16, could not be reproduced in mouse.

\subsection{Drug delivery capacity of PTPS carrying and FR $\alpha$-presenting exosomes}

To finally investigate the drug delivery capacity of the established vehicle system, the PTPS deficient mouse model was chosen. The mice were treated by oral and by intranasal application. Other administration options are not suitable because of the age, the small size of the KO and repetitive nature of the EV based therapy.

While the disease progression could not be intervened by oral administration the intranasal application showed positive effects on the growth and the performance in the behavioral assay of the KO mice. In the fourth week after birth even a significant higher BW in comparison to not EV-treated $\mathrm{KO}$ mice could be measured. Introducing an EV-based drug delivery of an enzyme replacement therapy to a neurodegenerative mouse model, the disease progression could be slowed down. The mice showed a significant improvement in comparison to the not EV-treated mice. The delivery of the enzyme depends on exosomes since in the control animal being treated only with the enzyme no effect was observed.

The efficiency in treatment was observed by the gain in the BW as well as in the improved performance and motor coordination of the treated mice. The mice were not more active, but fitter and able to perform better than the control mice in the Rota Rod experiment. The overall performance of the mice increased significantly in contrary to the not EV-treated KO mice. Further, the EV-treated mice could not be distinguished from healthy mice in the first week after birth. In the continuing weeks the mice showed a slower onset of symptoms (reduced coat care, less activity). 
Considering the set of symptoms, the disease onset could be postponed and the progression slowed down.

The vesicles were applied by intranasal route. The therapeutic capacity of the exosomes seemed to decrease with the age of the animals. This observation might have different causes. The neurodegenerative effect of a PTPS-deficiency is decreasing with age. For this reason, the curative efficiency of a PTPS replacement therapy might be less efficient. Also the amount of intranasally applicable EV suspension is limited to $10 \mu \mathrm{l}$ for animal protection reasons. Maybe at this point the amount of treatment was not sufficient anymore.

\subsection{Outlook}

This project describes the first successful approach to treat an enzyme deficiency by exosome delivery therapy. There are publications on the capacity of exosomes to deliver supportive small molecules to improve healing or to reduce resistance towards administered drugs. For this purpose, this project implies an important proof of concept for the therapeutic application of EVs. However, there are still more experiments required to characterize this therapeutic delivery system.

One central question that still needs to be clarified is the role and significance of the folate receptor. It is conceivable that not modified vesicles might have a similar effect for drug delivery to the CNS. It might be that the measured effect is related to the small amount of vesicles that are able to leak through the inefficient barrier of the olfactory bulb no matter with or without the FR $\alpha$ expression.

Apart from the EVs, there will be experiments with artificial NPs presenting FR $\alpha$. These particles are being equipped with sepiapterin. Their behavior in similar experiments in comparison to pristine NPs, resolving their uptake as well as the biological performance will shed light on the importance of $F R \alpha$. In case the nanoparticles show similar or even better efficiency in the mouse model this would support the importance of FR $\alpha$ mediated targeting. 


\section{Bibliography}

ADMYRE, C., JOHANSSON, S. M., QAZI, K. R., FILEN, J. J., LAHESMAA, R., NORMAN, M., NEVE, E. P. A., SCHEYNIUS, A. \& GABRIELSSON, S. 2007. Exosomes with Immune Modulatory Features Are Present in Human Breast Milk. The Journal of Immunology, 179, 1969-1978.

ALVAREZ-ERVITI, L., SEOW, Y., YIN, H., BETTS, C., LAKHAL, S. \& WOOD, M. J. 2011. Delivery of siRNA to the mouse brain by systemic injection of targeted exosomes. Nature Biotechnology, 29, 341.

ANTES, T. J., KEVIN, K. \& WU, F. 2015. Methods for microvesicle isolation and selective removal. Google Patents.

BALAJ, L., ATAI, N. A., CHEN, W., MU, D., TANNOUS, B. A., BREAKEFIELD, X. O., SKOG, J. \& MAGUIRE, C. A. 2015. Heparin affinity purification of extracellular vesicles. Scientific Reports, 5.

BENNETT, M. J. \& RAKHEJA, D. 2013. The neuronal ceroid-lipofuscinoses. Developmental disabilities research reviews, 17, 254-259.

BESSE, B., CHARRIER, M., LAPIERRE, V., DANSIN, E., LANTZ, O., PLANCHARD, D., LE CHEVALIER, T., LIVARTOSKI, A., BARLESI, F. \& LAPLANCHE, A. 2016. Dendritic cell-derived exosomes as maintenance immunotherapy after first line chemotherapy in NSCLC. Oncoimmunology, 5, e1071008.

BIRN, H., NIELSEN, S. \& CHRISTENSEN, E. I. 1997. Internalization and apical-tobasolateral transport of folate in rat kidney proximal tubule. American Journal of Physiology-Renal Physiology, 272, F70-F78.

BIRN, H., ZHAI, X., HOLM, J., HANSEN, S. I., JACOBSEN, C., CHRISTENSEN, E. I. \& MOESTRUP, S. K. 2005. Megalin binds and mediates cellular internalization of folate binding protein. The FEBS journal, 272, 4423-4430.

BLAU, N., DURAN, M. \& GIBSON, K. M. 2008. Laboratory guide to the methods in biochemical genetics, Springer.

BONAFÉ, L., THÖNY, B., LEIMBACHER, W., KIERAT, L. \& BLAU, N. 2001. Diagnosis of dopa-responsive dystonia and other tetrahydrobiopterin disorders by the study of biopterin metabolism in fibroblasts. Clinical Chemistry, 47, 477-485.

BÜRGISSER, D. M., THÖNY, B., REDWEIK, U., HESS, D., HEIZMANN, C. W., HUBER, R. \& NAR, H. 1995. 6-Pyruvoyl tetrahydropterin synthase, an enzyme with a novel type of active site involving both zinc binding and an intersubunit catalytic triad motif; site-directed mutagenesis of the proposed active center, characterization of the metal binding site and modelling of substrate binding. Journal of molecular biology, 253, 358-369.

BUZZI, D., CORRADO, A., JANCAR, J., ZOCCO, D., CHIESI, A. \& STRANCAR, A. 2014. Development of a Separation Method for Exosomes by means of Large Pore Monolithic Supports. Siena: BIAseperations.

CHANG, L., BERTANI, P., GALLEGO-PEREZ, D., YANG, Z., CHEN, F., CHIANG, C., MALKOC, V., KUANG, T., GAO, K. \& LEE, L. J. 2016. 3D nanochannel electroporation for high-throughput cell transfection with high uniformity and dosage control. Nanoscale, 8, 243-252.

CHANG, M., COOPER, J. D., SLEAT, D. E., CHENG, S. H., DODGE, J. C., PASSINI, M. A., LOBEL, P. \& DAVIDSON, B. L. 2008. Intraventricular enzyme 
replacement improves disease phenotypes in a mouse model of late infantile neuronal ceroid lipofuscinosis. Molecular Therapy, 16, 649-656.

CHENG, Y. \& SCHOREY, J. S. 2016. Targeting soluble proteins to exosomes using a ubiquitin tag. Biotechnology and Bioengineering, 113, 1315-1324.

CLOT, F., GRABLI, D., CAZENEUVE, C., ROZE, E., CASTELNAU, P., CHABROL, B., LANDRIEU, P., NGUYEN, K., PONSOT, G. \& ABADA, M. 2009. Exhaustive analysis of $\mathrm{BH} 4$ and dopamine biosynthesis genes in patients with Dopa-responsive dystonia. Brain, 132, 1753-1763.

DUDEŠEK, A., RÖSCHINGER, W., MUNTAU, A. C., SEIDEL, J., LEUPOLD, D., THÖNY, B. \& BLAU, N. 2001. Molecular analysis and long-term follow-up of patients with different forms of 6-pyruvoyl-tetrahydropterin synthase deficiency. European journal of pediatrics, 160, 267-276.

ELZAOUK, L., LAUFS, S., HEERKLOTZ, D., LEIMBACHER, W., BLAU, N., RÉSIBOIS, A. \& THÖNY, B. 2004. Nuclear localization of tetrahydrobiopterin biosynthetic enzymes. Biochimica et Biophysica Acta (BBA) - General Subjects, $1670,56-68$.

ELZAOUK, L., LEIMBACHER, W., TURRI, M., LEDERMANN, B., BÜRKI, K., BLAU, N. \& THÖNY, B. 2003. Dwarfism and low insulin-like growth factor-1 due to dopamine depletion in Pts-/-mice rescued by feeding neurotransmitter precursors and H4-biopterin. Journal of Biological Chemistry, 278, 28303-28311.

ERICKSON, H. P. 2009. Size and Shape of Protein Molecules at the Nanometer Level Determined by Sedimentation, Gel Filtration, and Electron Microscopy. Biological Procedures Online, 11, 32-51.

ESCREVENTE, C., KELLER, S., ALTEVOGT, P. \& COSTA, J. 2011. Interaction and uptake of exosomes by ovarian cancer cells. BMC cancer, 11, 108.

FAVRETTO, M. E., CluitMANS, J. C. A., BOSMAN, G. J. C. G. M. \& BROCK, R. 2013. Human erythrocytes as drug carriers: Loading efficiency and side effects of hypotonic dialysis, chlorpromazine treatment and fusion with liposomes. Journal of Controlled Release, 170, 343-351.

FUHRMANN, G., SERIO, A., MAZO, M., NAIR, R. \& STEVENS, M. M. 2015. Active loading into extracellular vesicles significantly improves the cellular uptake and photodynamic effect of porphyrins. Journal of Controlled Release, 205, 35-44.

GALIAN, C., BJÖRKHOLM, P., BULLEID, N. \& VON HEIJNE, G. 2012. Efficient Glycosylphosphatidylinositol (GPI) Modification of Membrane Proteins Requires a C-terminal Anchoring Signal of Marginal Hydrophobicity. Journal of Biological Chemistry, 287, 16399-16409.

GHANTA, K. S., DOKSHIN, G. A., MIR, A., KRISHNAMURTHY, P. M., GNEID, H., EDRAKI, A., WATTS, J., SONTHEIMER, E. \& MELLO, C. 2018. 5' modifications improve potency and efficacy of DNA donors for precision genome editing. bioRxiv.

GIMONA, M., PACHLER, K., LANER-PLAMBERGER, S., SCHALLMOSER, K. \& ROHDE, E. 2017. Manufacturing of Human Extracellular Vesicle-Based Therapeutics for Clinical Use. International Journal of Molecular Sciences, 18, 1190.

GOLABEK, A. A., WUJEK, P., WALUS, M., BIELER, S., SOTO, C., WISNIEWSKI, K. E. \& KIDA, E. 2004. Maturation of Human Tripeptidyl-peptidase I in Vitro. Journal of Biological Chemistry, 279, 31058-31067. 
GOULD, S. J. \& RAPOSO, G. 2013. As we wait: coping with an imperfect nomenclature for extracellular vesicles. Journal of Extracellular Vesicles, 2, 20389.

GRAPP, M., JUST, I. A., LINNANKIVI, T., WOLF, P., LÜCKE, T., HÄUSLER, M., GÄRTNER, J. \& STEINFELD, R. 2012. Molecular characterization of folate receptor 1 mutations delineates cerebral folate transport deficiency. Brain, 135, 2022-2031.

GRAPP, M., WREDE, A., SCHWEIZER, M., HÜWEL, S., GALLA, H.-J., SNAIDERO, N., SIMONS, M., BÜCKERS, J., LOW, P. S., URLAUB, H., GÄRTNER, J. \& STEINFELD, R. 2013. Choroid plexus transcytosis and exosome shuttling deliver folate into brain parenchyma. Nature Communications, 4.

GREENING, D. W., XU, R., JI, H., TAURO, B. J. \& SIMPSON, R. J. 2015. A protocol for exosome isolation and characterization: evaluation of ultracentrifugation, density-gradient separation, and immunoaffinity capture methods. Proteomic Profiling. Springer.

GUHANIYOGI, J., SOHAR, I., DAS, K., STOCK, A. M. \& LOBEL, P. 2009. Crystal Structure and Autoactivation Pathway of the Precursor Form of Human Tripeptidylpeptidase 1, the Enzyme Deficient in Late Infantile Ceroid Lipofuscinosis. Journal of Biological Chemistry, 284, 3985-3997.

HAO, H., QI, H. \& RATNAM, M. 2003. Modulation of the folate receptor type $\beta$ gene by coordinate actions of retinoic acid receptors at activator Sp1/ets and repressor AP-1 sites. Blood, 101, 4551-4560.

HEIJNEN, H. F. G., SCHIEL, A. E., FIJNHEER, R., GEUZE, H. J. \& SIXMA, J. J. 1999. Activated Platelets Release Two Types of Membrane Vesicles: Microvesicles by Surface Shedding and Exosomes Derived From Exocytosis of Multivesicular Bodies and - -Granules. Blood, 94, 3791-3799.

HELVIG, S., AZMI, I. D., MOGHIMI, S. M. \& YAGHMUR, A. 2015. Recent advances in cryo-TEM imaging of soft lipid nanoparticles. Aims Biophysics, 2, 116-130.

HOSSEINI, H. M., HALABIAN, R., AMIN, M. \& FOOLADI, A. A. I. 2015. Texosomebased drug delivery system for cancer therapy: from past to present. Cancer biology \& medicine, $12,150$.

IKEZAWA, H. 2002. Glycosylphosphatidylinositol (GPI)-anchored proteins. Biological and pharmaceutical bulletin, 25, 409-417.

IMBARD, A., BENOIST, J.-F. \& BLOM, H. J. 2013. Neural Tube Defects, Folic Acid and Methylation. International Journal of Environmental Research and Public Health, 10, 4352-4389.

IMMORDINO, M. L., DOSIO, F. \& CATTEL, L. 2006. Stealth liposomes: review of the basic science, rationale, and clinical applications, existing and potential. International Journal of Nanomedicine, 1, 297.

KANG, D., OH, S., AHN, S.-M., LEE, B.-H. \& MOON, M. H. 2008. Proteomic analysis of exosomes from human neural stem cells by flow field-flow fractionation and nanoflow liquid chromatography- tandem mass spectrometry. Journal of proteome research, 7, 3475-3480.

KARNS, L. R., NG, S.-C., FREEMAN, J. A. \& FISHMAN, M. C. 1987. Cloning of complementary DNA for GAP-43, a neuronal growth-related protein. Science, 236, 597-600. 
KE, C.-Y., MATHIAS, C. J. \& GREEN, M. A. 2003. The folate receptor as a molecular target for tumor-selective radionuclide delivery. Nuclear medicine and biology, 30, 811-817.

KOOIJMANS, S. A., STREMERSCH, S., BRAECKMANS, K., DE SMEDT, S. C., HENDRIX, A., WOOD, M. J., SCHIFFELERS, R. M., RAEMDONCK, K. \& VADER, P. 2013. Electroporation-induced siRNA precipitation obscures the efficiency of siRNA loading into extracellular vesicles. Journal of Controlled Release, 172, 229-238.

KOTMAKÇı, M. \& AKBABA, G. L. E. 2017. Exosome Isolation: Is There an Optimal Method with Regard to Diagnosis or Treatment? Novel Implications of Exosomes in Diagnosis and Treatment of Cancer and Infectious Diseases. InTech.

KOUREMBANAS, S. 2015. Exosomes: vehicles of intercellular signaling, biomarkers, and vectors of cell therapy. Annual review of physiology, 77, 13-27.

LENER, T., GIMONA, M., AIGNER, L., BÖRGER, V., BUZAS, E., CAMUSSI, G., CHAPUT, N., CHATTERJEE, D., COURT, F. A. \& PORTILlO, H. A. D. 2015. Applying extracellular vesicles based therapeutics in clinical trials-an ISEV position paper. Journal of Extracellular Vesicles, 4, 30087.

LI, L., ZHANG, L. \& KNEZ, M. 2016. Comparison of two endogenous delivery agents in cancer therapy: Exosomes and ferritin. Pharmacological Research, 110, 1-9.

LI, P., KASLAN, M., LEE, S. H., YAO, J. \& GAO, Z. 2017. Progress in Exosome Isolation Techniques. Theranostics, 7, 789-804.

LIANG, X., POTTER, J., KUMAR, S., ZOU, Y., QUINTANILLA, R., SRIDHARAN, M., CARTE, J., CHEN, W., ROARK, N. \& RANGANATHAN, S. 2015. Rapid and highly efficient mammalian cell engineering via Cas9 protein transfection. Journal of Biotechnology, 208, 44-53.

LIU, K., LIU, T., LEE, N., CHENG, L., HSIAO, K. \& NIU, D. 2008. Long-term follow-up of taiwanese chinese patients treated early for 6-pyruvoyl-tetrahydropterin synthase deficiency. Archives of Neurology, 65, 387-392.

LOBB, R. J., BECKER, M., WEN WEN, S., WONG, C. S. F., WIEGMANS, A. P., LEIMGRUBER, A. \& MÖLLER, A. 2015. Optimized exosome isolation protocol for cell culture supernatant and human plasma. Journal of Extracellular Vesicles, 4, 27031.

LÖTVALL, J., HILL, A. F., HOCHBERG, F., BUZÁS, E. I., DI VIZIO, D., GARDINER, C., GHO, Y. S., KUROCHKIN, I. V., MATHIVANAN, S., QUESENBERRY, P., SAHOO, S., TAHARA, H., WAUBEN, M. H., WITWER, K. W. \& THÉRY, C. 2014. Minimal experimental requirements for definition of extracellular vesicles and their functions: a position statement from the International Society for Extracellular Vesicles. Journal of Extracellular Vesicles, 3, 26913.

LOW, P. S. \& KULARATNE, S. A. 2009. Folate-targeted therapeutic and imaging agents for cancer. Current Opinion in Chemical Biology, 13, 256-262.

LU, M., XING, H., YANG, Z., SUN, Y., YANG, T., ZHAO, X., CAI, C., WANG, D. \& DING, P. 2017. Recent advances on extracellular vesicles in therapeutic delivery: Challenges, solutions, and opportunities. European Journal of Pharmaceutics and Biopharmaceutics, 119, 381-395.

LUAN, X., SANSANAPHONGPRICHA, K., MYERS, I., CHEN, H., YUAN, H. \& SUN, D. 2017. Engineering exosomes as refined biological nanoplatforms for drug delivery. Acta Pharmacologica Sinica, 38, 754. 
LUKACS, Z., SANTAVUORI, P., KEIL, A., STEINFELD, R. \& KOHLSCHÜTTER, A. 2003. Rapid and Simple Assay for the Determination of Tripeptidyl Peptidase and Palmitoyl Protein Thioesterase Activities in Dried Blood Spots. Clinical Chemistry, 49, 509-511.

MARCUS, M. E. \& LEONARD, J. N. 2013. FedExosomes: engineering therapeutic biological nanoparticles that truly deliver. Pharmaceuticals, 6, 659-680.

MASCARO, I., CERAVOLO, F., FERRARO, S., PROCOPIO, D., FALVO, F., GRISOLIA, M., LEONE, G., SALPIETRO, V., POLIZZI, A. \& RUGGIERI, M. 2016. Neurological Involvement in Tetrahydrobiopterin Deficiency. Journal of Pediatric Biochemistry, 6, 019-024.

MCKELVEY, K. J., POWELL, K. L., ASHTON, A. W., MORRIS, J. M. \& MCCRACKEN, S. A. 2015. Exosomes: mechanisms of uptake. Journal of circulating biomarkers, $4,7$.

MITRAGOTRI, S., BURKE, P. A. \& LANGER, R. 2014. Overcoming the challenges in administering biopharmaceuticals: formulation and delivery strategies. Nature reviews Drug discovery, 13, 655.

MOMEN-HERAVI, F., BALAJ, L., ALIAN, S., MANTEL, P.-Y., HALLECK, A. E., TRACHTENBERG, A. J., SORIA, C. E., OQUIN, S., BONEBREAK, C. M. \& SARACOGLU, E. 2013. Current methods for the isolation of extracellular vesicles. Biological Chemistry, 394, 1253-1262.

MUNAGALA, R., AQIL, F., JEYABALAN, J. \& GUPTA, R. C. 2016. Bovine milkderived exosomes for drug delivery. Cancer Letters, 371, 48-61.

NANBO, A., KAWANISHI, E., YOSHIDA, R. \& YOSHIYAMA, H. 2013. Exosomes Derived from Epstein-Barr Virus-Infected Cells Are Internalized via CaveolaDependent Endocytosis and Promote Phenotypic Modulation in Target Cells. Journal of Virology, 87, 10334-10347.

NEVERMAN, N. J., BEST, H. L., HOFMANN, S. L. \& HUGHES, S. M. 2015. Experimental therapies in the neuronal ceroid lipofuscinoses. Biochimica et Biophysica Acta (BBA) - Molecular Basis of Disease, 1852, 2292-2300.

NIU, D.-M. 2011. Disorders of BH4 metabolism and the treatment of patients with 6pyruvoyl-tetrahydropterin synthase deficiency in Taiwan. Brain and Development, $33,847-855$.

OTTO, G. P. \& NICHOLS, B. J. 2011. The roles of flotillin microdomains - endocytosis and beyond. Journal of Cell Science, 124, 3933-3940.

PAL, A., KRAETZNER, R., GRUENE, T., GRAPP, M., SCHREIBER, K., GRøNBORG, M., URLAUB, H., BECKER, S., ASIF, A. \& GÄRTNER, J. 2008. The structure of tripeptidyl peptidase I provides insight into the molecular basis of late infantile neuronal ceroid lipofuscinosis. Journal of Biological Chemistry.

PAN, B.-T. \& JOHNSTONE, R. M. 1983. Fate of the transferrin receptor during maturation of sheep reticulocytes in vitro: selective externalization of the receptor. Cell, 33, 967-978.

PARDRIDGE, W. M. 2003. Blood-brain barrier drug targeting: the future of brain drug development. Molecular interventions, 3, 90.

PARDRIDGE, W. M. 2005. The blood-brain barrier: Bottleneck in brain drug development. NeuroRX, 2, 3-14.

PETERSEN, K. E., MANANGON, E., HOOD, J. L., WICKLINE, S. A., FERNANDEZ, D. P., JOHNSON, W. P. \& GALE, B. K. 2014. A review of exosome separation 
techniques and characterization of B16-F10 mouse melanoma exosomes with AF4UV-MALS-DLS-TEM. Analytical and bioanalytical chemistry, 406, 7855-7866.

PIETRZIK, K., BAILEY, L. \& SHANE, B. 2010. Folic Acid and L-5Methyltetrahydrofolate. Clinical Pharmacokinetics, 49, 535-548.

RAJ, D. A., FIUME, I., CAPASSO, G. \& POCSFALVI, G. 2012. A multiplex quantitative proteomics strategy for protein biomarker studies in urinary exosomes. Kidney International, 81, 1263-1272.

RAKHEJA, D. \& BENNETT, M. J. 2018. Neuronal ceroid-lipofuscinoses. Translational Science of Rare Diseases, 3, 83-95.

RAPOSO, G. \& STOORVOGEL, W. 2013. Extracellular vesicles: exosomes, microvesicles, and friends. J Cell Biol, 200, 373-383.

RECORD, M., CARAYON, K., POIROT, M. \& SILVENTE-POIROT, S. 2014. Exosomes as new vesicular lipid transporters involved in cell-cell communication and various pathophysiologies. Biochimica et Biophysica Acta (BBA)-Molecular and Cell Biology of Lipids, 1841, 108-120.

REKKER, K., SAARE, M., ROOST, A. M., KUBO, A.-L., ZAROVNI, N., CHIESI, A., SALUMETS, A. \& PETERS, M. 2014. Comparison of serum exosome isolation methods for microRNA profiling. Clinical biochemistry, 47, 135-138.

REVELO, N. H., KAMIN, D., TRUCKENBRODT, S., WONG, A. B., REUTER-JESSEN, K., REISINGER, E., MOSER, T. \& RIZZOLI, S. O. 2014. A new probe for superresolution imaging of membranes elucidates trafficking pathways. The Journal of Cell Biology, 205, 591-606.

REVELO, N. H. \& RIZZOLI, S. O. 2016. The Membrane Marker mCLING Reveals the Molecular Composition of Trafficking Organelles. Current Protocols in Neuroscience, 74, 2.25.1-2.25.21.

ROSS, J. F., CHAUDHURI, P. K. \& RATNAM, M. 1994. Differential regulation of folate receptor isoforms in normal and malignant tissues in vivo and in established cell lines. Physiologic and clinical implications. Cancer, 73, 2432-2443.

SABHARANJAK, S. \& MAYOR, S. 2004. Folate receptor endocytosis and trafficking. Advanced Drug Delivery Reviews, 56, 1099-1109.

SATO, Y. T., UMEZAKI, K., SAWADA, S., MUKAI, S.-A., SASAKI, Y., HARADA, N., SHIKU, H. \& AKIYOSHI, K. 2016. Engineering hybrid exosomes by membrane fusion with liposomes. Scientific Reports, 6, 21933.

SHARMA, P., VARMA, R., SARASIJ, R. C., IRA, GOUSSET, K., KRISHNAMOORTHY, G., RAO, M. \& MAYOR, S. 2004. Nanoscale Organization of Multiple GPI-Anchored Proteins in Living Cell Membranes. Cell, $116,577-589$.

SHEN, F., WU, M., ROSS, J. F., MILLER, D. \& RATNAM, M. 1995. Folate receptor type. Gamma. Is primarily a secretory protein due to lack of an efficient signal for glycosylphosphatidylinositol modification: protein characterization and cell type specificity. Biochemistry, 34, 5660-5665.

SHERIDAN, C. 2016. Exosome cancer diagnostic reaches market. Nature Biotechnology, $34,359$.

SIMPSON, R. J., JENSEN, S. S. \& LIM, J. W. 2008. Proteomic profiling of exosomes: current perspectives. Proteomics, 8, 4083-4099.

SKOTLAND, T., SANDVIG, K. \& LLORENTE, A. 2017. Lipids in exosomes: Current knowledge and the way forward. Progress in Lipid Research, 66, 30-41. 
SLEAT, D. E., WISEMAN, J. A., EL-BANNA, M., KIM, K.-H., MAO, Q., PRICE, S., MACAULEY, S. L., SIDMAN, R. L., SHEN, M. M. \& ZHAO, Q. 2004. A mouse model of classical late-infantile neuronal ceroid lipofuscinosis based on targeted disruption of the CLN2 gene results in a loss of tripeptidyl-peptidase I activity and progressive neurodegeneration. Journal of Neuroscience, 24, 9117-9126.

SOUNG, Y. H., FORD, S., ZHANG, V. \& CHUNG, J. 2017. Exosomes in cancer diagnostics. Cancers, 9, 8.

STERZENBACH, U., PUTZ, U., LOW, L.-H., SILKE, J., TAN, S.-S. \& HOWITT, J. 2017. Engineered exosomes as vehicles for biologically active proteins. Molecular Therapy, 25, 1269-1278.

STREMERSCH, S., VANDENBROUCKE, R. E., VAN WONTERGHEM, E., HENDRIX, A., DE SMEDT, S. C. \& RAEMDONCK, K. 2016. Comparing exosome-like vesicles with liposomes for the functional cellular delivery of small RNAs. Journal of Controlled Release, 232, 51-61.

SUBRA, C., LAUlagnier, K., PERRET, B. \& RECORD, M. 2007. Exosome lipidomics unravels lipid sorting at the level of multivesicular bodies. Biochimie, $89,205-212$.

SUDIMACK, J. \& LEE, R. J. 2000. Targeted drug delivery via the folate receptor. Advanced Drug Delivery Reviews, 41, 147-162.

SUMI-ICHINOSE, C., URANO, F., KURODA, R., OHYE, T., KOJIMA, M., TAZAWA, M., SHIRAISHI, H., HAGINO, Y., NAGATSU, T. \& NOMURA, T. 2001. Catecholamines and Serotonin Are Differently Regulated by Tetrahydrobiopterin A STUDY FROM 6-PYRUVOYLTETRAHYDROPTERIN SYNTHASE KNOCKOUT MICE. Journal of Biological Chemistry, 276, 41150-41160.

SUTARIA, D. S., BADAWI, M., PHELPS, M. A. \& SCHMITTGEN, T. D. 2017. Achieving the promise of therapeutic extracellular vesicles: the devil is in details of therapeutic loading. Pharmaceutical research, 34, 1053-1066.

SVENSSON, K. J., CHRISTIANSON, H. C., WITTRUP, A., BOURSEAU-GUILMAIN, E., LINDQVIST, E., SVENSSON, L. M., MÖRGELIN, M. \& BELTING, M. 2013. Exosome Uptake Depends on ERK1/2-Heat Shock Protein 27 Signaling and Lipid Raft-mediated Endocytosis Negatively Regulated by Caveolin-1. Journal of Biological Chemistry, 288, 17713-17724.

TAKAHASHI, Y., NISHIKAWA, M., SHINOTSUKA, H., MATSUI, Y., OHARA, S., IMAI, T. \& TAKAKURA, Y. 2013. Visualization and in vivo tracking of the exosomes of murine melanoma B16-BL6 cells in mice after intravenous injection. Journal of Biotechnology, 165, 77-84.

TAYLOR, D. D., ZACHARIAS, W. \& GERCEL-TAYLOR, C. 2011. Exosome isolation for proteomic analyses and RNA profiling. Serum/plasma proteomics. Springer.

THÉRY, C., AMIGORENA, S., RAPOSO, G. \& CLAYTON, A. 2006. Isolation and Characterization of Exosomes from Cell Culture Supernatants and Biological Fluids. Current Protocols in Cell Biology, 30, 3.22.1-3.22.29.

THÖNY, B. 2006. Tetrahydrobiopterin and its function. PKU and BH4: Advances in Phenylketonuria and Tetrahydrobiopterin Research. Heilbronn: SPS Publications.

TIAN, Y., LI, S., SONG, J., JI, T., ZHU, M., ANDERSON, G. J., WEI, J. \& NIE, G. 2014. A doxorubicin delivery platform using engineered natural membrane vesicle exosomes for targeted tumor therapy. Biomaterials, 35, 2383-2390. 
VAN DER MEEL, R., FENS, M. H. A. M., VADER, P., VAN SOLINGE, W. W., ENIOLA-ADEFESO, O. \& SCHIFFELERS, R. M. 2014. Extracellular vesicles as drug delivery systems: Lessons from the liposome field. Journal of Controlled Release, 195, 72-85.

VIAUD, S., PLOIX, S., LAPIERRE, V., THÉRY, C., COMMERE, P.-H., TRAMALLONI, D., GORRICHON, K., VIRAULT-ROCROY, P., TURSZ, T. \& LANTZ, O. 2011. Updated technology to produce highly immunogenic dendritic cell-derived exosomes of clinical grade: a critical role of interferon- $\gamma$. Journal of immunotherapy, 34, 65-75.

VLASSOV, A. V., MAGDALENO, S., SETTERQUiST, R. \& CONRAD, R. 2012. Exosomes: Current knowledge of their composition, biological functions, and diagnostic and therapeutic potentials. Biochimica et Biophysica Acta (BBA) General Subjects, 1820, 940-948.

WEBBER, J. \& CLAYTON, A. 2013. How pure are your vesicles? Journal of Extracellular Vesicles, 2, 19861.

WIBOWO, A. S., SINGH, M., REEDER, K. M., CARTER, J. J., KOVACH, A. R., MENG, W., RATNAM, M., ZHANG, F. \& DANN, C. E. 2013. Structures of human folate receptors reveal biological trafficking states and diversity in folate and antifolate recognition. Proceedings of the National Academy of Sciences, 110, $15180-15188$.

WISEMAN, J. A., MENG, Y., NEMTSOVA, Y., MATTESON, P. G., MILLONIG, J. H., MOORE, D. F., SLEAT, D. E. \& LOBEL, P. 2017. Chronic enzyme replacement to the brain of a late infantile neuronal ceroid lipofuscinosis mouse has differential effects on phenotypes of disease. Molecular Therapy-Methods \& Clinical Development, 4, 204-212.

WISNIEWSKI, K. E., KIDA, E., WALUS, M., WUJEK, P., KACZMARSKI, W. \& GOLABEK, A. A. 2001. Tripeptidyl-peptidase 1 in neuronal ceroid lipofuscinoses and other lysosomal storage disorders. European Journal of Paediatric Neurology, 5, 73-79.

WITWER, K. W., BUZÁS, E. I., BEMIS, L. T., BORA, A., LÄSSER, C., LÖTVALL, J., NOLTE-'T HOEN, E. N., PIPER, M. G., SIVARAMAN, S., SKOG, J., THÉRY, C., WAUBEN, M. H. \& HOCHBERG, F. 2013. Standardization of sample collection, isolation and analysis methods in extracellular vesicle research. Journal of Extracellular Vesicles, 2, 20360.

WOLF, D. A., HANSON, L. R., ARONOVICH, E. L., NAN, Z., LOW, W. C., FREY, W. H. \& MCIVOR, R. S. 2012. Lysosomal enzyme can bypass the blood-brain barrier and reach the CNS following intranasal administration. Molecular genetics and metabolism, 106, 131-134.

XU, R., GREENING, D. W., ZHU, H.-J., TAKAHASHI, N. \& SIMPSON, R. J. 2016. Extracellular vesicle isolation and characterization: toward clinical application. Journal of Clinical Investigation, 126, 1152-1162.

ZEELENBERG, I. S., OSTROWSKI, M., KRUMEICH, S., BOBRIE, A., JANCIC, C., BOISSONNAS, A., DELCAYRE, A., LE PECQ, J.-B., COMBADIÈRE, B. \& AMIGORENA, S. 2008. Targeting tumor antigens to secreted membrane vesicles in vivo induces efficient antitumor immune responses. Cancer Research, 68, 12281235. 
ZHANG, F., SUN, S., FENG, D., ZHAO, W.-L. \& SUI, S.-F. 2009. A Novel Strategy for the Invasive Toxin: Hijacking Exosome-Mediated Intercellular Trafficking. Traffic, $10,411-424$.

ZHANG, G. \& YANG, P. 2018. A novel cell-cell communication mechanism in the nervous system: exosomes. Journal of neuroscience research, 96, 45-52.

ZHAO, R., DIOP-BOVE, N., VISENTIN, M. \& GOLDMAN, I. D. 2011. Mechanisms of Membrane Transport of Folates into Cells and Across Epithelia. Annual review of nutrition, 31, 10.1146/annurev-nutr-072610-145133.

ZHUANG, X., XIANG, X., GRIZZLE, W., SUN, D., ZHANG, S., AXTELL, R. C., JU, S., MU, J., ZHANG, L., STEINMAN, L., MILlER, D. \& ZHANG, H.-G. 2011. Treatment of Brain Inflammatory Diseases by Delivering Exosome Encapsulated Anti-inflammatory Drugs From the Nasal Region to the Brain. Molecular Therapy, 19, 1769-1779.

ZLOTOGORSKI-HURVITZ, A., DAYAN, D., CHAUSHU, G., KORVALA, J., SALO, T., SORMUNEN, R. \& VERED, M. 2015. Human saliva-derived exosomes: comparing methods of isolation. Journal of Histochemistry \& Cytochemistry, 63, 181-189. 


\section{Curriculum Vitae}

\section{Kristina Lang}

Date of birth

09. 02. 1989

Place of birth

Pawlodar, Kazakhstan

\section{Education}

05/2015 - present GAUSS PhD program Molecular Medicine, Georg-August University Göttingen, Germany

PhD-Thesis in the Department of Child and Adolescent Health:

Exosomes as potential Transport Vehicles of Tetrahydrobiopterin, 6-Pyrovyoltetrahydrobiopterin-Synthase and Tripeptidyl-

Peptidase I

10/2012 - 09/2014 Master of Science in Chemistry, University of Münster, Germany Master-Thesis at the Institute for Pharmaceutical and Medicinal Chemistry:

Observation of glucose dehydrogenase and glucose-6-phosphate dehydrogenase as a NADPH-regeneration system on the cell surface of Escherichia coli via the autodisplay technology

10/2009 - 09/2012 Bachelor of Science in Water Science: Chemistry, Analytics and Microbiology, University of Duisburg-Essen, Germany Bachelor-Thesis at the Water Centre, Mülheim: Development and validation of a practicable method for the determination of natural and synthetic steroids in water by using the online-SPE-UPLC-MS/MS

$07 / 2009$ general qualification for university entrance Gymnasium Dionysianum in Rheine, Germany

\section{Publication}

Schuurmann, J., Quehl, P., Lindhorst, F., Lang, K. \& Jose, J. Autodisplay of glucose-6phosphate dehydrogenase for redox cofactor regeneration at the cell surface. Biotechnol Bioeng 114, 1658-1669 (2017). 